This dissertation has been

microfilmed exactly as received $\quad 65-13,229$

FRICKE, James Edward, 1939-

MONAURAL PHASE EFFECTS IN AUDITORY SIGNAL DETECTION.

The Ohio State University, Ph.D., 1965

Psychology, experimental

University Microfilms, Inc., Ann Arbor, Michigan 


\section{MONAURAL PHASE EFFECTS IN AUDITORY}

\section{SIGNAL DETECTION}

\section{DISSERTATION}

Presented in Partial Fulfillment of the Requirements of the Degree Doctor of Philosophy in the Graduate School of The Ohio State University

by

James Edward Fricke, B.S., M.A.

The Ohio State University

1965

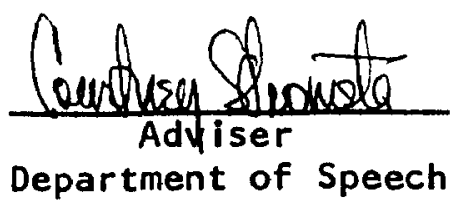




\section{VITA}

$\begin{array}{ll}\text { October 30, } 1939 & \text { Born - Chicago, Illinois } \\ 1961 & \text { B.S., Goshen College, Goshen, Indiana } \\ 1962-1963 & \begin{array}{l}\text { Office of Vocational Rehabilitation Trainee } \\ \text { The Ohio State University, Columbus, Ohio }\end{array} \\ 1963 & \text { M.A., The Ohio State University, Columbus, Ohio } \\ 1964-1965 & \text { U.S. Office of Education Fellow } \\ & \text { The Ohio State University, Columbus, Ohio }\end{array}$




\section{CONTENTS}

\section{Page}

TABLES

\section{$\checkmark$}

FIGURES

vi i

Chapter

I. INTRODUCTION I

II. REVIEW OF THE LITERATURE 6

The Theory of Signal Detectability . . . . . 6

Detectability of Complex Signals ....... 13

Monaural Phase Effects ............ 17

Summary of MPE Studies ............ 27

$\begin{array}{ll}\text { III. PROCEDURES } & 28\end{array}$

Stimuli.................... 28

Subjects .................. 38

Instructions and Test Procedures ........ 41

Mechanics of Presentation and Response Recording. 43

Summary . . . . . . . . . . . . 43

IV. RESULTS AND DISCUSSION 45

Results..................... 46

Hypothes is 1................ 46

Hypothes is II............... 46

Hypothes is III.............. 60

Hypothes is IV ............. 60

Hypothes is V............. 72

Hypothes is VI ............. 72

Subject Variability ...... . . . . . .

The Ideal Observer .............. 86

Discussion ................ . . . 86

The Aural Harmonics Explanation . . . . . . 86

Temporal Relationships of Nerve Potentials . . $\quad 89$

Spatial Relationships on the Basilar Membrane. 90

Summary ................ . . . .

$\begin{array}{ll}\text { V. SUMMARY } & 92\end{array}$ 
CONTENTS (contd.)

APPENDIXES

A. A MATHEMATICAL STATEMENT SHOWING THAT RMS VOLTAGE REMAINS CONSTANT REGARDLESS OF THE PHASE RELATIONSHIP OF THE COMPONENTS ........ 96

B. RESULTS OF THE FOURIER ANALYSES ON THE COMPLEX WAVEFORMS USED AS STIMULI IN THIS STUDY . . . . 97

C. RAW SCORE DATA ................. 100

D. RAW SCORE DATA ................. 102

E. RAW SCORE DATA .................... 104

F. RAW SCORE DATA ............... 105

G. RAW SCORE DATA ................... 106

H. RAW SCORE DATA .............. 107

BIBL IOGRAPHY ........................... 108 


\section{TABLES}

Table

Page

1. Average peak-to-peak voltages found for the complex waveforms prior to and after adjustment for equality.......... 40

2. The probability of a correct detection in a four-alternative forced choice test as a function of $\mathrm{d}^{\prime} . .$. . . . . . . . . . 47

3. Mean d'values and standard deviations for four subjects on six relative-phase conditions.. 49

4. Mean d' values and standard deviations for four subjects on six relative-phase conditions.. 50

5. Summary table of analys is of variance . . . 53

6. Summary table of analys is of variance . . . . 54

7. Critical differences between the means..... 56

8. Critical differences between the means ... . 57

9. Critical differences between the means..... 58

10. Critical differences between the means..... 59

11. Mean $d^{\prime}$ values and standard deviations for three subjects on two relative-phase conditions..61

12. Mean d'values and standard deviations for three subjects on two relative-phase conditions..62

13. Summary table of analys is of variance . . . 66

14. Summary table of analys is of variance .... 67

15. Critical differences between the means .... 68

16. Critical differences between the means.... 69

17. Critical differences between the means..... 70

18. Critical differences between the means..... 71 


\section{TABLES ( contd.)}

Table

Page

19. Mean d' values and standard deviations for two subjects on two relative-phase conditions.. 73

20. Mean d' values and standard deviations for two subjects on two relat ive-phase conditions.. 74

21. Summary table of analys is of variance . . . 76

22. Summary table of analys is of variance . . . 77

23. Critical differences between the means . . . 78

24. Critical differences between the means.... 79

25. Critical differences between the means . . . 80

26. Critical differences between the means..... 81

27. Performance of the ideal observer . . . . 87 


\section{FIGURES}

Figure Page

2. Schematic diagram of a complex waveform with a different relative-phase relationship of the components . . . . . . . . . . . 2

3. The four possible outcomes in the traditional signal detection problem........ 8

4. Schematic diagram of the traditional signal detection model .............. 9

5. Receiver-operating-characteristic curves for six different $\underline{d}^{\prime}$ values ............... 14

6. Changes in loudness of a fundamental as a function of adding various amounts of the second harmonic in three different relative-phase relationships .. 22

7. Schematic drawing of the complex waveform with a $0^{\circ}$ relative-phase relationship of components . . 29

8. Oscilloscope picture of the complex waveform with a $0^{\circ}$ relative-phase relationship of components . 29

9. Schematic drawing of the complex waveform with a $30^{\circ}$ relative-phase relationship of components. . 30

10. Oscilloscope picture of the complex waveform with a $30^{\circ}$ relative-phase relationship of components. 30

11. Schematic drawing of the complex waveform with a $60^{\circ}$ relative-phase relationship of components. . 31

12. Oscilloscope picture of the complex waveform with a $60^{\circ}$ relative-phase relationship of components. 31

13. Schematic drawing of the complex waveform with a $90^{\circ}$ relative-phase relationship of components. . 32

14. Oscilloscope picture of the complex waveform with a $90^{\circ}$ relative-phase relationship of components. 32

15. Schematic drawing of the complex waveform with a $120^{\circ}$ relative-phase relationship of components . 


\section{FIGURES (contd.)}

Figure Page

16. Oscilloscope picture of the complex waveform with

a $120^{\circ}$ relative-phase relationship of components . 33

17. Schematic drawing of the complex waveform with a

$150^{\circ}$ relative-phase relationship of components . . 34

18. Oscilloscope picture of the complex waveform with

a $150^{\circ}$ relative-phase relationship of components . 34

19. Schematic diagram of equipment used in the con-

struction of the stimulus tapes ....... 35

20. Schematic diagram of the equipment used in the

re-recording of the stimulus tapes....... 39

21. Averaged correct responses for four subjects on six relative-phase conditions ....... 51

22. Averaged correct responses for four subjects on six relative-phase conditions ........ 52

23. Averaged correct responses for three subjects on three relative-phase conditions . . . . . 63

24. Averaged correct responses for three subjects on three relative-phase conditions ....... 64

25. Averaged correct responses for two subjects on four relative-phase conditions . . . . . . 75

26. Illustrated correct responses for each subject on six relative-phase conditions at the easiest signal-to-noise ratio ........... 83

27. The performance of subject RW as compared to the other four subjects on a signal detection task where loudness was the independent variable . . 85 


\section{CHAPTER 1}

\section{INTRODUCT ION}

This study was designed to investigate the detectability of a complex auditory signal as a function of the relative phase relationship between the components of that complex waveform.

In order to begin on a common ground, the meaning of relative phase shift must be established. For this discussion the most elementary example of a complex wave, that is, one composed of two sine waves can be used. As shown in Figure 1 , the frequency of $\mathrm{H}_{2}$, the second harmonic, is exactly twice that of $H_{1}$, the first harmonic or fundamental frequency. This is shown by the fact that two complete cycles of $\mathrm{H}_{2}$ are equal to the period of one cycle of $\mathrm{H}_{1}$. The frequency ratio is $2: 1$; the frequency of the second harmonic equals twice that of the fundamental. The crossing of the zero axis corresponds to the neutral pressure pattern of the molecules in the conveying medium. $H_{1}$ and $H_{2}$ both cross the zero axis at the same points, $A$ and $A^{\prime}$ in Figure 1. Both go from this point into the compression portion of their respective cycles. These two components are said to have a relative phase of 0 degrees $\left(^{\circ}\right)$ when measured at points $A$ and $A^{\prime}$. The distance $A D$ on the time line represents one complete cycle of wave $H_{2} \cdot$ This distance encompasses $360^{\circ}$ of this waveform. The same distance, $A D$, covers only one-half of the $H_{1}$ period, hence $180^{\circ}$. 
Distance AC covers one-half period of $\mathrm{H}_{2}$, or $180^{\circ}$, but only one-quarter period of $H_{1}$, or $90^{\circ}$. Suppose now that the complex wave is composed of $H_{1}$ and $H_{2}^{\prime}$, as seen in Figure 2. $H_{2}^{\prime}$ crosses the zero axis at points $B$ and $C$, while $H_{1}$ is crossing at points $A$ and $D$. If the distance $A B$ equals one-fourth the distance $A D$, the relative-phase relationship between the components of the complex wave is said to be $45^{\circ}$ when measured at points $A$ and $A^{\prime}$. That is, $\frac{1}{4} \times 180^{\circ}=45^{\circ}$.

As $\mathrm{H}_{2}$ ' is changed further in time, so that the distance $A B$ approaches equaling one-haif the distance $A D$, the relative phase of the components moves up toward $90^{\circ}$. When the distance $A B$ equals that of $A D, \mathrm{H}_{2}{ }^{\prime}$ will have returned to the time relationship seen in Figure 1 .

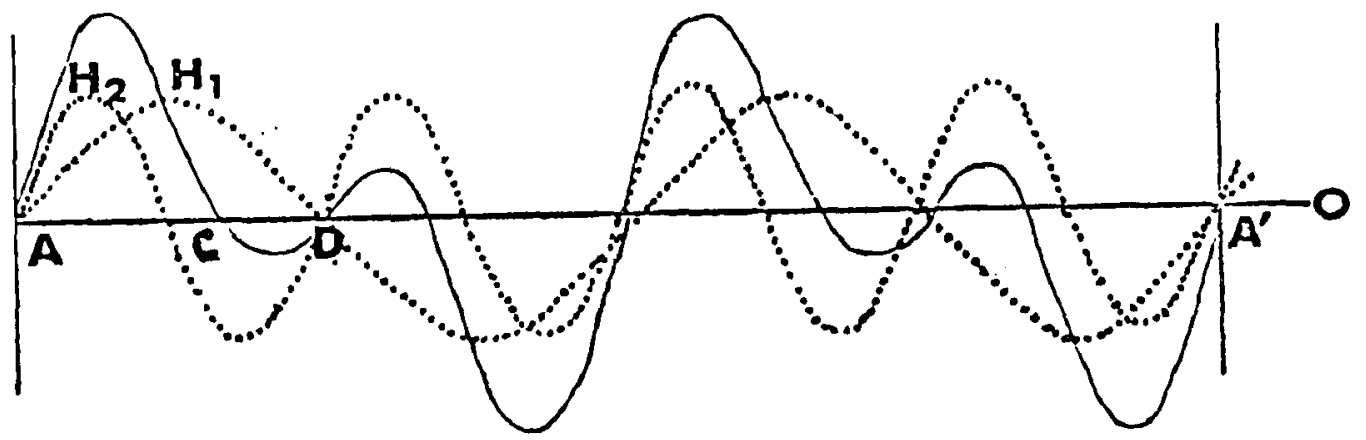

Figure 1. Schematic diagram showing a complex waveform and its two sine wave components.

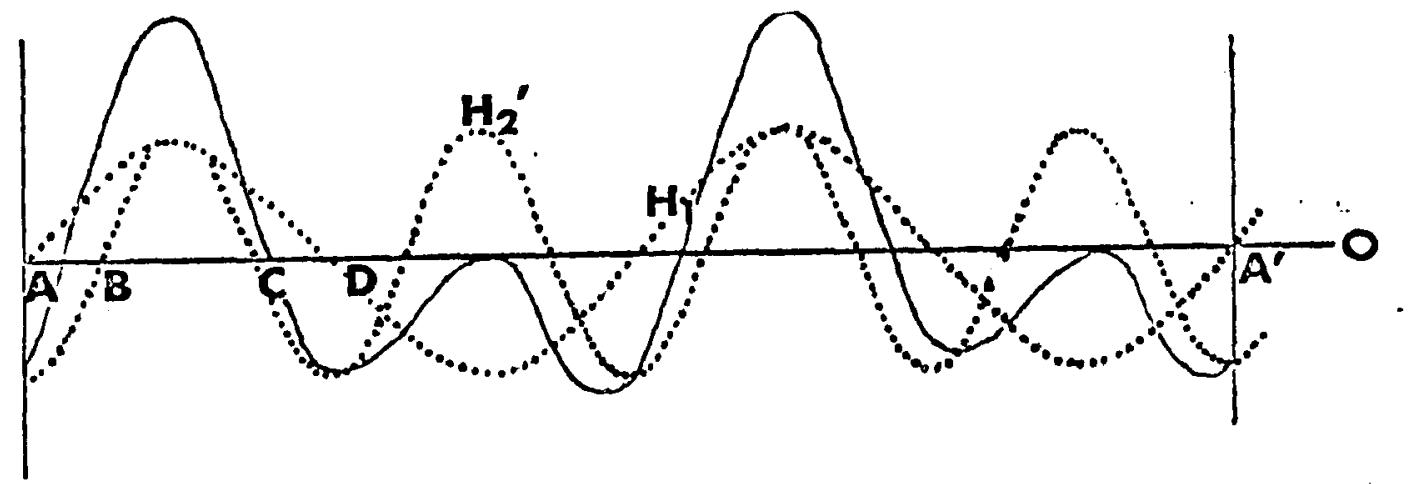

Figure 2. Schematic diagram showing a complex waveform and its two sine wave components, with a different relative-phase relationship than is seen in Figure 1. 
Therefore, the relative phase of the components can never exceed $180^{\circ}$. For a trigonometric discussion of this point, see Stevens and Davis (33). Auditory detection of relative phase shifts within a complex signal have been subject to speculation for almost a century. It is generally accepted that shifts in relative phase relationships are accompanied by subjective changes in loudness, timbre, and pitch, but these changes are admittedly small. The common psychophysical procedure used in determining if relative phase relationships result in subjective auditory differences is to present a pair of stimuli differing only in their relative phase. The subject is then asked to state whether the two were the same or different. An inherent problem with this and any similar psychophysical method is that there is no way of determining the criterion that the subject uses in making his same-or-different judgment. For this reason, as well as for a second to be discussed shortly, the phase-shifted signals were put within the framework of the theory of signal detectability. By utilizing this theory, discussed in more detail in Chapter II, the subject's criterion for judgment can be quant if ied.

The theory of signal detectability has had two almost separate evolutions, originally coming from mathematical-decision theory, with later developments in psychophysics. The original conception of signal detection dealt with the auditory signal as a voltage waveform mixed in a background of noise, and attempted to determine the ideal manner in which this waveform might be divided into a decision space of "Yes, there was a signal present," or "No, there was not a signal present." 
For this theoretical model an "ideal observer" (a mathematical concept, derived without reference to how actual human observers perform in the same situation) was developed. This ideal observer utilized all of the information in the input to arrive at the yes or no decision.

The phychophysical work in signal-detectability theory has largely been devoted to determining how well a human observer performs as compared to the ideal. Since human performance is usually inferior to the ideal observer, it is necessary to attempt to ident ify what aspects of the signal are lost in the auditory mechanism or in the decision process.

Having a dual innervation, as it were, signal detectability covers a broad range of variables under the same framework. This utility also brings with it some inherent difficulties, not the least of which is a lack of communication between the mathematicians and psychophysical investigators. Besides this semantic problem, and while signal detectability theory is still relatively new, there seems to be a dearth of overall, readable reviews on the topic; see, however, Green (14), Tanner and Birdsall (38), Swets, Tanner and Birdsall (36) and Clarke and Bilger (4).

Within the framework of the theory of signal detectability, psychological variables such as motivation, knowledge of results, and duration of observation have been investigated. The physical parameters of signal complexity, duration, frequency, and amplitude, have been investigated extensively. Models for the performance of an ideal observer have been developed and refined. 
The model that is most usually accepted for the detection of complex auditory signals is that outlined by Green (13) in 1958. In this model Green proposed that the detectability of a complex auditory signal is a statistical summation of the detectability of the components of the complex. This model ignores the relative phase of the components of the complex signal in the detection task. This, then, was the second reason for using the theory of signal detectability as the instrument for studying the effect of relative phase relationships on the detection of a complex signal. If there are differences in the detectability of a complex signal as a function of phase relationships between the component sinusoids, another parameter will have to be added to Green's model.

The following chapter will describe the theory of signal detectability and then trace the historical development of research on the acoustic effects of relative phase relationships between components of a complex signal. 
CHAPTER 11

REVIEW OF THE LITERATURE

The Theory of Signal Detectability

The theory of signal detectability developed from statistical decision theory in the early $1950^{\prime} \mathrm{s}$ as a result of military concern over problems in radar. From this beginning the theory was adopted into the realm of psychophysics. The majority of this work was done by the University of Michigan Electronic Defense Group.

It was felt that the theory of signal detectability afforded an opportunity to control the criterion upon which the human observer based his judgment of whether a signal was present or not. In the classical psychophysical task, the perceptual judgment is supposed to be based on only the stimulus parameter that is being varied, for example, the physical intensity of a tone that is "just-noticeablydifferent" than another tone. The intensity variable is quantifiable in definitive terms. The aspect that is uncontrollable is what "just-noticeably-different" means to the particular observer who is listening. The subject's criterion of judgment, in the classical psychophysical task, can never be on anything but a conversational bas is. 
In order to illustrate this more clearly, it is necessary to look at a standard signal-detection situation. Three elements are basic to the signal-detection task, a noise distribution, a signalplus-noise distribution, and a receiver. This receiver need not be a human operator, but could be a mathematical formulation as was the case in the early work in signal detection. The response required from the receiver is a statement of whether the particular time sample under observation contained noise alone, or whether it contained signal-plus-noise.

If the receiver indicates the sample was from the signal-plusnoise condition, and the sample actually did come from this condition, the response is called a "hit" and is indicated as $\mathrm{A} / \mathrm{SN}$. If the receiver indicates the sample came from the signal-plus-noise condition, but noise alone was presented during the time interval, the response is called a "false alarm" and labeled A/N. If the response is that noise alone was present during the interval, and in actuality noise alone was present, the response is termed a "correct rejection" and labeled $B / N$. The other alternative, the situation where the receiver says a signal was not present in the condition when the signal was present, is termed a "miss" and indicated a B/SN. These four alternatives are shown schematically in Figure 3. As can be seen from the matrix in Figure 3, the " $\mathrm{hit}$ " and "correct rejection" represent correct detections by the receiver, whereas the other two possibilities represent errors in response. 
To arrive at a decision about a sample, the receiver applies a measuring instrument (auditory experience for the human observer; mathematical calculation for the ideal observer) to the sample. The instrument measures the sample and compares it to the range of values it will accept as signal-plus-noise. If the sample equals or exceeds a certain cut-off point or criterion, the response will be "Yes, there was a signal present." A sample falling below the criterion will result in a response of "No, there was no signal present."

The two conditions, noise alone and signal-plus-noise, are assumed to have frequency distributions (called also a probability density) which can be thought of as normal-distribution functions. In most work associated with signal-detectability theory, these two conditions are assumed to be Gaussian functions with equal standard deviations. Figure 4 shows these distributions plotted with the

Sample Presented

Signal + Noise Noise Alone

\begin{tabular}{|c|c|c|c|}
\hline & & $(\mathrm{SN})$ & $(\mathrm{N})$ \\
\hline $\begin{array}{l}\text { Signal- } \\
\text { Plus- } \\
\text { Noise }\end{array}$ & (A) & $\begin{array}{l}\text { hit } \\
\text { AlsN }\end{array}$ & $\begin{array}{c}\text { false } \\
\text { alarm } \\
A / N\end{array}$ \\
\hline $\begin{array}{l}\text { Noise } \\
\text { Alone }\end{array}$ & (B) & $\begin{array}{l}\text { miss } \\
\text { B/SN }\end{array}$ & $\begin{array}{c}\text { correct } \\
\text { rejection } \\
B / N\end{array}$ \\
\hline
\end{tabular}

Figure 3. The four possible outcones in the traditional signal detection problem. 


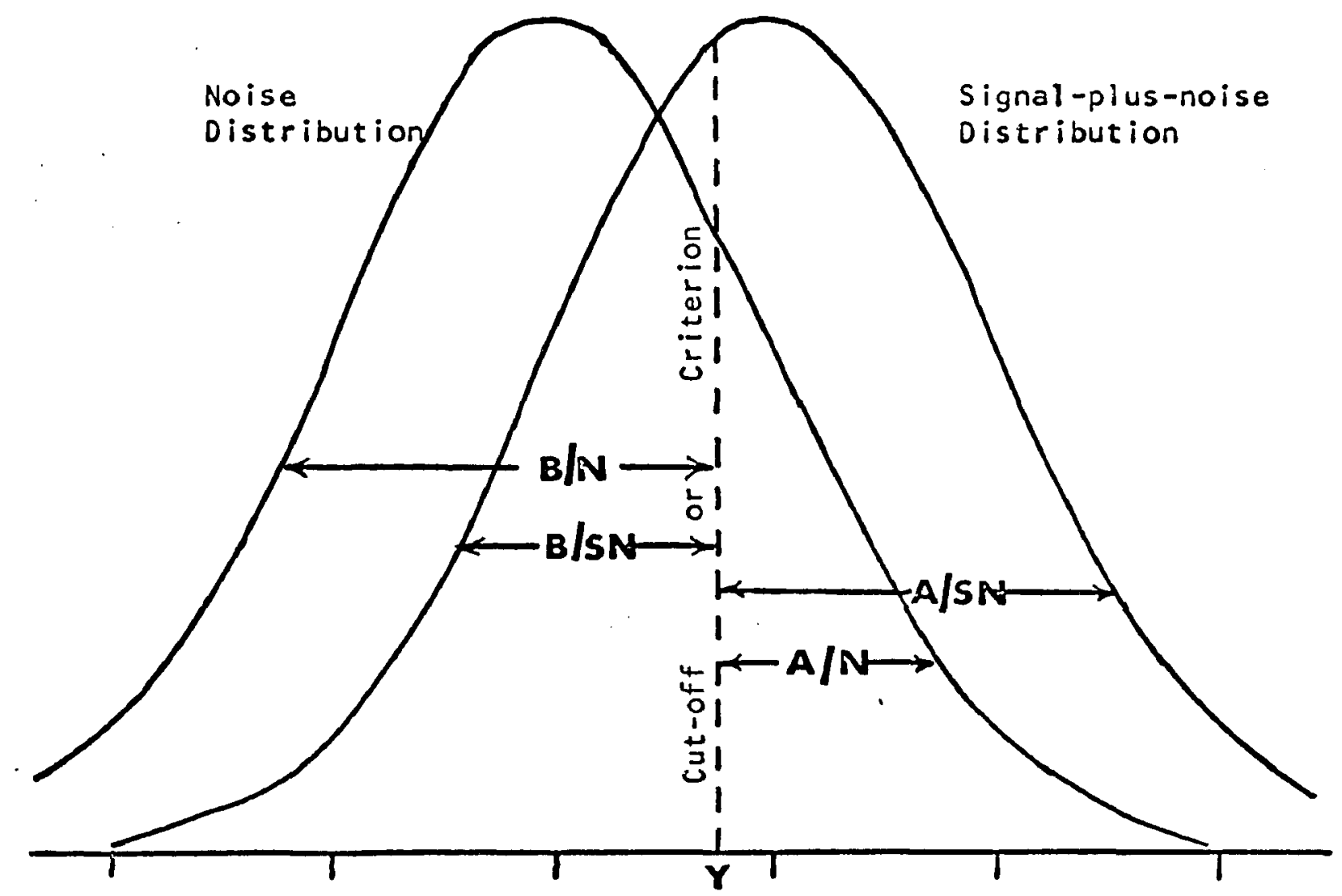

little like signalplus-noise

much like signalplus-noise

Figure 4. Schematic diagram of the traditional signal detection model. The receiver will identify all samples to the left of the cut-off (or criterion) as noise; and all samples to the right of the cut-off as signal-plus-noise. 
abscissa values ranging from a point representing "little like signal-plus-noise" to a point "much like signal-plus-noise." Notice that there are samples from the noise distribution that fall within the area being called signal-plus-noise, and that there are samples from the signal-plus-noise distribution which fall within the area being called noise alone.

It should be obvious that the relative strength of the signal in the noise will be the determining factor in the difference between the means of the two conditions. As the signal becomes stronger with respect to the noise the difference between the means of the two curves becomes greater. This results in a decrease. in the probabilities representing incorrect responses, and a corresponding increase in the probabilities representing correct decisions.

The distance between the two means determines the goodness of the instrument that is deciding between the two distributions. The index most often used to state the degree of separation of the two means is the statistic d'. Since signal detectability can be determined on the basis of both a human observer and a mathematical model, it follows that two definitions of d' would be in order.

For the human operator, the definition of d', generally stated, is that it is the difference between the two means divided by the standard deviation of one of the distributions (remembering, as stated previously, that the two distributions are generally thought of as being normal functions with equal standard deviations). Another way of stating the meaning of d' would be that it represents the goodness 
of the measuring instrument or the strength of the signal with respect to the noise. As a formula, the expression is given as

$$
\underline{d}^{\prime}=\frac{M_{n}-M_{s n}}{\sigma n \text { or sn }}
$$

The definition of $\underline{d}^{\prime}$ when an ideal observer is considered is based only on the physical dimensions of the signal and noise. The formula usually appears as

$$
\underline{d}^{\prime}=\left[\frac{2 E}{N_{O}}\right]^{\frac{1}{2}}
$$

where $E$ is the energy of the signal and $N_{0}$ is the noise power in a unit bandwidth. The derivation of this definition is too cumbersome for this discussion, but the reader is referred to Clarke and Bilger (4) for a concise development of this formula.

By means of $\underline{d}^{\prime}$ the goodness of the measuring instrument for differentiating between the signal-plus-noise and noise-alone conditions can be determined. The receiver's performance in the detection task has not yet been specified, however. For this it is necessary to go back to the concept of the criterion.

of the four possible outcomes of the presentation---hit, miss, false alarm, or correct rejection---it is possible to establish conditional probabilities of the receiver's performance. For example, the probability of a hit, $p(A / S N)$, plus the probability of a miss, $p(B / S N)$, equals one. That is, in the distribution of signal-plus-noise, regardless of the position of the cut-off line, the sum of the hits and misses is still equal to the total area under the curve of signalplus-noise. The probabilities of each will sum to unity. By the 
same token, the probability of a correct rejection, $P(A / N)$, plus the probability of a false alarm, $p(B / N)$, equals one.

The two conditional probabilities which are of interest in the signal-detection task are those associated with the hit situation and those associated with the false alarm.

It can be seen from Figure 4 that shifts in the criterion will change the probabilities associated with these responses. The subject is capable of shifting the criterion at will. In the extreme cases, a probability of zero for the faise alarm event would result when the criterion was established to the extreme right of the abscissa; or, a probability of zero for the hit event would occur when the criterion was established to the extreme left. Possibly a hypothetical case can best illustrate the mobility of the criterion.

The young sheepherder who cried "Wolf!" so frequently had obviously shifted the criterion for judgment to the far left, resulting in the large number of false alarms. Had the young man employed a criterion that was shifted to the extreme right he would probably never have found immortality due to a shortened life-span. The average sheepherder would employ a criterion between these two extremes.

The theory of signal detectability. allows the experimenter to quantify the criterion that the subject is employing, and with this known, the result is a pure measure of the sensitivity of the organism.

The criterion can be illustrated graphically by plotting the probability of a hit against the probability of a false alarm, as seen 
in Figure 5. Looking at the curve associated with a d' of 1.00 , it can be seen that both probabilities can vary from zero to one, depending on the location of the point on the curve. If the probability associated with one event is high, however, the probability associated with the other event is low. A shift of the criterion or cut-off line shown in Figure 4 will change the location of the point on the curve, but as long as the difference between the means remains the same (that is, the value of d' remains constant) the plot points will always fall on that particular receiver-operating-characteristic (ROC) curve.

\section{Detectability of Complex Signals}

Three different models have been proposed for the detection of complex auditory signals. Briefly they are (a) the no-summation model which suggests that the detectability of a complex signal is no better than the detectability of the most detectable component of that complex signal; (b) the multiple-independent-thresholds model which suggests that an increase in detectability of a complex signal will result because only one threshold needs to be exceeded by the complex waveform, and with more components the likelihood of exceeding one threshold increases; and (c) the statistical-summation model which asserts that the outputs from several critical bands within the auditory system combine linearly to improve the detectability of the signal.

Marill (27) found that when the complex signal is composed of two widely separated frequencles (500 and 1000 cps would constitute a wide 


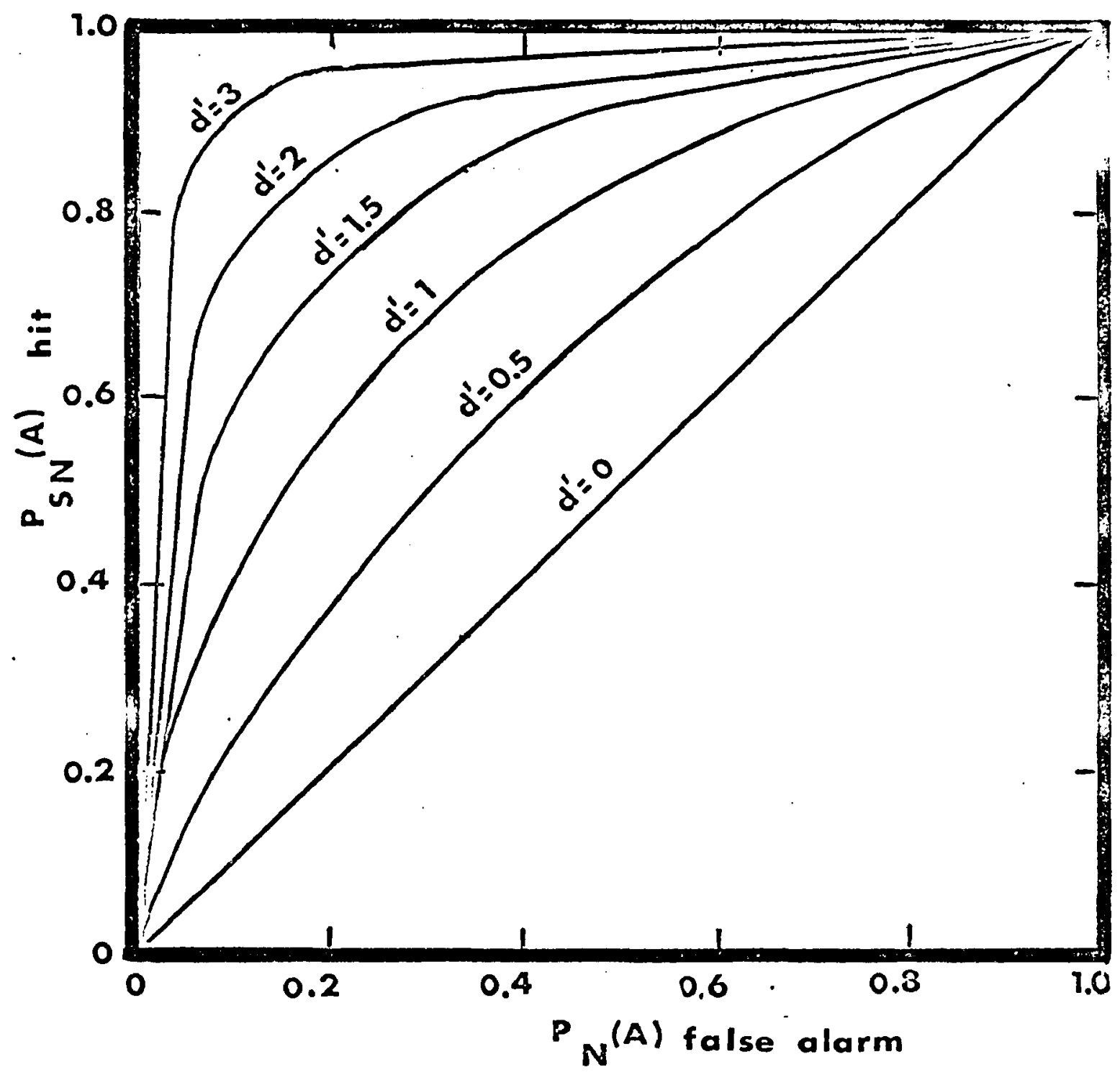

Figure 5. Receiver-operating-characteristic curves for six different d'values. With the d'value held constant, the subject's responses will fall anywhere on the line for that value, depending on the criterion of the subject. Probability of a false alarm is plotted on the abscissa, and probability of a hit is plotted on the ordinate. 
separation) there is no-summation of the two components and the complex remains only as detectable as either one of the components. When the frequencies are close together Marill reported that there is a summation effect.

Tanner, Swets and Green (39) have also reported data which support the conclusion that the observer apparently listens to only one frequency region when the two components are widely separated in frequency. Schafer and Gales (31) found that there is an increase in detectability with a complex signal, although these authors did not utilize the framework of signal detectability as it is now employed. These authors were first to hypothesize the independent-thresholds model for complex signals.

Green (13) tested the three models for detecting complex-auditory signals by utilizing two-component sine waves made up of combinations of the frequencies $500,1000,1823$, and $2000 \mathrm{cps}$. He combined these sine waves "without regard for phase" and suggested that on the bas is of the findings the statistical-summation model seemed to best $f i t$ the data. He reported that the no-summation model did not fit the data in 53 out of 54 cases tested. These results stand in contrast with the results of Marill.

Green demonstrated that two equally-detectable components, when combined, result in a signal that is on the average $1.5 \mathrm{~dB}$ more detectable than either of the components. Because of this, it was necessary to re-define d' for the ideal observer when a complex signal was being used. 
The formula proposed by Green was

$$
\underline{d}_{z}^{\prime}=\left[\left(\underline{d}^{\prime} f_{1}\right)^{2}+\left(\underline{d}^{\prime} f_{2}\right)^{2}\right]^{\frac{1}{2}}
$$

where $\underline{d}^{\prime} z$ stands for the goodness of the measuring instrument to separate the noise and signal-plus-noise distributions when the signal is a two-component complex waveform; $\underline{d}^{\prime} f_{1}$ denotes the detectability of one component alone in noise, and $\underline{d}^{\prime} f_{2}$ refers to the detectability of the second component alone in noise. The more general statement of the formula would be

$$
\underline{d}_{c}^{\prime}=\left[\sum_{i=1}^{n}\left(d^{\prime}\right)^{2}\right]^{2}
$$

Green, Mckey and Licklider (15) tested this model with a complex waveform of the first 16 harmonics beginning at 250 cps and found that it fit the data rather well. These authors were able to support the statistical-summation model and labeled as "unlikely" the multipleindependent-thresholds model.

The relative phase relationships of the complex signals used in the Green, Mckey and Licklider study were varied in two ways. In one condition an "all-cosine" phase relationship was used. This phase pattern signifies that all components of the waveform have a maxima at a particular instant in time. The other phase relationship used by these authors was a random relationship where all components were begun in time on a random basis.

Since the $\underline{d}^{\prime}$ index for both sine waves and complex signals is derived from the energy of the signals, and phase is not a direct 
factor in determining energy, Green, Mckey and Licklider stated:

The results are cons istent with the assumption that variations in phase pattern, which are ignored in Green's model, do not affect the detectability of a compound signal. obviously, however, the meager evidence does not permit us to conclude that phase is not important in detection. "Allcosine phase" is descrlptive of the waveform impressed upon the earphones. The earphones and the ear, itself, undoubtedly introduce relative phase shifts. Whether or not some particular phase pattern is unusual in respect of detectability remains a difficult and unresolved experimental question.

This study, then, was designed to investigate the detectability of a complex signal as a function of the relative phase of the components of that complex signal. Positive results could contribute not only to knowledge of auditory perception of relative phase, but could necessitate an alteration of Green's model for detecting complex auditory signals.

\section{Monaural Phase Effects}

Monaural phase effects (MPEs) have been the subject of theoretical speculation as well as empirical investigation since the Helmholtzresonance theory. In this respect, the time continuum since Helmholtz is divided into two rather well-defined eras, with the midpoint being in the early 1930's. The first era was characterized by the general opinion that the single ear cannot distinguish the relative phase relationships within a complex signal, whereas the more recent period has demonstrated the antithes is of this opinion.

Helmholtz (16) conducted a series of experiments with tuning forks, investigating, among other things, the effect of relative phase shifts of the components within a complex wave. He concluded that ". . differences in musical quality of tone depend solely on the presence and 
strength of partial tones, and in no respect on the differences in phase under which these partial tones enter into composition." While this particular statement does not specifically state that phase is undiscernable, there has been considerable difference of opinion as to whether Helmholtz had intended to say that the ear is phase deaf (6).

There was a between-stimulus interval in the work of Helmholtz which amounted to ". . the expiration of the few seconds necessary for resetting the apparatus. . "(16). Beasley (2) and more recently Craig and Jeffress (8) have pointed out that an interval of several seconds would be detrimental to the absolute judgment of sameness or difference. Craig and Jeffress replicated the Helmholtz experiment with more modern equipment and found that increasing the inter-stimulus interval from .4 to 1.0 seconds made subject judgments significantly poorer.

Shortly after the publication of On the Sensations of Tone, several other investigators examined MPEs. For the most part they reported negative results, but as Beasley (2) has pointed out in his review of the early work, a large number of these negative results were due to uncontrolled physical conditions.

Koenig $(19,20)$ stands out as the only one of the early-period writers to suggest that the ear can detect, monaurally, phase changes within a complex signal. He said that not only are there quality changes, but there are intensity changes as well. Koenig reasoned that if the quality of a tone depends in part on the relative strength 
of the harmonics, and if phase alters this relative strength, then phase actually introduces subjective changes.

In demonstrating the effect of phase, Koenig drew large-scale representations of compound wave forms with different relative phase relationships. Each curve was reproduced on thin metal and carefully cut out. These waveforms were fastened to the rim of a disc and rotated at various speeds whlle an air jet passed over the edge. Besides differences in intensity of the signal, Koenig also reported the auditory perception of quality differences.

Beasley (2) has suggested that the siren wave used by Koenig did not change precisely with the changes in the curvature of the siren plates, and this could possibly play a role in the subjective results found by Koenig.

Herman (17) also duplicated the work of Koenig with a siren disc. He concluded that changes in intensity were the result of changes in the wave patterns of the siren disc and not the result of phase changes. Herman agreed with the Helmholtz "phase deaf" implication. Gray (12) sided with the majority in 1899 by stating that the single ear cannot ". . distinguish a phase change in a complete harmony." Gray based his conclusions on experimentation with tuning forks.

A "floating phase effect" (more commonly referred to as monaural beats) was shown by ter Kuile (40) shortly after the turn of the century. He demonstrated this effect by using tertiary harmony from two tuning forks, one of which was slightly mistuned. While this was 
a definite example of the ear hearing a phase effect, it still did nothing to refute the then common idea that phase effects were not distinguishable in a complex signal of perfect-harmonic structure.

Lindig $(23,24)$ concurred with ter Kuile that beats were a phase effect, but he insisted that the quality of a tone was not changed in any other way by changing the relative phase of the partials.

Max Meyer (29) wrote of MPEs in his 1903 publication. His prophetic conclusions that under certain conditions phase alterations may change the quality of a tone were not based on personal experimentation, but rather were the result of purely theoretical formulations.

Using alternating-current generators and telephone receivers, Lloyd and Agnew ( $2 \theta$ reported that the relative phase relationship between the partials of a complex signal were not important in the resulting quality of the signal. In this study the authors varied the relative phase relationship between the partials as the signal was being cont inuously presented. They reported some differences with changes in the relative phases, but added that further investigation revealed these subjective changes to be the result of uncontrolled physical variables.

Miller (30) summed up the findings of the early work on MPEs and suggested that the concensus was in favor of phase being a nondiscriminable auditory event. The work of Lloyd and Agnew (26) in 1909 signaled the end of the first period of investigation for 
MPEs. There was a lull in the research on the topic, almost as though the null hypothes is had been accepted.

The work of Beasley $(1,2)$ turned the thinking on MPEs by demonstrating in several convincing articles that relative phase shifts in a complex signal are discernible. Beasley used a specially designed audio-signal generator which was capable of combining various frequencies as well as adjusting the phase relationships between them. Beasley had his subjects listen to pairs of stimuli and then judge them for sameness or difference on the basis of tonal quality. In these studies the author employed a two-component complex wave, but adjusted the frequency ratio. The stimuli were presented for 30 seconds with the phase relaticaships between the partials continually varying in one condition but remaining constant in the other. In one part of the study the intensity level of the combined signal was $10 \mathrm{~dB}$ sensation level.' At this level phase changes could not be detected by his three experienced listeners. Beasley then raised the intensity to a level of 25-30 dB SL. He indicated that even though the harmonics were still at a below-threshold level, the subjects could now detect the phase shifting condition with an accuracy of 90 percent. The subjects reported the changes in the tone involved timbre. Beasley stated that intensity changes were present, but seemingly were small in magnitude.

Chapin and Firestone (5) showed that intensity changes with the shift of relative phase between the partials of a complex signal.

1 Reference level, subject's auditory threshold. 
They presented two subjects with a 108 cps fundamental at $104 \mathrm{~dB}$ SPL. Five harmonics were combined with the fundamental (one at a iime), and the relative phase of the two signals was varied. The tonal quality, as well as the loudness of the combination were found to change with phase shifts. The resulting combinations were judged to be from $3.5 \mathrm{~dB}$ below to $7 \mathrm{~dB}$ greater than that of the fundamental. The results of this study were said to be a function of the ear creating subjective harmonics which can either add to or subtract from the total signal depending on the relative phase of the components. Figure 6 shows the results of the intensity changes due to the relative phase of the components.

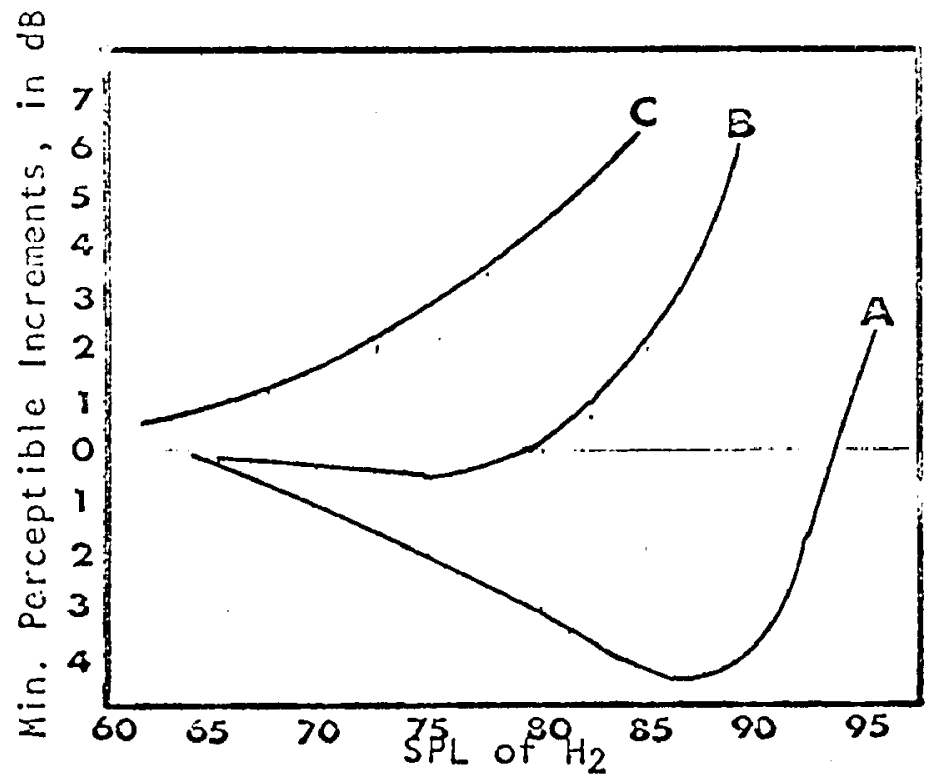

Figure 6. Change in loudness of a 108 eps fundamental at 104 dB SPL as a function of adding various amounts of the second harmonic in three different relative phase relationships: $(A)$ the second harmonic is $180^{\circ}$ out of phase with respect to (C); (B) represents an intermediate value between these two. 
Licklider (22) used a complex tone of 16 harmonics with a fundamental of $250 \mathrm{cps}$ and reported that in almost all cases a change in relative phase between the harmonics resulted in discriminable changes in pitch or timbre. In general, Licklider reported that low-frequencycomponent changes resulted in less effect than did the changes in the high-frequency components.

Schroeder ( 32 ) reported that peak factor seems to be the determiner of timbre. He used a periodic waveform of constant amplitude which contained up to 31 discernible harmonics. As the phase of the harmonics was changed relative to the fundamental, both timbre and pitch were altered. In fact, Schroeder reported that certain manipulations of the phase relationship allowed him to play simple melodies. If the envelope of the signal remained constant even after shifting the relative phase, there were no (or at least very small) subjective changes. The phase changes which led to identical peak factors had smaller but still audible quality differences.

Mathes and Miller ( 28 ) had earlier noted that the "peakedness" of the envelope was closely associated with timbre--higher peak factors being rougher in quality and smaller peak factors being smoother. It had been noted that a change in the time envelope of a waveform could be made by altering the relative phases of the components, either individually or in a group. Mathes and Miller summarized the findings, some new with their work, others previously found, partially as follows. 
1. The tone quality of a complex steady-state sound depends not only upon the components present, but also, over certain ranges of frequency and level, upon the envelope shape as controlled by relative amplitudes and phases.

2. That is, contrary to a widespread impression that the ear acts as an analyzer of frequencies regardless of their relative phases, large changes can result in aural perception through changes only in phase among systematically related groups of components.

3. The degree of harshness is related to the relative length and depth of the recurrent depressions in the envelope wave.

8. A marked periodicity in the envelope wave was associated with a sense of basic pitch. In certain complex patterns this periodicity could be doubled or tripled by the phase shift of a single component, which, in turn produced a corresponding change in this apparent pitch.

In a follow-up to the Mathes and Miller study, David, Miller and Mathews (9) attempted to determine if changing the shape of the envelope in a more complex waveform---speech---by altering the relative phase relationship between partials affected the subjective quality of the product. These authors embarked on this task, hoping to decide if relative phase of the partials is a necessary parameter in speech synthesis. Previous to their work, phase had been ignored in simulation studies. The authors concluded that spectral phase information does contribute to speech quality, particularly when listening over earphones. They did indicate that in the present state of speech synthes is other distortions may mask phase effects.

Craig and Jeffress $(6,7)$ reported a significant study in which a two-component complex signal was modified with regard to the relative 
phase relationship between its components. Besides variations in phase, they systematically altered the intensities of both the fundamental and second harmonic. These investigators were attempting to quantify an earlier informal discovery of Wood who noted that an asymetrically-peak-clipped sinusoid was different in timbre when the clipped portion was in the rarefaction as compared to the compression portion of the cycle.

By creating a two-component complex signal with a relative phase relation of $0^{\circ}$, Craig and Jeffress had, effectively, either a flattopped or flat-bottomed waveform (the position of the leads to the earphone would be the determiners of whether the flat portion was in the compression or rarefaction portion of the cycle). As the second harmonic was shifted out of phase with respect to the fundamental, the resulting waveform became more peaked. Craig and Jeffress utilized phase relationships of $0^{\circ}, 45^{\circ}, 90^{\circ}$ and $135^{\circ}$. Examples of waveforms similar to these can be seen in Figures 7-18 of Chapter III.

The task of subjects used in the Craig and Jeffress study was to determine, in effect, whether a given stimulus had the "clipped" portion in the compression orrarefaction half of the cycle.

Sixty judgments were made in each of the conditions. Thirty of the stimuli were presented with the flat portion of the wave in the compression half of the cycle, and the other 30 had the flat portion of the wave in the rarefaction half of the cycle.

The authors suggested that a possible expected result would have been for chance to be in effect at the low-intensity levels of 
the second harmonic, and for the responses to either raise or lower monotonically with increasing intensities of the second harmonic. Rather than this, the results demonstrated an increase away from chance, up through the middle intensities of the second harmonic, followed by a move back toward chance at high-intensity levels. This was followed in one case by a drop below the chance level at the highintensity levels of the second harmonic. The authors suggested that this indicated multiple mechanisms of phase detection. They proposed that there are certain "critical intensity levels" of the stimulus components, resulting in three different monaural-phase effects. They indicated that the breaking point for these "critical levels" were at about $75 \mathrm{~dB}$ SPL for the fundamental and at about $40 \mathrm{~dB}$ SPL for the second harmonic.

The low MPEs, where both components are below their "critical levels," resulted in "slight changes in pitch and/or timbre." For the mid-MPEs, where the second harmonic was above the "critical level" but the fundamental remained below it, there were also slight changes in pitch and/or timbre. For the high MPEs, when both components were above their "critical levels," the results were mainly changes in loudness. Pitch and timbre became secondary in these high MPE conditions.

One of the interesting findings of the Craig and Jeffress study was the large inter-subject differences. They reported that certain combinations of phase and intensity produced tones which sounded higher pitched, louder or purer to some listeners, but lower pitched and softer or less pure to others. 
Summary of MPE Studies

The preceding section has traced the development of thinking on monaural phase effects. It has shown that the current opinion holds that monaural phase relationships are a significant auditory experience, being subjectively detected as pitch, quality, and intensity changes. Moreover, it has been shown that changes in phase which result in changes in the peak characteristics of the time envelope serve as the possible bas is of these subjective differences.

The following chapter will describe the procedures used in this study. 


\section{CHAPTER III}

\section{PROCEDURES}

This study was designed to investigate the detectability of a complex signal as a function of the relative phase of the components of that complex waveform. The signal used in this investigation was composed of a fundamental frequency and its second harmonic.

\section{$\underline{\text { Stimul i }}$}

The complex signal was composed of a fundamental frequency of 525 cps and a second harmonic of $1050 \mathrm{cps}$. The combination of the two components was altered through six phase relationships: $0^{\circ}, 30^{\circ}, 60^{\circ}$, $90^{\circ}, 120^{\circ}$, and $150^{\circ}$. The resulting waveforms can be seen in Figures $7-18$.

The voltages of the two sine waves were varied in two ways. In one condition, the peak-to-peak voltage of the two components was equal, as monitored on an oscilloscope (Tektronix, Type 502). In the second condition, the voltage of the $525 \mathrm{cps}$ fundamental was twice that of the second harmonic. This made the two signals subjectively equal in loudness (11).

A beat-frequency oscillator (Bruel \& Kjaer, Type 1014) was used to generate the fundamental sine wave. The output of the oscillator was divided and the two lines, as seen in Figure 19, went to (a) a pulse 


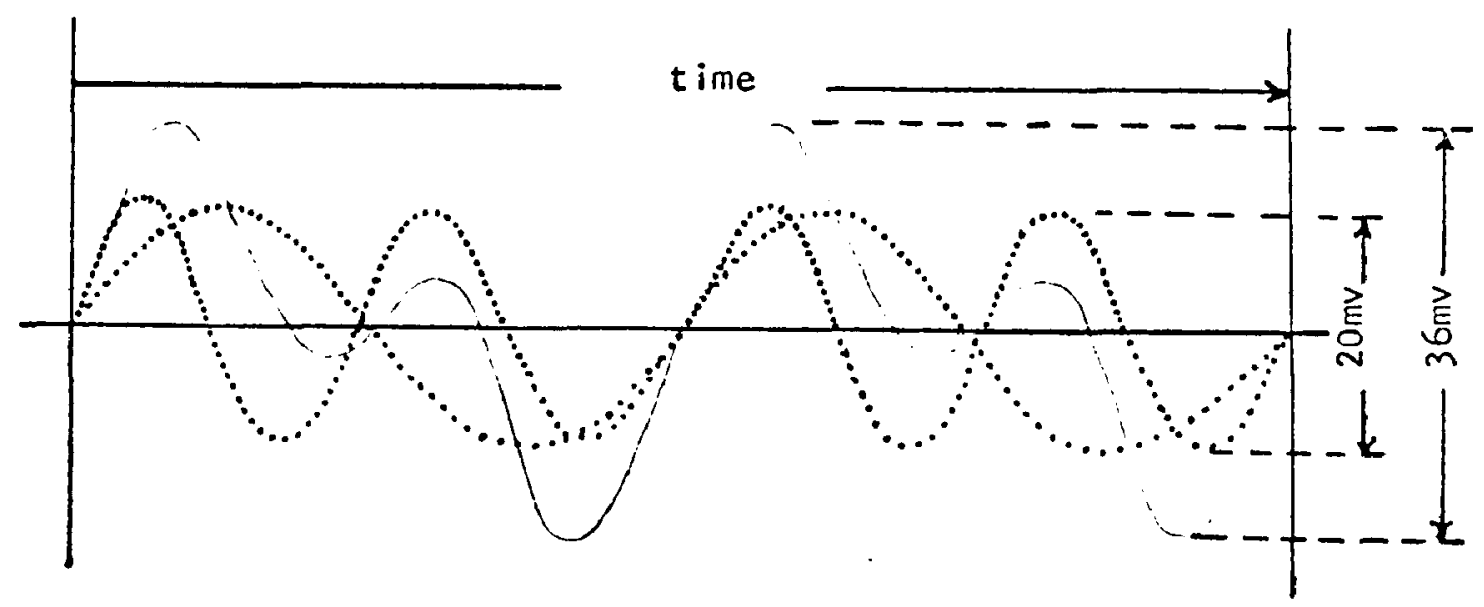

Figure 7. Schematic drawing of the complex waveform composed of two sine waves of equal peak-to-peak voltage. Peak-to-peak voltage of the complex wave is only as estimate. The relative-phase relationship of the components is $0^{\circ}$.

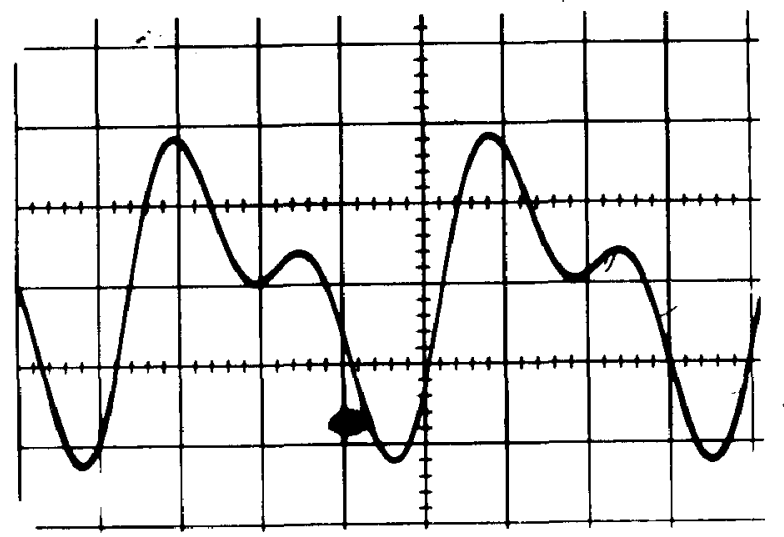

Figure 8. Oscilloscope picture of complex waveform composed of two sine waves of equal peak-to-peak voltage. The relative phase relationship of the components is $0^{\circ}$. 


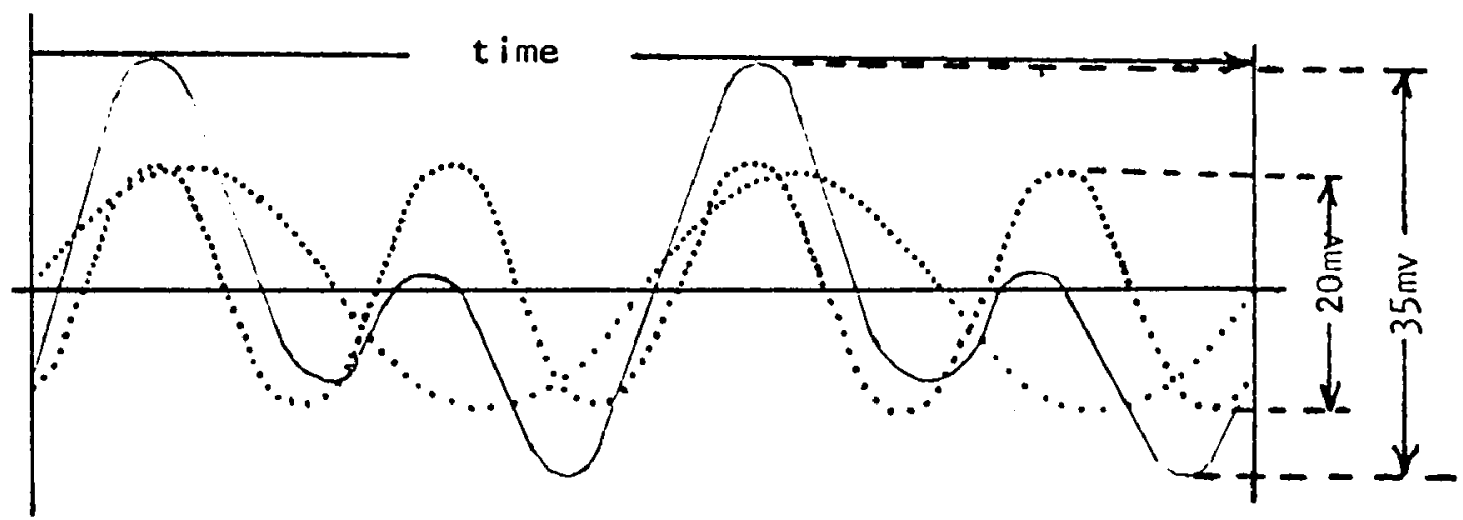

Figure 9. Schematic drawing of the complex waveform composed of two sine waves of equal peak-to-peak voltage. Peak-to-peak voltage of the complex wave is only an estimate. The relative-phase relationship of the components is $30^{\circ}$

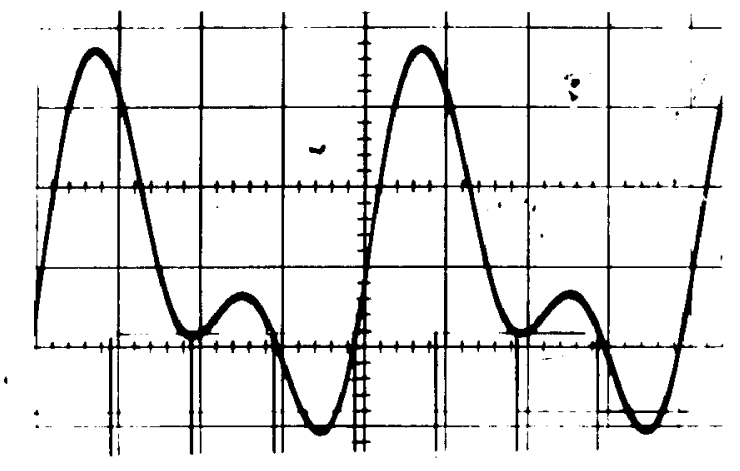

Figure 10. Oscilloscope picture of complex waveform composed of two sine waves of equal peak-to-peak voltage. The relative-phase relationship of the components is $30^{\circ}$. 


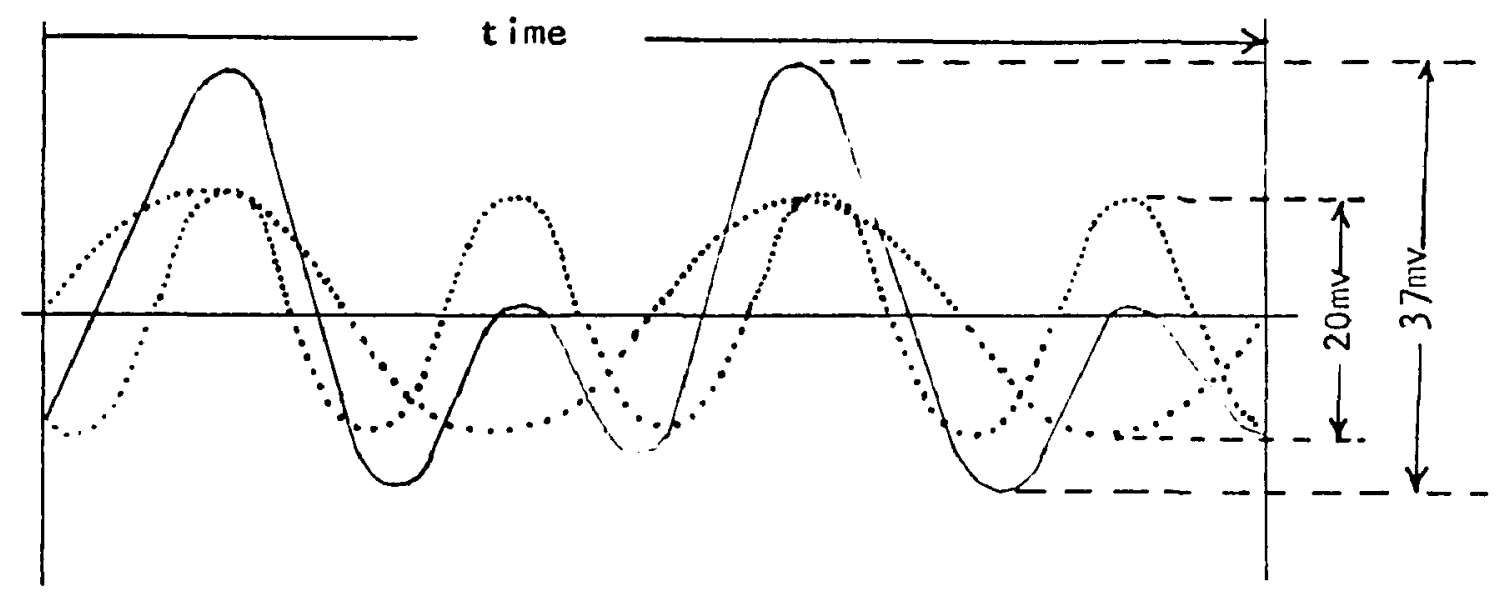

Figure 11. Schematic drawing of the complex waveform composed of two sine waves of equal peak-to-peak voltage. Peak-to-peak voltage of the complex wave is only an estimate. The relative-phase relationship of the components is $60^{\circ}$.

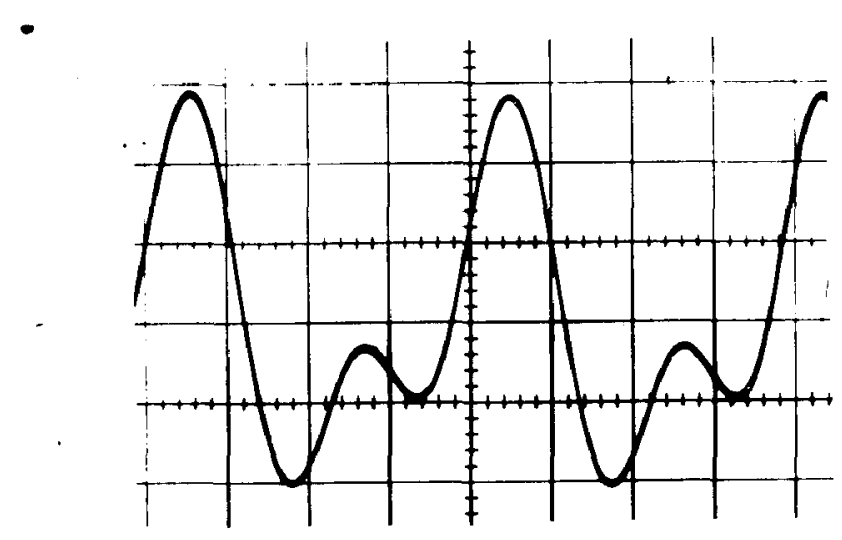

Figure 12. 0scilloscope picture of complex waveform composed of two sine waves of equal peak-to-peak voltage. The relative-phase relationship of the components is $60^{\circ}$. 


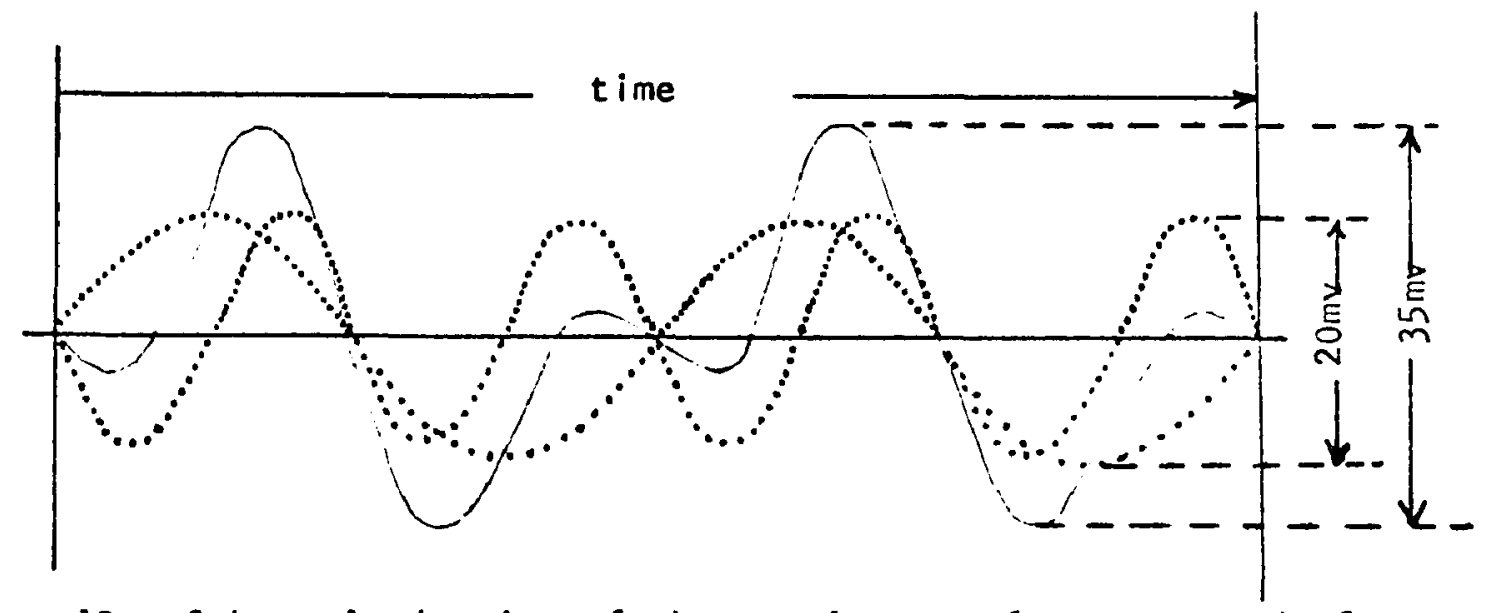

Figure 13. Schematic drawing of the complex waveform composed of two sine waves of equal peak-to-peak voltage. Peak-to-peak voltage of the complex wave is only an estimate. The relative-phase relationship of the components is $90^{\circ}$.

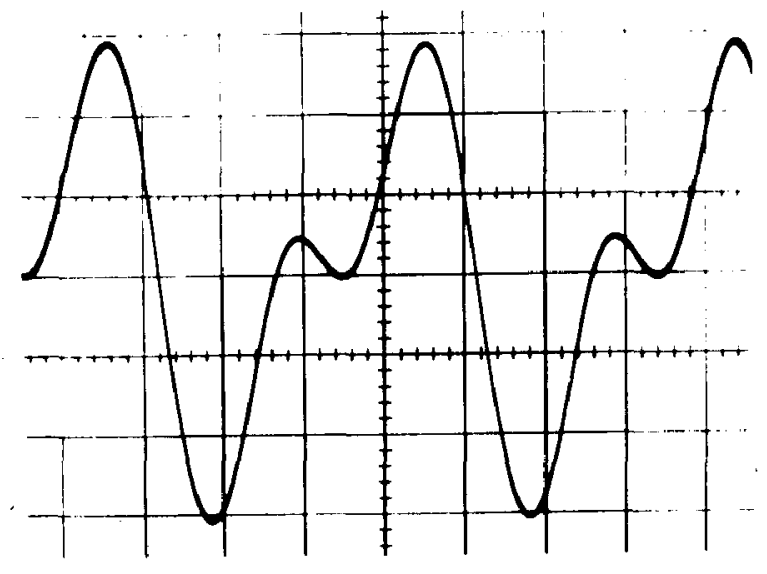

Figure 14. 0scilloscope picture of complex waveform composed of two sine waves of equal peak-to-peak voltage. The relative phase relationship of the components is $90^{\circ}$. 


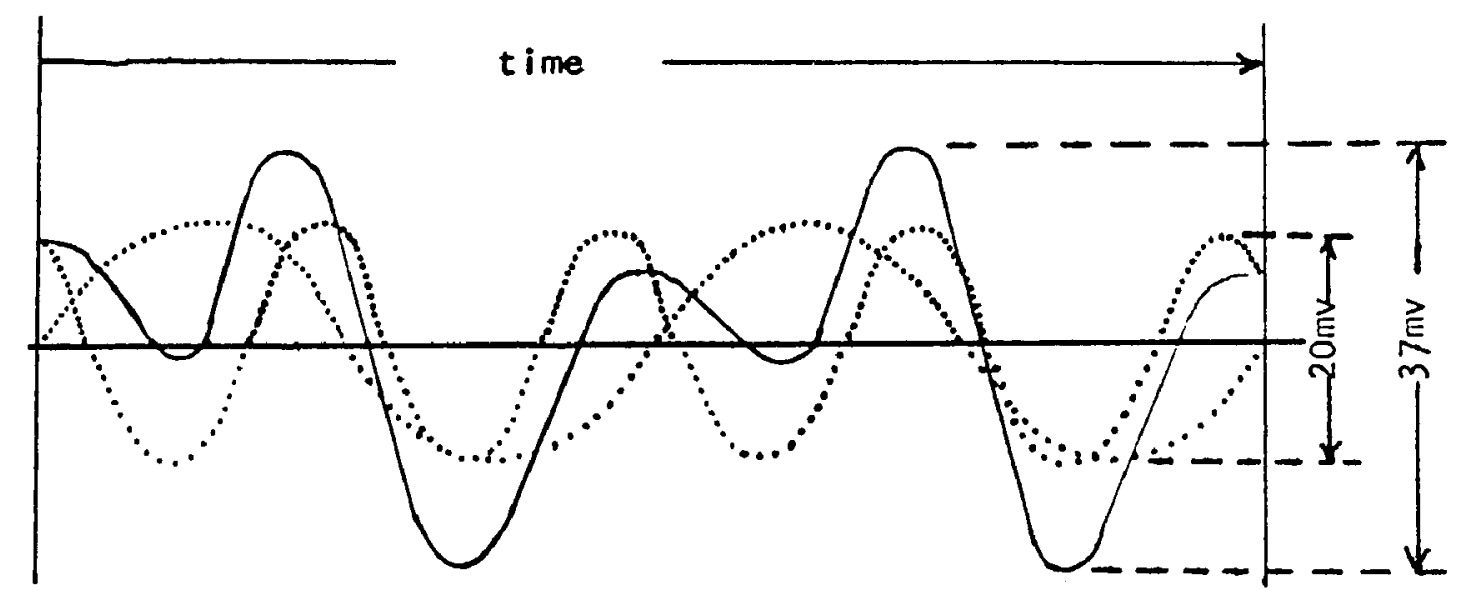

Figure 15. Schematic drawing of the complex waveform composed of two sine waves of equal peak-to-peak voltage. Peak-to-peak voltage of the complex wave is only an estimate. The relative-phase relationship of the components is $120^{\circ}$.

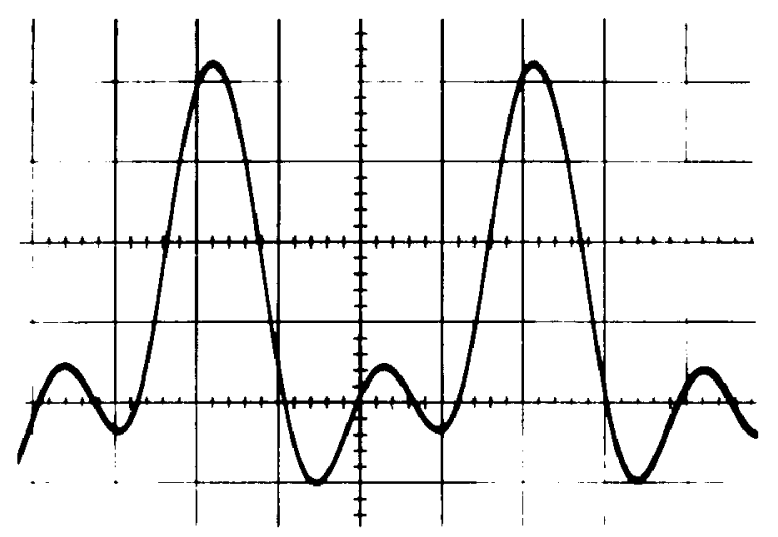

Figure 16. Oscilloscope picture of complex waveform composed of two sine waves of equal peak-to-peak voltage. The relative-phase relationship of the components is $120^{\circ}$. 


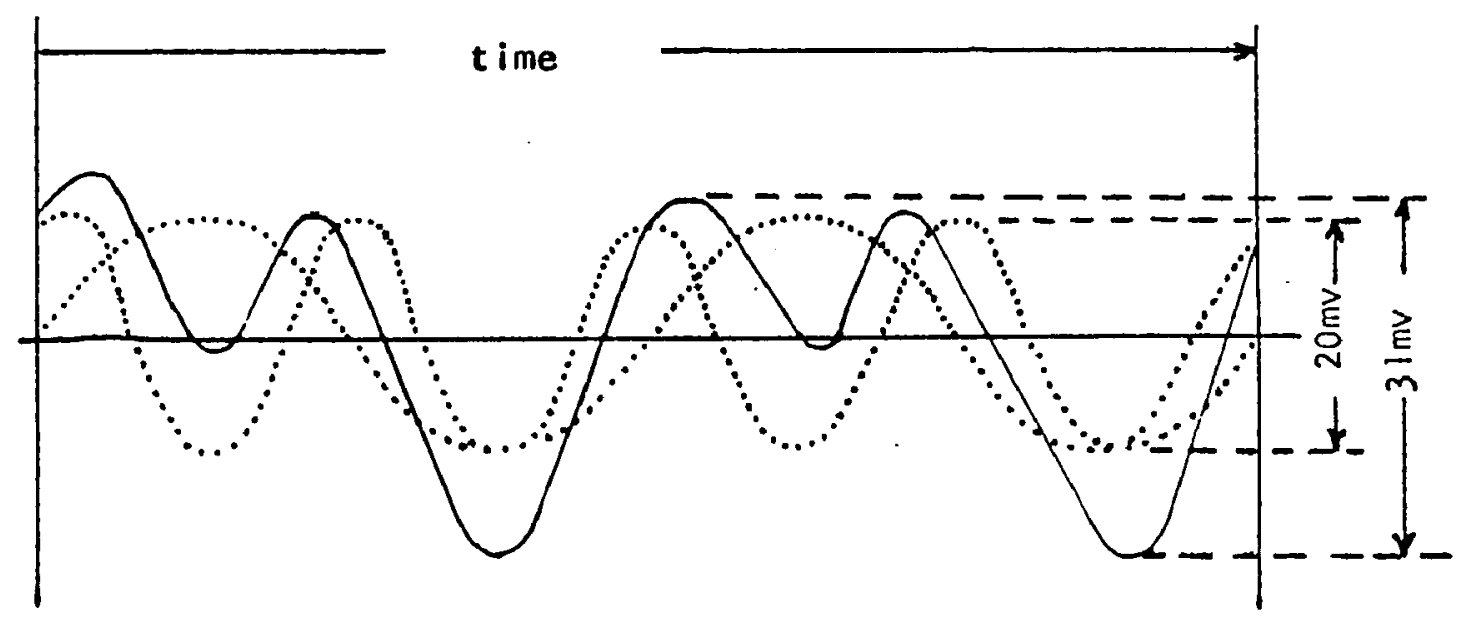

Figure 17. Schematic drawing of the complex waveform composed of two sine waves of equal peak-to-peak voltage. Peak-to-peak voltage of the complex wave is only an estimate. The relative-phase relationship of the components is $150^{\circ}$

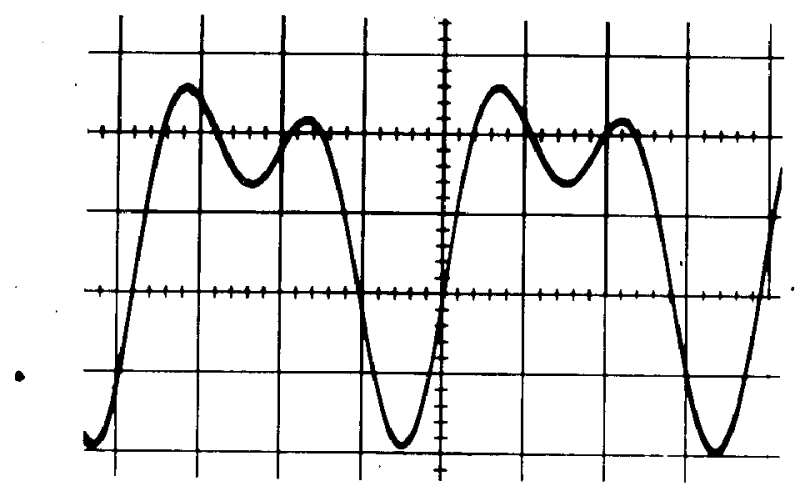

Figure 18. Oscilloscope picture of complex waveform composed of two sine waves of equal peak-to-peak voltage. The relative-phase relationship of the components is $150^{\circ}$. 


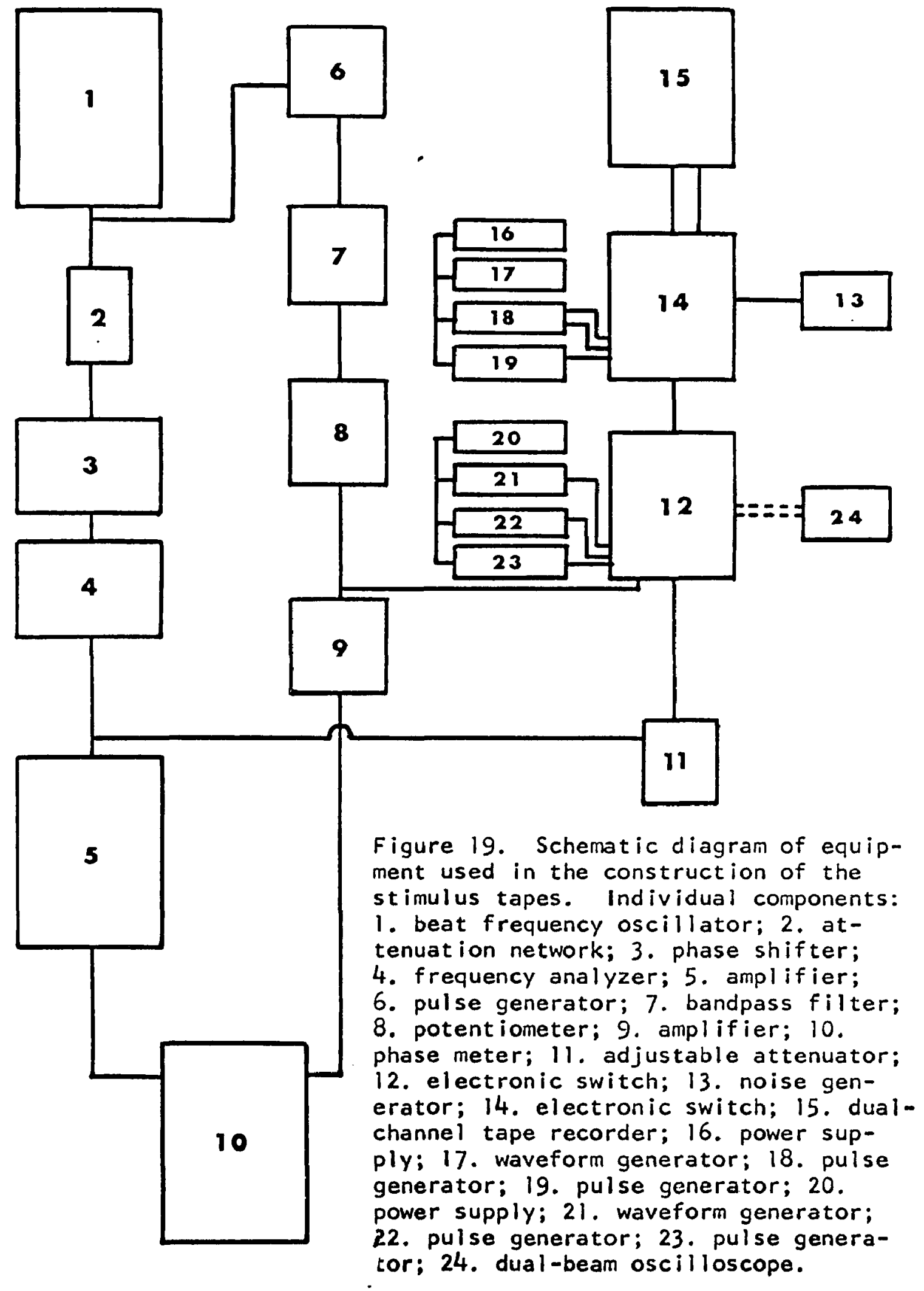


generator (Tektronix, Type 161) where the frequency was doubled and passed through a bandpass filter (T.T. Electronics, 90 dB per octave roll-off) of $1050 \mathrm{cps}$; and (b) an attenuator (Daven, Spec. 2410) into the phase shifter (34). The output of the phase shifter was passed through a frequency analyzer (Bruel \& Kjaer. Type 2105) and into one channel of an electronic switch (Grason-Stadler, Model No. 829890). Prior to this termination the phase-angle meter (Acton, Type 320-AB) was connected in parallel to provide for continual monitoring of the relative phase of the two components. The output from a noise generator (Grason-Stadler, Model 455B) was fed to the second channel of the same electronic switch.

A second electronic switch (Grason-Stadler, Moder 829D), coupled with two pulse generators (Tektronix, Type 161 and 163) and a waveform generator (Tektronix, Type 162), was used to form the signal and noise into synchronous bursts of $100 \mathrm{mill}$ iseconds. The rise and decay times of the signal and noise bursts were held constant at 2.5 milliseconds. The two output channels from the electronic switch were terminated in separate channels of a dual-channel tape recorder (Ampex, Model 601-2).

A second waveform generator (Tektronix, Type 162) and two additional pulse generators (Tektronix, Type 163) gated four bursts of both signal and noise before resetting. An adjustment of the waveform generator allowed the experimenter to pass any one of the four signal bursts while suppressing the other three. Four hundred frames (a frame consisted of the four noise bursts and one burst of signal presented simultaneously with one of the noise bursts) were recorded for each phase relationship. 
level throughout all of the recordings. The mixed signal was then recorded (Ampex, Model PR-10).

The resulting tapes, 12 in number, contained 400 frames each. Forty sets of judgments covering a signal-to-noise ratio range of $10 \mathrm{~dB}$ (average threshold being somewhere in the middle, as previously described) were contained on each tape. Listening time for each tape was approximately 30 minutes.

With a complex signal containing sine waves of equal peak-topeak voltage, the root-mean-squared (RMS) value of the resulting signal will remain constnat regardless of the phase relationships of the components. (Appendix A describes the above statement mathematically.) However, as can be seen in Figures 7-18, the peak-topeak voltage of the resulting complex waves do not remain constant with shift of the relative phase of the components.

Four more tapes were constructed in which the peak-to-peak voltages of the resulting complex waves were equated. From the group of six tapes in which the peak-to-peak voltages of the twocomponent sine waves was equal, Tape five, representing a $120^{\circ}$ relative-phase relationship, was selected as the standard. The peak-to-peak voltage of this complex signal was measured on an oscilloscope. Two other tapes in this group, Tapes two and four, representing the $30^{\circ}$ and $90^{\circ}$ relative phase relationships were randomly selected. The peak-to-peak voltages of these complex signals were measured. By means of an additional attenuation network preceding the attenuation network shown in the signal channel 
of Figure 20, it was possible to adjust the voltages of these two tapes to equal that of the chosen standard. With this accomplished, Tapes two and four were re-recorded as before.

In the condition where the voltages of the two sine wave components of the complex signal were subjectively equal in loudness, the same procedure was followed in the construction of two additional tapes. Table 1 shows the peak-to-peak voltage measurements of the six tapes involved in this adjustment.

It was necessary to determine if the shifted phase relationships introduced additional overtones which might play a part in the resulting signal to be detected. For this reason, Fourier analyses of the complex signals were made. The procedure and results are described in Appendix B. Suffice it to say here that there were no extensive differences in the resulting signals, regardless of the phase relationships of the components.

\section{Subjects}

Four subjects, two male and two female, were originally employed as listeners. Three of the subjects were enrolled in The Ohio State University, two as graduate students and the third as an undergraduate, all in the Department of Speech. The fourth subject was a recent graduate, employed in the Speech and Hearing Clinic. The ages of the subjects ranged from 21 to 25 with a mean age of 22. Due to the performance of one of the four subjects it was later necessary to use a fifth subject. This subject was a 21-year-old male, undergraduate, majoring in speech and hearing. 
A random order was followed in choosing which of the four signal bursts was going to be recorded in the 400 frames.

The twelve master tapes (six phase relationships in each of two peak-to-peak voltage conditions) were re-recorded in order to mix the noise and signals at different signal-to-noise ratios.

In a pllot study twelve persons listened to the combined signaland-noise frames to determine a "threshold" of detectability. The attenuator setting of the signal channel at "threshold" was averaged for the 12 subjects and this point served as the midpoint of the signalto-noise ratio range. A signal-to-noise ratio range of $10 \mathrm{~dB}$ was employed, from six dB above to four dB below this "threshold." Figure 20 represents the schematic lay-out of the re-recording process.

As can be seen in Figure 20, the output of the signal channel of the dual-channel recorder was bridged with an attenuation network (Daven, Type $T-690-A$ ) so that the ten signal intensities could be established. The output of the noise channel was also bridged with an attenuation network (Daven, Type T-690-A), to maintain a constant

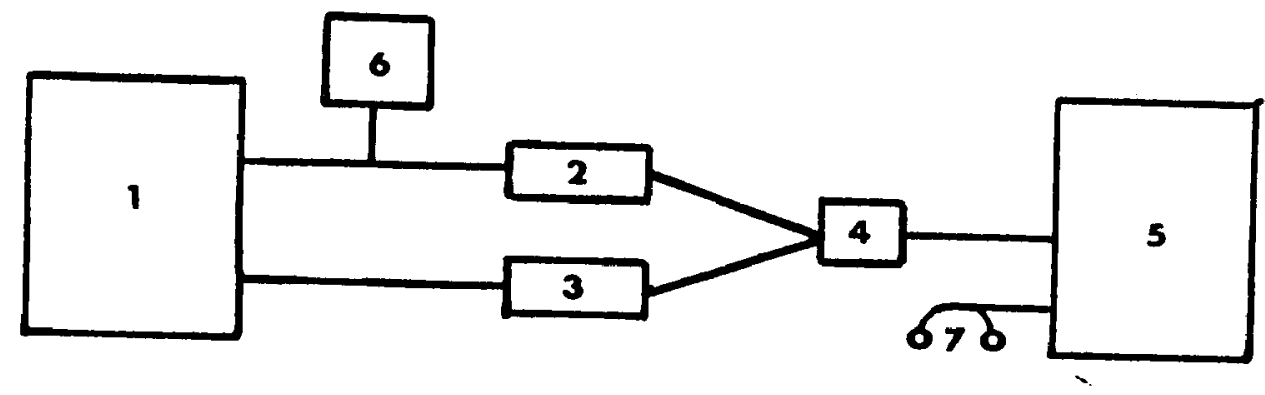

Figure 20. Schematic diagram of equipment used in the re-recording of the stimulus tapes. Individual components: (1) dual-channel tape recorder; (2), (3) attenuation networks; (4) potientiometer: tape recorder; (6) voltmeter; (7) earphones. 
Table 1. Average peak-to-peak voltages of the complex waveforms prior to and after adjustment for equality. The $120^{\circ}$-stimuluscondition tapes were used as the standards, to which the other stimuli were adjusted. The first three phase relationships on the Table were composed of sine waves having equal peak-to-peak voltage prior to being mixed to form the complex waveform. The other three stimulus tapes had component sine waves of subjectively-equal loudness.

\begin{tabular}{ccc}
$\begin{array}{c}\text { Relative } \\
\text { Phase Relationship }\end{array}$ & $\begin{array}{c}\text { Average } \\
\text { Peak-to-Peak Voltage } \\
\text { of Complex Waveform }\end{array}$ & $\begin{array}{c}\text { Average Peak- } \\
\text { to-Peak Voltage of } \\
\text { Complex Waveform After } \\
\text { Attenuation }\end{array}$ \\
\hline $30^{\circ}$ & $92 \mathrm{mv}$ & $25 \mathrm{mv}$ \\
$90^{\circ}$ & $116 \mathrm{mv}$ & $25 \mathrm{mv}$ \\
$120^{\circ}$ & $102 \mathrm{mv}$ & $24 \mathrm{mv}$ \\
& & $20 \mathrm{mv}$ \\
$30^{\circ}$ & $78 \mathrm{mv}$ & $19 \mathrm{mv}$ \\
$60^{\circ}$ & $96 \mathrm{mv}$ & $19 \mathrm{mv}$
\end{tabular}


There was an accumulation of data as to the hearing acuity and discrimination abilities of four of the five subjects. The subjects were chosen for their conscientiousness and willingness to act as subjects.

The listening times were chosen by the subjects and all of the data were gathered over a four-week period.

\section{Instructions and Test Procedures}

A practice tape was used to introduce each of the subjects to the task by giving them opportunity to experience the sequence of presentations. The following is the text of the practice tape:

You are about to begin a task in signal detection. Generally, signal detection is the judgment of whether a signal is present in a given noise field. More specifically, you are going to be presented with four short bursts of noise. One of the four will be different from the other three. You will be asked to tell which one is different. Here is a sample of the four bursts of noise.

Could you tell that one was different? It was number two. Now here is what a signal alone sounds like.

Listen now to another frame (containing four noise bursts), and try to tell which one is different.

Did you hear it? It was number two again. Here it is again.

You no doubt detected it that time. Now, this frame is an example of the easiest signal detection task that you will be hearing. Following now will be ten frames. Type the number of the burst that is different on the typewriter in front of you.

The correct answers to the ten frames were: $3,4,1$, $1,4,3,3,2,3,4$. You probably did well on these, but possibly you missed number ten. This is understandable 
since it represented the most difficult of the signal detection tasks that you will encounter.

The tapes that you will be hearing are designed so that only about $50 \%$ correct is possible.

One thing is important; if you don't know which interval contained the signal, guess. It's mandatory that you make a response to every frame.

You will now receive a series of practice frames. Roll the answer sheet up until you see the word STOP appear above the black space indicator at the left of the roller. Your first answer will be typed on this 1 ine. After you have responded, move the carriage bar so that the roller advances to the next line. Under the word STOP you will see a number. This is the correct answer to the first frame. Compare your response with this correct answer. Continue in this manner throughout the fifty practice frames.

How did you do? You will probably do better as you get more practice. Were you sure to make some response after each frame?

On the tapes you will be listening to, there will be 400 frames. After each 50 frames there will be a pause. You will stop the recorder and insert the next answer sheet into the typewriter. Begin the recorder when you are set to listen again.

The tapes can be run at your own convenience, but it is important that you give the task your undivided attention when you do begin. Each tape lasts for 30 minutes.

We will now rewind the practice tape to the beginning and let you listen to it again.

Each subject listened to the practice tape four times. After the practice series each of the subjects 1 istened to the sixteen tapes in essentially a random order. There was no formal randomization established for each subject; rather, they listened to the tapes in the order of the answer blanks in their manila test folders. 
Mechanics of Presentation and Response Recording

As was indicated above, the stimuli were presented via magnetic tape (Ampex, Model PR-10) and delivered through an earphone (TDH-39) encased in a donut-type protector. A dummy earphone and donut-type protector was placed over the opposite ear.

All listening was done in a sound-treated room (Industrial Acoustics Company, Model 403). An overstuffed chair afforded comfort during the 1 istening sessions. A single 100-watt 1 ight bulb illuminated the room.

As indicated in the foregoing practice instructions, the responses were typed on a portable typewriter held in the lap of the listener. The correct answer appeared when the carriage returned to the next 1 ine.

In the early listening sessions an amber light located on the desk in front of the subjects flashed just prior to the next frame. It was designed to serve as a warning for the coming of a new frame. All subjects indicated that the light was not observed during the listening task, so it was removed from the test room. The intervals between frames were consistent and the 1 isteners learned this rhythm, negating the need for a warning light.

\section{Summary}

In this chapter the creation of the stimulus tapes was described, the experimental subjects, their instructions, and practice sessions were mentioned, and the method of presentation and response recording 
were discussed. The following chapter will be concerned with an analysis and discussion of the data. 


\section{RESULTS AND DISCUSSION}

This study was designed to investigate the detectability of a complex signal as a function of the relative phase of the components of that complex waveform. The complex waveform was composed of a fundamental of $525 \mathrm{cps}$ and a second harmonic of 1050 cps. Six phase relations of the second harmonic with respect to the fundamental were used: $0^{\circ}, 30^{\circ}, 60^{\circ}, 90^{\circ}, 120^{\circ}$, and $150^{\circ}$. The voltages of the two components of the complex signal were varied in two ways: in one condition the two components were equal in peak-to-peak voltage, and in the other condition the voltages of the two were subjectively equal in loudness.

Four 100-millisecond bursts of noise, one of which contained the complex waveform, were presented to the subject and he was forced to choose which of the four contained the signal. Ten different signal-tonoise ratios, covering a range of $10 \mathrm{~dB}$ around a subjective "threshold" value, were used. Forty judgments at each signal-to-noise ratio were made in each phase condition.

If shifts of the relative phase of the components are important to the signal detectability model, differences in the level of detectability will be seen; however, if shifts of relative phase are of no significance, the subject responses for all conditions will be similar. 


\section{Results}

A total of six null hypotheses were placed under test. These will be discussed in pairs, the difference between each of the pairs being the voltages of the sine waves that compose the complex signal.

Hvoethes is 1 . There is no difference in the detectability of a complex auditory signal, composed of two sine waves of equal peak-topeak voltage prior to being mixed to form the complex waveform, regardless of the relative phase of the components.

Hypothes is 11. There is no difference in the detectability of a complex auditory signal, composed of two sine waves of subjectively equal loudness prior to being mixed to form the complex waveform, regardless of the relative phase of the components.

A Lindquist Type VI mixed design analysis of variance (25) was used to test each hypothesis. The raw scores from the six relative phase relationships at each of the two component voltages conditions (shown in Appendixes $C$ and $D$ ) were converted to $\underline{d}^{\prime}$ values for use in the two analyses.

To convert the data to these $\underline{d}^{\prime}$ values ${ }^{2}$ Table 2 was used. This table, taken from Green, Mckey and Licklider (15), was derived from the formula

$$
p(c)=\int_{-\infty}^{+\infty} \Phi^{3}(x) \quad \phi\left(x-\underline{d}^{\prime}\right) d x
$$

2 Swets (35) has shown that d' yields highly consistent results whether the yes-no or forced-choice procedures are used in the detection task. He verified this for from two to eight alternatives in the forced-choice task. 
Table 2. The probability of a correct detection in a four-alternative forced choice test as a function of d'. Taken from Green, Mckey and Licklider (15).

\begin{tabular}{|c|c|c|c|}
\hline $\begin{array}{l}\text { Probability of a } \\
\text { Correct Detection }\end{array}$ & $\underline{d}^{\prime}$ & $\begin{array}{l}\text { Probability of a } \\
\text { Correct Detection }\end{array}$ & $\underline{d}^{\prime}$ \\
\hline $\begin{array}{l}0.25 \\
0.26 \\
0.27 \\
0.28 \\
0.29 \\
0.29 \\
0.30 \\
0.31 \\
0.3 \\
0\end{array}$ & $\begin{array}{l}0.00 \\
0.04 \\
0.08 \\
0.12 \\
0.16 \\
0.20 \\
0.24 \\
0.27 \\
0.30 \\
0.34 \\
0.37 \\
0.41 \\
0.43 \\
0.47 \\
0.50 \\
0.52 \\
0.56 \\
0.58 \\
0.61 \\
0.64 \\
0.68 \\
0.71 \\
0.74 \\
0.77 \\
0.81 \\
0.84 \\
0.87 \\
0.91 \\
0.94 \\
0.97 \\
1.00 \\
1.03 \\
1.06 \\
1.09 \\
1.12 \\
1.16 \\
1.19 \\
1.22\end{array}$ & $\begin{array}{l}0.63 \\
0.04 \\
0.67 \\
0.67 \\
0.67 \\
0.67 \\
0.68 \\
0.69 \\
0.79 \\
0.70 \\
0.71 \\
0.72\end{array}$ & $\begin{array}{l}1.26 \\
1.29 \\
1.32 \\
1.35 \\
1.38 \\
1.42 \\
1.46 \\
1.50 \\
1.53 \\
1.57 \\
1.61 \\
1.65 \\
1.69 \\
1.73 \\
1.77 \\
1.80 \\
1.85 \\
1.89 \\
1.93 \\
1.98 \\
2.03 \\
2.08 \\
2.13 \\
2.18 \\
2.24 \\
2.29 \\
2.36 \\
2.42 \\
2.50 \\
2.60 \\
2.70 \\
2.80 \\
2.92 \\
3.02 \\
3.14 \\
3.25\end{array}$ \\
\hline
\end{tabular}


where $p(c)$ is the probability of a correct detection; ( $x$ ) is a normal distribution function with some mean and unit standard deviation; and $\varnothing\left(x-d^{\prime}\right)$ is a normal density function with a mean d' higher than the other mean and the same standard deviation. The formula states that the probability of drawing four random samples, three from a certain distribution (noise) and the fourth from a distribution with a higher mean than the others (signal-plus-noise), is directly related to the separation of the means of the distributions.

The probability of a correct detection will, for the purposes of this study, be equal to the obtained percentage found by dividing the number of possible correct into the number correct; therefore, 30 correct out of 40 possible would be equal to a probability of a correct detection of .75 . This figure can then be converted to a d' value of 1.69 by means of Table 2 .

Tables 3-4 give the means and standard deviations for four subjects associated with the two hypotheses under test. Figures 21-22 show the mean raw scores in graphic form.

On the basis of the analyses of variance both hypotheses were rejected at the .01 percent level of confidence. Tables 5-6 summarize the analyses.

The source of variance $A$ represents the variance between the signal-to-noise levels at each of the six relative phase conditions. The source of variance $B$ represents the variance between the relative phase relationships at each of the ten signal-to-noise ratio levels. A critical difference value was calculated for both the $A$ and $B$ sources of 
Table 3. Mean $\mathrm{d}^{\prime}$ values and standard deviations for four subjects on the six relative-phase-relationship conditions where the complex waveform was composed of component $s$ ine waves of equal peak-to-peak voltage prior to being mixed to form the complex signal.

\begin{tabular}{|c|c|c|c|c|c|c|c|c|c|c|c|}
\hline & & 1 & 2 & 3 & $\begin{array}{c}\text { nal - } \\
4\end{array}$ & $\begin{array}{c}- \text { No is } \\
5\end{array}$ & $\begin{array}{l}\text { Rat } \\
6\end{array}$ & $\begin{array}{l}\text { Rang } \\
7\end{array}$ & 8 & 9 & 10 \\
\hline \multirow[t]{2}{*}{$0^{\circ}$} & $M$ & 0.22 & 0.28 & 0.03 & 0.06 & 0.12 & 0.41 & 0.41 & 0.19 & 0.30 & 0.20 \\
\hline & SD & 0.16 & 0.21 & 0.06 & 0.07 & 0.24 & 0.23 & 0.14 & 0.21 & 0.25 & 0.29 \\
\hline \multirow[t]{2}{*}{$30^{\circ}$} & $\bar{M}$ & 0.85 & 0.77 & 0.66 & 0.52 & 0.55 & 0.44 & 0.50 & 0.32 & 0.30 & 0.11 \\
\hline & SD & 0.40 & 0.50 & 0.29 & 0.40 & 0.15 & 0.40 & 0.48 & 0.23 & 0.26 & 0.08 \\
\hline \multirow{2}{*}{$60^{\circ}$} & $\bar{M}$ & 1.45 & 1.44 & 0.91 & 1.05 & 0.71 & 0.47 & 0.62 & 0.45 & 0.34 & 0.19 \\
\hline & SD & 0.36 & 0.42 & 0.26 & 0.36 & 0.27 & 0.27 & 0.34 & 0.18 & 0.04 & 0.09 \\
\hline \multirow{2}{*}{$90^{\circ}$} & $\bar{M}$ & 2.26 & 1.85 & 1.89 & 1.42 & 1.08 & 0.99 & 0.94 & 0.70 & 1.05 & 0.61 \\
\hline & SD & 0.16 & 0.05 & 0.48 & 0.34 & 0.35 & 0.12 & 0.27 & 0.35 & 0.37 & 0.30 \\
\hline \multirow{2}{*}{$120^{\circ}$} & $\bar{M}$ & 3.18 & 2.42 & 2.06 & 1.50 & 1.62 & 1.27 & 0.83 & 0.79 & 0.77 & 0.54 \\
\hline & SD & 0.33 & 0.37 & 0.26 & 0.17 & 0.30 & 0.14 & 0.18 & 0.27 & 0.21 & 0.20 \\
\hline \multirow[t]{2}{*}{$150^{\circ}$} & $\bar{M}$ & 1.05 & 0.78 & 0.91 & 0.71 & 0.62 & 0.63 & 0.11 & 0.20 & 0.28 & 0.16 \\
\hline & SD & 0.20 & 0.15 & 0.28 & 0.20 & 0.08 & 0.22 & 0.14 & 0.14 & 0.23 & 0.13 \\
\hline
\end{tabular}


Table 4. Mean d' values and standard deviations for four subjects on the six relative-phase-relationship conditions where the complex waveform was composed of component sine waves of subjectively equal loudness prior to being mixed to form the complex signal.

\begin{tabular}{|c|c|c|c|c|c|c|c|c|c|c|c|}
\hline & & 1 & 2 & $3^{5}$ & $\begin{array}{c}\text { gna l - } \\
4 \\
\end{array}$ & $\begin{array}{c}- \text { Nois } \\
5\end{array}$ & $\begin{array}{l}\text { Rat i } \\
6 \\
\end{array}$ & $\begin{array}{c}0 \text { Rang } \\
7\end{array}$ & 8 & 9 & 10 \\
\hline \multirow{2}{*}{$0^{\circ}$} & $\bar{M}$ & 0.45 & 0.51 & 0.52 & 0.42 & 0.24 & 0.58 & 0.32 & 0.17 & 0.19 & 0.32 \\
\hline & SD & 0.32 & 0.29 & 0.40 & 0.15 & 0.18 & 0.07 & 0.27 & 0.16 & 0.15 & 0.15 \\
\hline \multirow{2}{*}{$30^{\circ}$} & $\bar{M}$ & 1.82 & 1.43 & 1.02 & 0.47 & 0.44 & 0.50 & 0.32 & 0.46 & 0.56 & 0.56 \\
\hline & $S D$ & 0.70 & 0.36 & 0.09 & 0.00 & 0.40 & 0.48 & 0.23 & 0.33 & 0.31 & 0.14 \\
\hline \multirow{2}{*}{$60^{\circ}$} & $\bar{M}$ & 2.39 & 2.11 & 1.59 & 1.49 & 1.41 & 0.79 & 0.97 & 0.99 & 0.73 & 0.27 \\
\hline & SD & 0.36 & 0.42 & 0.55 & 0.30 & 0.49 & 0.33 & 0.48 & 0.28 & 0.25 & 0.22 \\
\hline \multirow{2}{*}{$90^{\circ}$} & $\bar{M}$ & 2.58 & 2.14 & 1.49 & 1.72 & 1.03 & 1.24 & 0.93 & 1.11 & 0.53 & 0.80 \\
\hline & SD & 0.28 & 0.42 & 0.45 & 0.37 & 0.30 & 0.31 & 0.15 & 0.34 & 0.37 & 0.41 \\
\hline \multirow[t]{2}{*}{$120^{\circ}$} & $\bar{M}$ & 2.48 & 1.56 & 1.83 & 1.61 & 1.17 & 1.13 & 1.13 & 0.75 & 0.78 & 0.51 \\
\hline & SD & 0.66 & 0.55 & 0.42 & 0.35 & 0.11 & 0.21 & 0.11 & 0.05 & 0.17 & 0.24 \\
\hline \multirow[t]{2}{*}{$150^{\circ}$} & $\bar{M}$ & 1.49 & $i .53$ & 1.03 & 1.05 & 0.98 & 0.53 & 0.47 & 0.57 & 0.33 & 0.51 \\
\hline & SD & 0.21 & 0.48 & 0.22 & 0.13 & 0.21 & 0.17 & 0.12 & 0.30 & 0.20 & 0.15 \\
\hline
\end{tabular}




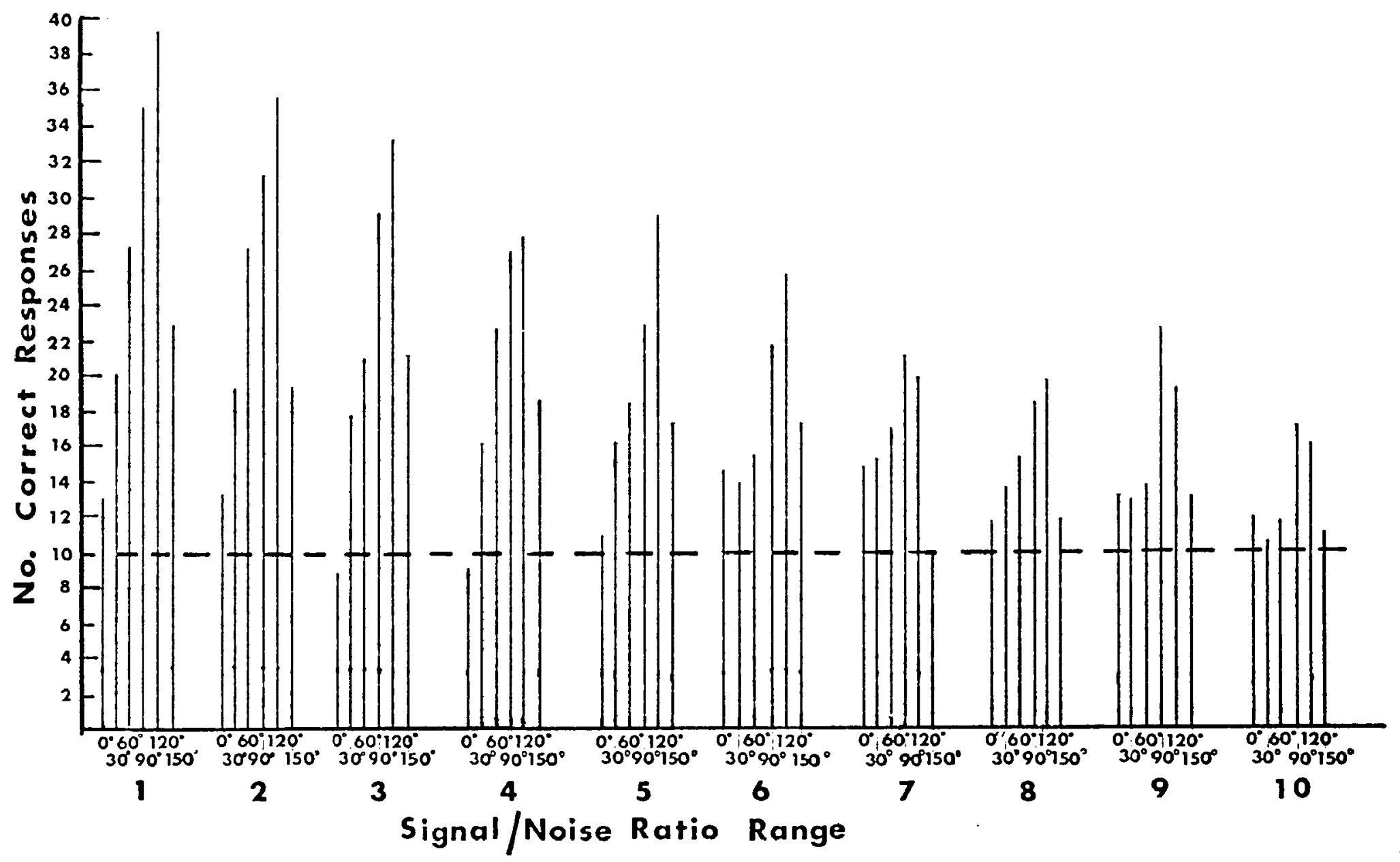

Figure 21. Averaged correct responses for four subjects on the six stimulus tapes wherc the peak-to-peak voltages of the component sine waves was equal. 


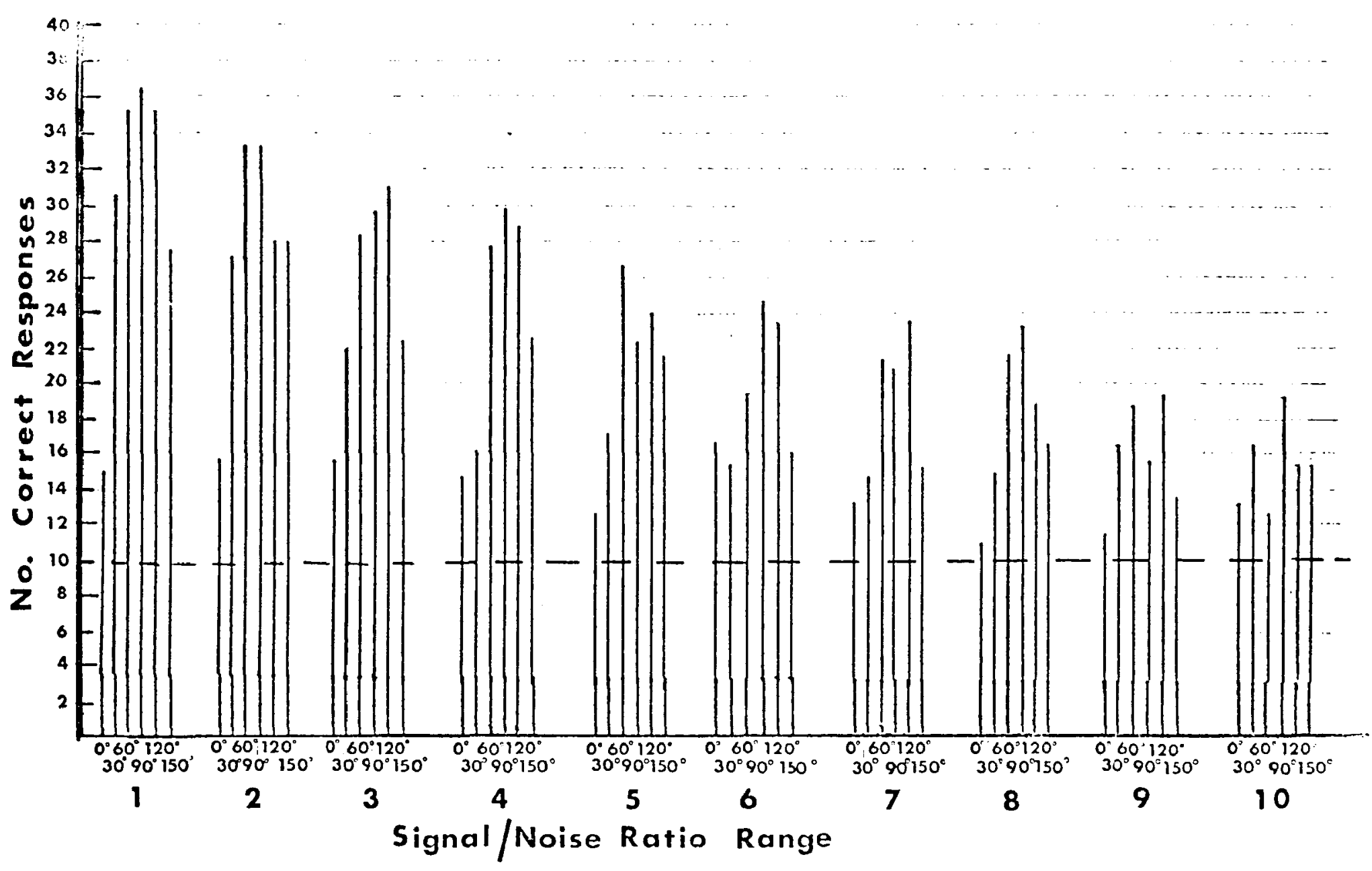

Figure 22. Averaged correct responses for four subjects on the six stimulus tapes where the peak-to-peak voltage of the components were subjectively equal in loudness prior to being mixed to form the complex waverorm. 
Table 5. Summary table of analysis of variance of $\underline{d}^{\prime}$ scores for four subjects on six relative-phase-relationship conditions where the complex signal was composed of two sine waves of equal peak-to-peak voltage prior to being mixed to form the complex waveform. Source of variance $A$ represents the variance between the signal-to-noise levels. Source of variance B represents the variance between the phaserelation conditions.

\begin{tabular}{ccccc}
$\begin{array}{l}\text { Source of } \\
\text { Variance }\end{array}$ & df & Sum of Squares & Mean Square & F* \\
\hline A & 9 & 31.4511 & 3.4946 & 53.11 \\
B & 5 & 48.1886 & 9.6377 & 8.27 \\
AB & 45 & 18.8831 & .4196 & 7.71 \\
Error A & 27 & 1.7758 & .0658 & .1165 \\
Error B & 15 & 1.7467 & .0544 \\
Error AB & 135 & 7.3485 & & \\
\hline Total & 236 & 109.3939 & &
\end{tabular}


Table 6. Summary table of analys is of variance of $\underline{d}^{\prime}$ scores for four subjects on six relative-phase-relationship conditions where the complex signal was composed of two sine waves of subjectively equal loudness prior to being mixed to form the complex waveform. Source of variance $A$ represents the variance between the signal-to-noise levels. Source of variance B represents the variance between the phase-relation conditions.

\begin{tabular}{ccccc}
$\begin{array}{l}\text { Source of } \\
\text { Variance }\end{array}$ & df & Sum of Squares & Mean Square & F* \\
\hline A & 9 & 44.9708 & 4.9968 & 146.11 \\
B & 5 & 30.5830 & 6.1166 & 21.52 \\
$A B$ & 45 & 13.7334 & .3052 & 3.18 \\
Error $A$ & 27 & .9238 & .0342 & .2842 \\
Error B & 15 & 4.2623 & .0961 & \\
Error $A B$ & 135 & 12.9742 & & \\
\hline Total & 236 & 107.4476 & &
\end{tabular}


variance, in order to locate the significant differences between the treatment means.

The location of significant differences between the signal-tonoise ratio levels, at any given phase relationship, was of secondary importance to this study. It can be generalized that the easier the signal-to-noise tasks will be significantly different than the more difficult signal-to-noise tasks, and Tables 7-8 bear out this fact. There was one exception that should be noted. At the $0^{\circ}$ relative phase condition (component 5 ine waves of equal peak-to-peak vol tage) it can be seen that there were no significant differences between the means, as shown in Table 7. This would seem to warrant the conclusion that when the relative phase relationship between the components was $0^{\circ}$, the subjects performed at chance level over the entire signal-tonoise ratio range.

The location of the significant differences between the means of the relative-phase conditions, at any given signal-to-noise ratio, was of more direct importance to the hypotheses under test. The locations of these critical differences are shown in Tables 9-10. As can be seen from these tables, there were numerous significant differences between the average scores of the relative-phase relationships. Figures 21-22 display these differences. Also from these tables it can be noted that as the signal-to-noise condition becomes more difficult, fewer significant differences occur between the means of the relative-phase relationships. 
Table 7. Differences between the means at the ten signal-to-noise ratio levels for ail six relative-phase conditions. The means are derivod from the socres obtained by four subjects on the complex signal that vas composed of sine waves of equal peak-to-peak voltage prior to being mixed to form the complex signal. oo

S/N Ratio Levels

12345078910

1. - $\quad 2916101919382$

$2 \quad-25221613139228$

$3 \quad-393335162717$

- 6́ 3535232424

- 29297138

- 0221121

- 221121

$30-111$

10

$30^{\circ}$

S/M Ratio Leveis

12345678910

- 81933304135535574

- 1125223327454766

- 14112216343655

- 382202241

- 115232544

- 5121433

$\begin{array}{ll}7 & -\quad 182039 \\ 3 & -\quad 221\end{array}$

10

$-\quad 19$

$$
60^{\circ}
$$

S/N Ratio Levels

12345678910

- $45440749883100 \mathrm{mll} 126$

- 53397397829912125

- 1420.4429465772

- 345843607186

- 249263752

- 1521328

- 272343

$-1126$

10

$-15$

$S / N$ Ratio Leva!s

12345678910

$-413734218127132156121265$

- 4437785 g. 25 60 124

- 478190552984123

- 344347723781

- 91438347

- 529631

- 241133

-359
$-\quad 44$

10

$120^{\circ}$

S/N Ratio Levels

12345678910

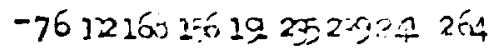

- $36928011 \equiv 15,103,165,183$

- 564479123127123152

- 122367717396

- 25899395108

- 4448073

$-4629$

225
$-\quad 23$

10

$150^{\circ}$

S/N Ratio Levels

12345678910

$-273434434274857789$

$-137163567595062$

$-20292850726375$

- $\quad 860524355$

- 251403446

- 52 43 3547

9175
$-\quad 84$

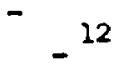

$\because$ A critical difference of .45 or more is significant at the .01 level of confidence. 
Table 3 . Differences between the means at the ten signal-to-noise levels for all six relative-phase conditions. The means are derived from the socres obtained by four subjects on the complex sigial tinat was composed of sine waves of equal subjective loudness prior co being mixed to form the complex waveform.

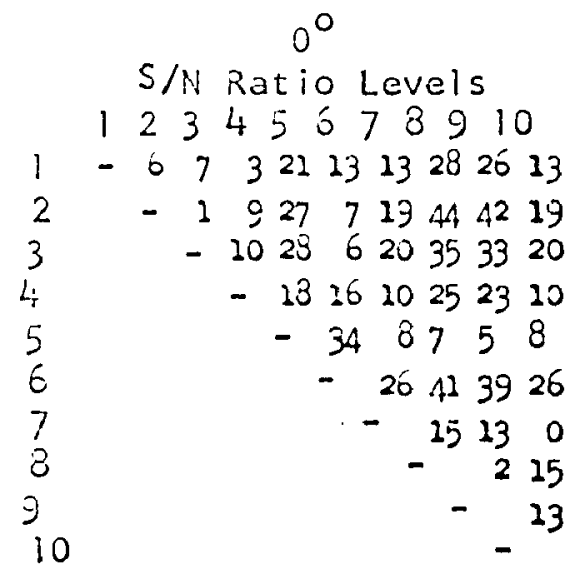

$30^{\circ}$

S/in Ratio Levels

$123456 \% 5 \% 10$

$-3950 \quad 3513813215013616126$

$-41969993111978787$

- 55535270564646

- 3315199

- 61221212

- 18466

- 142424

- 1010

10

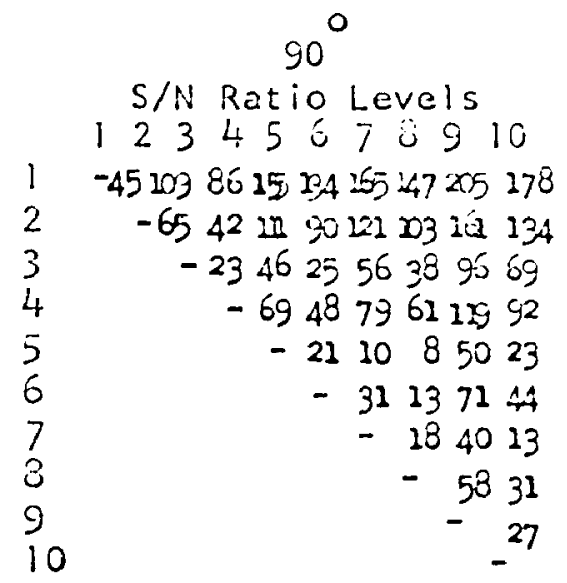

$120^{\circ}$

S/N Ratio Levels

12345673910

-92 65871313121810177

$\begin{array}{llllll}-27 & 53943438173105\end{array}$

- $226670701010 \equiv 132$

- 4448488683110

- 44423966

- 0383562

- 333562 - $\quad 324$

9

10

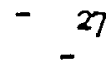

$150^{\circ}$

S/N Ratio Levels

12345678910

$S / N$ Ratio Levels

12345678910

$-23809098501419166212$

$-526270132141212138134$

- 101380626086132

- 870525076122

- 62444268114

- 2820652

- 22470

$-2672$

$-46$
- 446445296102921598

$-50485510026696120102$

- 255056467052

- 75258437254

- 4551416547

- 64202

10144
$-\quad 246$

9

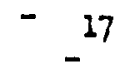

10

or more is significant at the .01 level of

$*$ A critical difference of confidence. 
Table 9. Differences between the means of the six relative-phase relationships at the ten signal-to-noise ratio levels. The means are derived from the scores obtained by four subjects on the complex signal that was composed of sine waves of equal peak-to-peak voltage prior to being mixed to form the complex waveform.

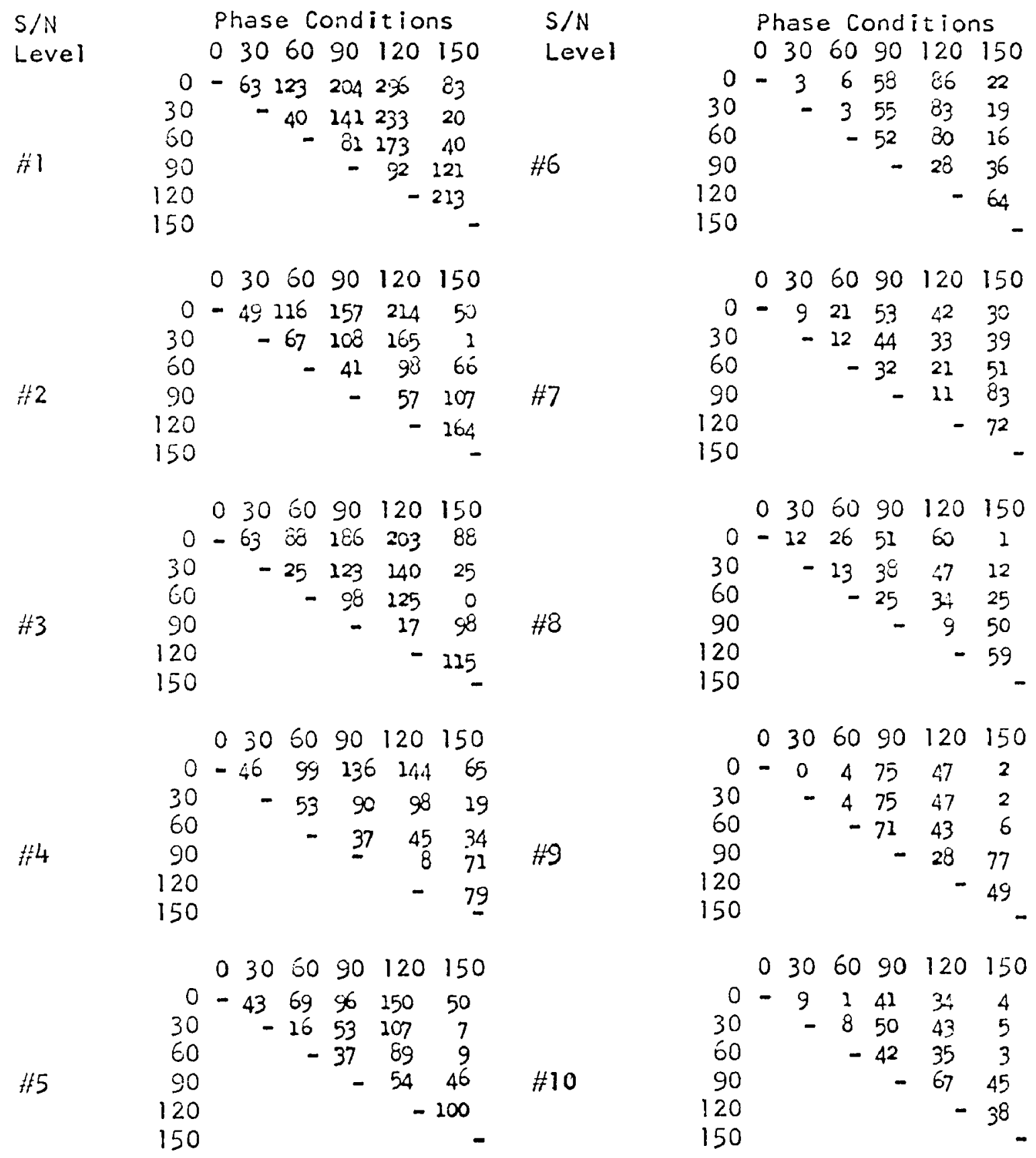

$*$ A critical difference of .63 or more is significant at the .01 level of confidence. 
Table 10. Differences between the means of the six relative-phase relationships at the ten signal-to-noise ratio levels. The means are derived from the scores obtained by four subjects on the complex waveform that was composed of sine waves of equal subjective loudness prior to being mixed to form the complex signal.

$S / N$

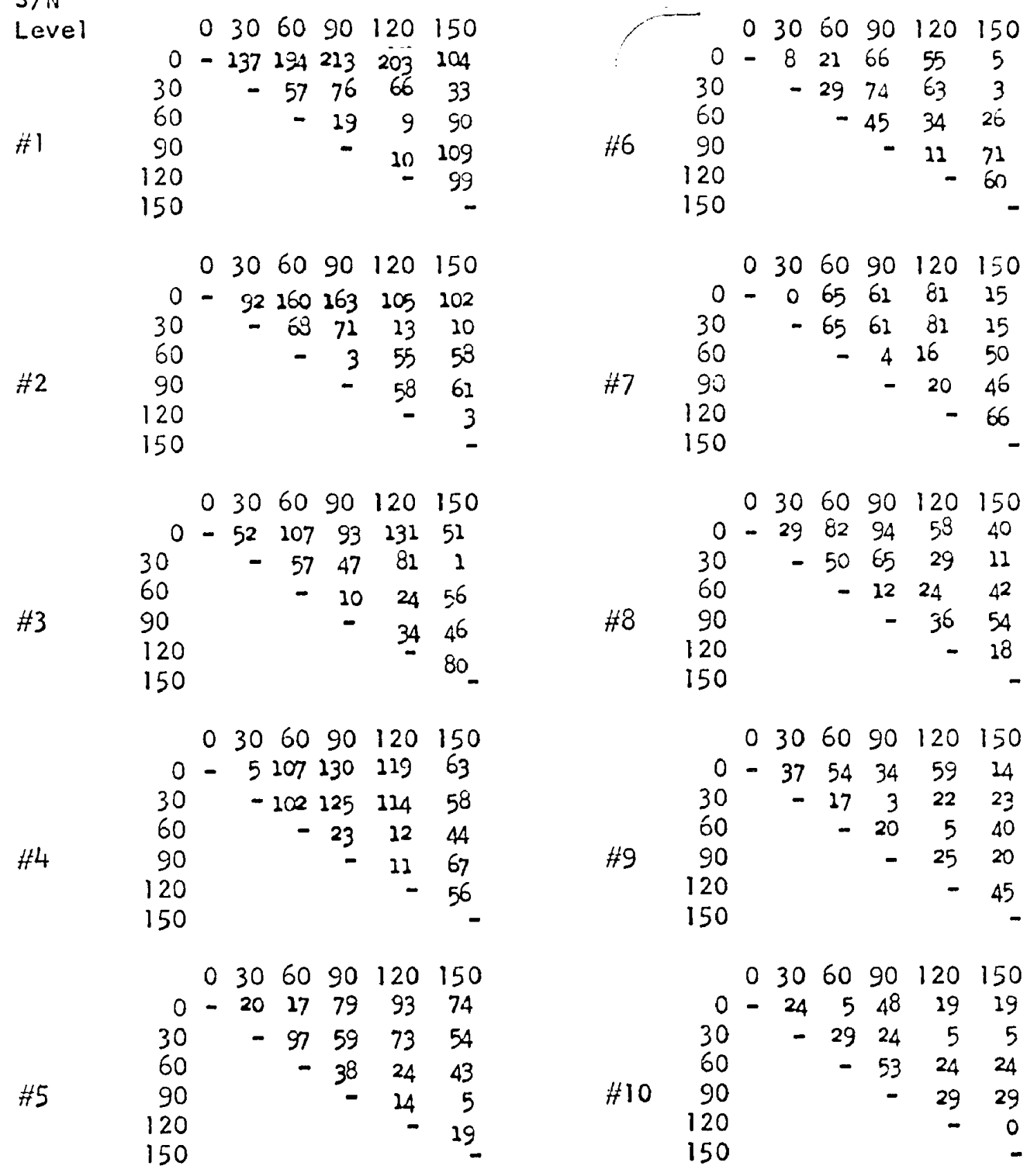

$*$ A critical difference of .63 or more is significant at the $.0 i$ level of confidence 
The next step in the analys is was to determine if differences in the peak-to-peak voltages of the complex waveform (which change as a function of relative-phase shift of the components, even though RMS remains constant) were basic to the significant differences that were found in the detectability of the complex signal as a function of relative-phase relationships.

To test this, the following two hypotheses were investigated:

Hypothesis 111. There is no difference in the detectability of. a complex auditory signal, composed of two sine waves of equal peak-topeak voltage prior to being mixed to form the complex waveform, regardless of the relative phase of the components when the peak-to-peak voltages of the complex signals are equal.

Hypothes is 1V. There is no difference in the detectability of a complex auditory signal, composed of two sine waves of subjectively equal loudness prior to being mixed to form the complex waveform, regardless of the relative phase of the components when the peak-to-peak vol tage of the complex signals are equal.

In order to test these hypotheses, two analyses of variance were performed on the raw score data (Appendixes $E$ and $F$ ) that had been transformed into $\underline{d}^{\prime}$ values. The mean-d' values and associated standard deviations are 1 isted in Tables $11-12$ and the graphic representation of the raw-score means can be seen in Figures $23-24$. Only three subjects were tested in these conditions due to the large amount of listening time that was required under the first two hypotheses. 
Table 11. Mean d' values and standard deviations for three subjects on two relative-phase-relationship conditions where the peak-to-peak voltage of the complex wave was equated to a standard. The corresponding d' values for three subjects on the phase conditions where RMS was held constant are compared to the peak-to-peak adjusted conditions. The $120^{\circ}$ phase condition was the standard to which the other conditions were adjusted. All relative-phase conditions were composed of component sine waves of equal peak-to-peak voltage prior to being mixed to form the complex signal.

\begin{tabular}{|c|c|c|c|c|c|c|c|c|c|c|c|}
\hline & \multicolumn{10}{|c|}{ Signal-to-Noise Ratio Range } \\
\hline & & 1 & 2 & 3 & 4 & 5 & 6 & 7 & 8 & 9 & 10 \\
\hline \multirow[t]{2}{*}{$30^{\circ}$} & $\underset{P-t 0}{M}$ & $\begin{array}{l}0.90 \\
-P\end{array}$ & 0.96 & 0.32 & & 0.59 & 0.26 & 0.62 & 0.40 & 0.42 & 0.24 \\
\hline & SD & 0.37 & 0.20 & 0.14 & 0.24 & 0.44 & 0.13 & 0.15 & 0.18 & 0.30 & 0.26 \\
\hline \multirow{2}{*}{$30^{\circ}$} & $\underset{\text { RMS }}{M}$ & 0.71 & 0.70 & 0.52 & 0.47 & 0.47 & 0.27 & 0.28 & 0.33 & 0.19 & 0.08 \\
\hline & SD & 0.36 & 0.60 & 0.08 & 0.47 & 0.00 & 0.26 & 0.25 & 0.29 & 0.09 & 0.07 \\
\hline \multirow{2}{*}{$90^{\circ}$} & ${ }_{P-t o}^{M}$ & ${ }_{-P}^{1.63}$ & 1.14 & 1.39 & 1.12 & 0.64 & 1.12 & 0.82 & 0.35 & 1.14 & 0.40 \\
\hline & SD & 0.29 & 0.24 & 0.13 & 0.30 & 0.19 & 0.16 & 0.34 & 0.14 & 0.13 & 0.17 \\
\hline \multirow[t]{2}{*}{$90^{\circ}$} & $\underset{\text { RMS }}{M}$ & 2.25 & 1.86 & 1.71 & 1.26 & 0.91 & 0.96 & 1.05 & 0.60 & 1.04 & 0.59 \\
\hline & SD & 0.20 & 0.05 & 0.41 & 0.17 & 0.06 & 0.13 & 0.18 & 0.35 & 0.45 & 0.37 \\
\hline \multirow[t]{2}{*}{$120^{\circ}$} & $\stackrel{M}{R M S}$ & 3.16 & 2.25 & 2.04 & 1.46 & 1.63 & 1.22 & 0.85 & 0.74 & 0.80 & 0.46 \\
\hline & SD & 0.40 & 0.20 & 0.31 & 0.18 & 0.39 & 0.12 & 0.22 & 0.31 & 0.24 & 0.16 \\
\hline
\end{tabular}


Table 12. Mean d' values and standard deviations for three subjects on two relative-phase-relationship conditions where the peak-to-peak voltage of the complex wave was equated to a standard. The corresponding d' values for three subjects on the phase conditions where RMS was held constant are compared to the peak-to-peak adjusted conditions. The $120^{\circ}$ phase condition was the standard to which the other two conditions were adjusted. All relative-phase conditions were composed of component sine waves of equal subjective loudness prior to being mixed to form the complex signal.

\begin{tabular}{|c|c|c|c|c|c|c|c|c|c|c|c|}
\hline & & 1 & 2 & 3 & $\begin{array}{c}\text { nal }-t \\
4\end{array}$ & $\begin{array}{c}\mathrm{o}-\text { No is } \\
5\end{array}$ & $\begin{array}{l}\text { Rat i } \\
6\end{array}$ & $\begin{array}{l}\text { Rang } \\
7\end{array}$ & 8 & 9 & 10 \\
\hline \multirow[t]{2}{*}{$30^{\circ}$} & $\underset{P-\text { to }}{M}$ & $-P$ & 1.44 & 0.84 & 0.93 & & 0.40 & 0.59 & 0.73 & 0.58 & \\
\hline & SD & 0.20 & 0.74 & 0.32 & 0.30 & 0.28 & 0.18 & 0.33 & 0.09 & 0.33 & 0.14 \\
\hline \multirow{2}{*}{$30^{\circ}$} & $\underset{R M S}{M}$ & 1.39 & 1.67 & 0.83 & 1.28 & 0.80 & 0.56 & 0.71 & 0.36 & 0.47 & 0.32 \\
\hline & SD & 0.12 & 0.24 & 0.56 & 0.03 & 0.45 & 0.08 & 0.12 & 0.10 & 0.24 & 0.04 \\
\hline \multirow[t]{2}{*}{$60^{\circ}$} & $\underset{P-t o}{M}$ & $-P$ & 1.40 & 1.88 & 1.52 & 1.17 & 1.17 & 1.12 & 0.74 & 0.74 & 0.40 \\
\hline & SD & 0.51 & 0.55 & 0.50 & 0.37 & 0.13 & 0.24 & 0.13 & 0.05 & 0.16 & 0.11 \\
\hline \multirow[t]{2}{*}{$60^{\circ}$} & $\underset{R M S}{M}$ & 2.09 & 1.58 & 1.04 & 0.57 & 0.76 & 0.45 & 0.50 & 0.46 & 0.64 & 0.57 \\
\hline & SD & 0.53 & 0.27 & 0.09 & 0.17 & 0.08 & 0.08 & 0.44 & 0.41 & 0.32 & 0.17 \\
\hline \multirow{2}{*}{$120^{\circ}$} & $\underset{\text { RMS }}{M}$ & 2.51 & 2.21 & 1.61 & 1.60 & 1.46 & 0.80 & 1.09 & 0.96 & 0.76 & 0.30 \\
\hline & SD & 0.33 & 0.46 & 0.68 & 0.25 & 0.58 & 0.40 & 0.51 & 0.33 & 0.29 & 0.27 \\
\hline
\end{tabular}




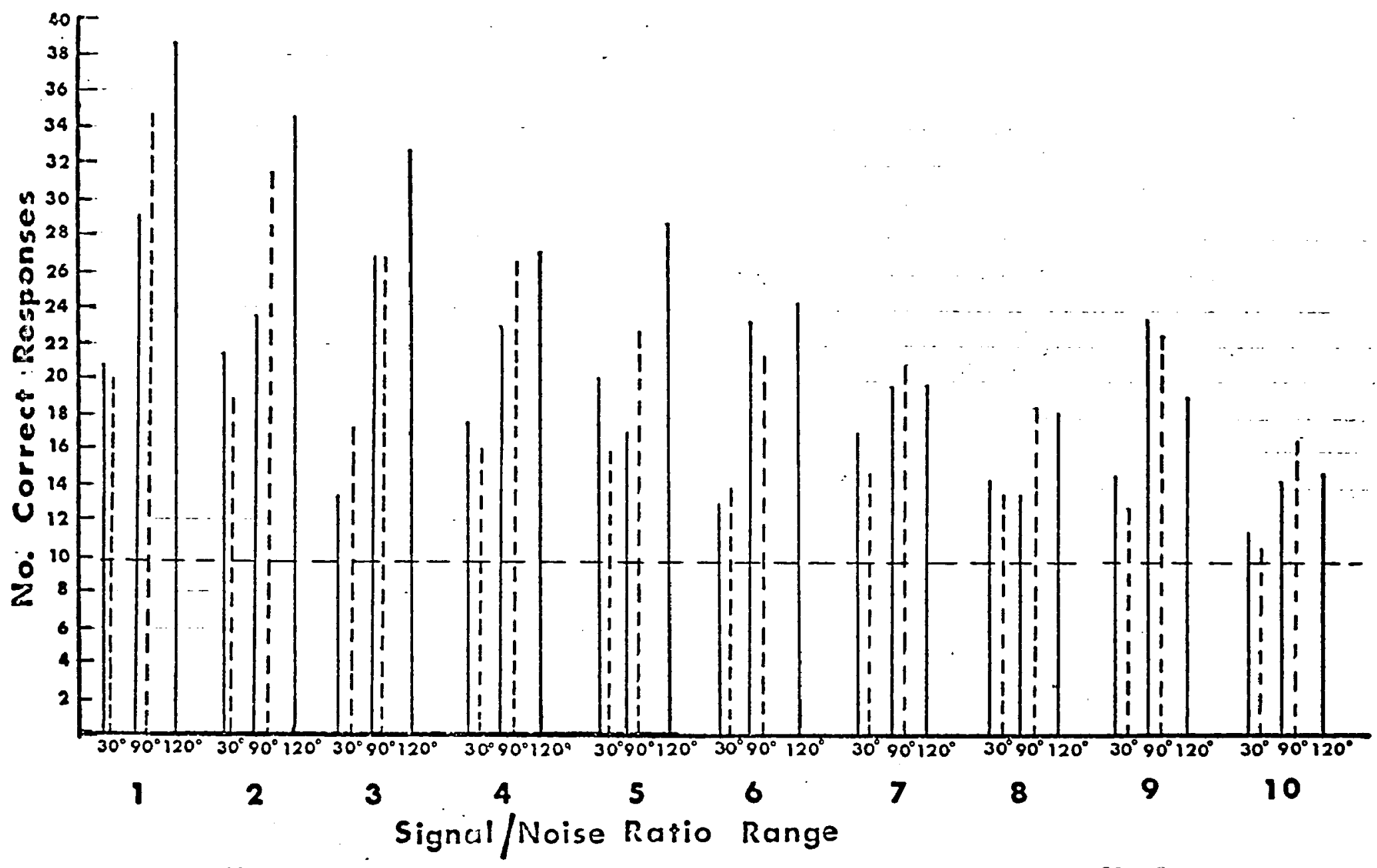

Figure 23. Averaged correct responses for three subjects on the three phaserelationship conditions where the peak-to-peak voltages of the complex signal had been equated ( $s$ ine waves were of equal peak-to-peak voltage prior to being mixed to form the complex signal). Dashed vertical lines represent the average scored for the subjects on the phase-relationship conditions where RMS was held constant. 


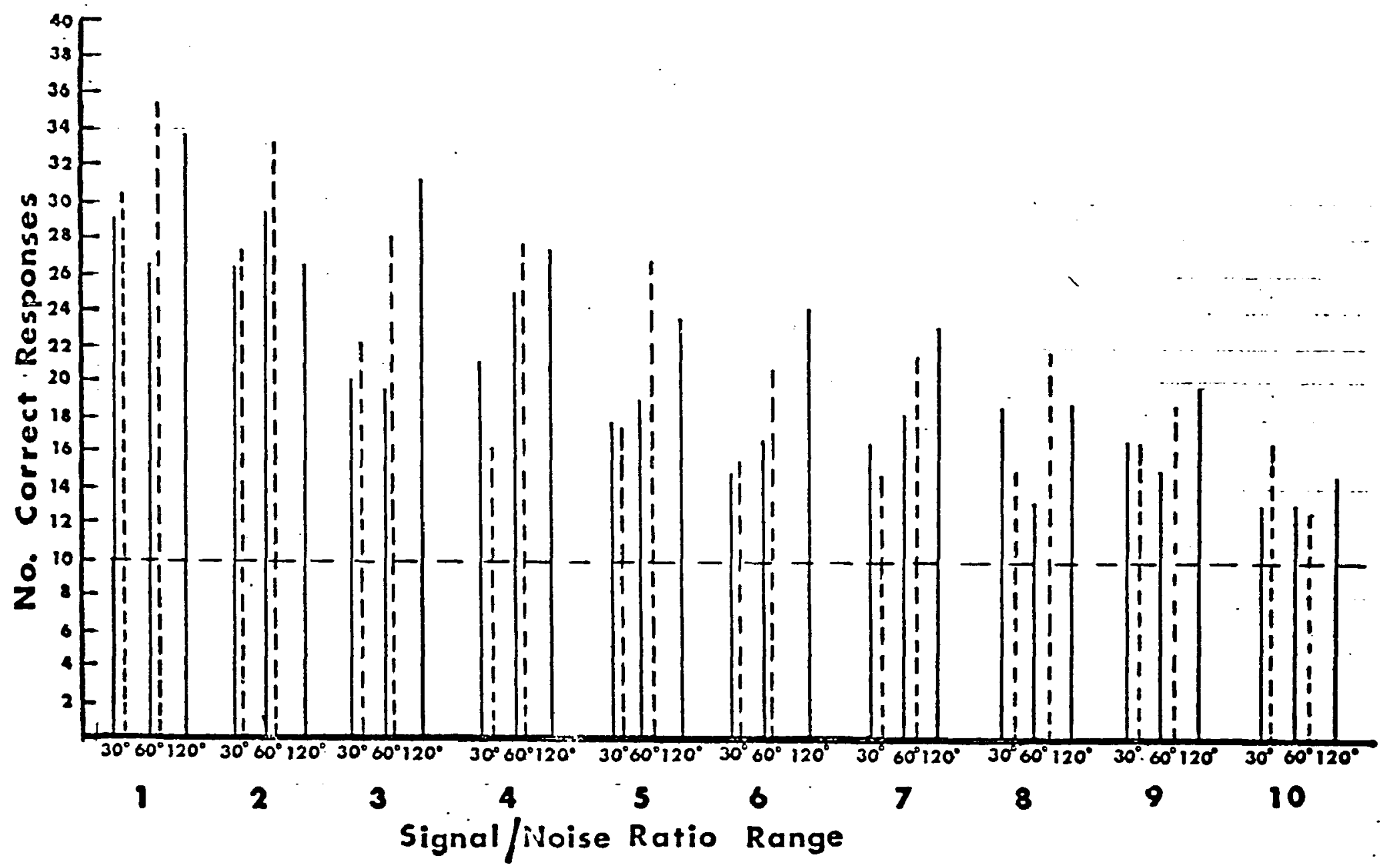

Figure 24. Averaged correct responses for three subjects on the three phaserelationship conditions where the peak-to-peak voltages of the complex signal had been equated (sine waves were of equal subjective loudness prior to being mixed to form the complex signal). Dashed vertical lines represent the average scored for the subjects on the phase-relationship conditions where RMS was held constant. 
On the basis of the analyses of variance both hypotheses were rejected at the .01 level of confidence. The summaries of these analyses, shown in Tables 13-14, show significant $F$ values for both $A$ and $B$ sources of variance. The critical-difference tests, Tables 1518, demonstrated that the differences were between (a) the high and low ends of the signal-to-noise ratio range; and (b) the relative-phase conditions.

The scores of the three subjects used in this part of the study were compared to the scores of these same three subjects when RMS was held constant over relative-phase shifts. As seen in the criticaldifference Tables 17,18 there were no significant differences found when the scores of the RMS and peak-to-peak adjusted conditions at any one relative-phase condition were compared.

It was concluded from these analyses that the differences in detectability of a two-component complex signal shifted in relative phase are not due to the resulting changes in the peak-to-peak voltage of the complex waveform.

The final two hypotheses under test investigated the detectability of a complex signal shifted in relative phase of the components with a reversal of signal polarity (i.e. earphone leads reversed). This reversal had the effect of changing the compression half of the cycle into the rarefaction half, and visa versa. The theoretical implications of this reversal suggest that if the ear "reads" the waveform envelope, as several investigators have suggested, the responses should be different when the polarity is reversed, since this causes a change in the envelope shape. 
Table 13. Summary table of analysis of variance of $\mathrm{d}^{\prime}$ scores for three subjects on two relative-phase conditions where peak-to-peak vol tage of the complex waveform was equated to a standard. Scores are compared to the corresponding scores on the phase-relationship conditions where RMS was held constant. The component sine waves in all phase conditions were equal in peak-to-peak voltage prior to being mixed to form the complex signal. The source of variance $A$ represents the variance between the signal-to-noise levels. Source of variance B represents the variance between the phase-relation conditions.

\begin{tabular}{ccccc}
$\begin{array}{l}\text { Source of } \\
\text { Variance }\end{array}$ & df & Sum of Squares & Mean Square & F* \\
\hline A & 9 & 23.5863 & 2.6207 & 42.20 \\
B & 4 & 23.9369 & 5.9842 & 47.27 \\
AB & 36 & 10.9579 & .3044 & 5.98 \\
Error A & 18 & 1.1177 & .0621 & \\
Error B & 8 & 1.0131 & .1266 & \\
\hline
\end{tabular}

Total $\quad 147 \quad 64.2742$

$* F_{.01}=3.60(\underline{d f} 18,9) ; 7.01(\underline{d f} 8,4) ; 1.88($ df 72,36$)$ 
Table 14. Summary table of analys is of variance of d' scores for three subjects on two relative-phase conditions where peak-to-peak voltage of the complex waveform was equated to a standard. Scores are compared to the corresponding scores on the phase-relationship conditions where RMS was held constant. The component sine waves in all conditions were equal in subjective loudness prior to being mixed to form the complex signal. The source of variance A represents the variance between the signal-to-noise levels. Source of variance $B$ represents the variance between the phase-relation conditions.

Source of df Sum of Squares Mean Square

F*

\begin{tabular}{|c|c|c|c|c|}
\hline$A$ & 9 & 33.4326 & 3.7147 & 53.45 \\
\hline$B$ & 4 & 7.3541 & 1.8385 & 5.93 \\
\hline$A B$ & 36 & 5.9298 & .1647 & 2.10 \\
\hline Error A & 18 & 1.2514 & .0695 & \\
\hline Error B & 8 & 2.4785 & .3098 & \\
\hline Error $A B$ & 72 & 5.6347 & .0783 & \\
\hline Total & 147 & 56.0811 & & \\
\hline
\end{tabular}


Table 15. Differences between the means at the ten signal-to-noise ratio levels for five relative-phesc conditions, two of which have been ecuated to a standard for peak-to-peak voltage of the complex waveform. The means are derived from the socres of three subjects on the complex signal that was composed of sine waves of equal peakto-peak voltage prior to being mixed to form the complex signal.

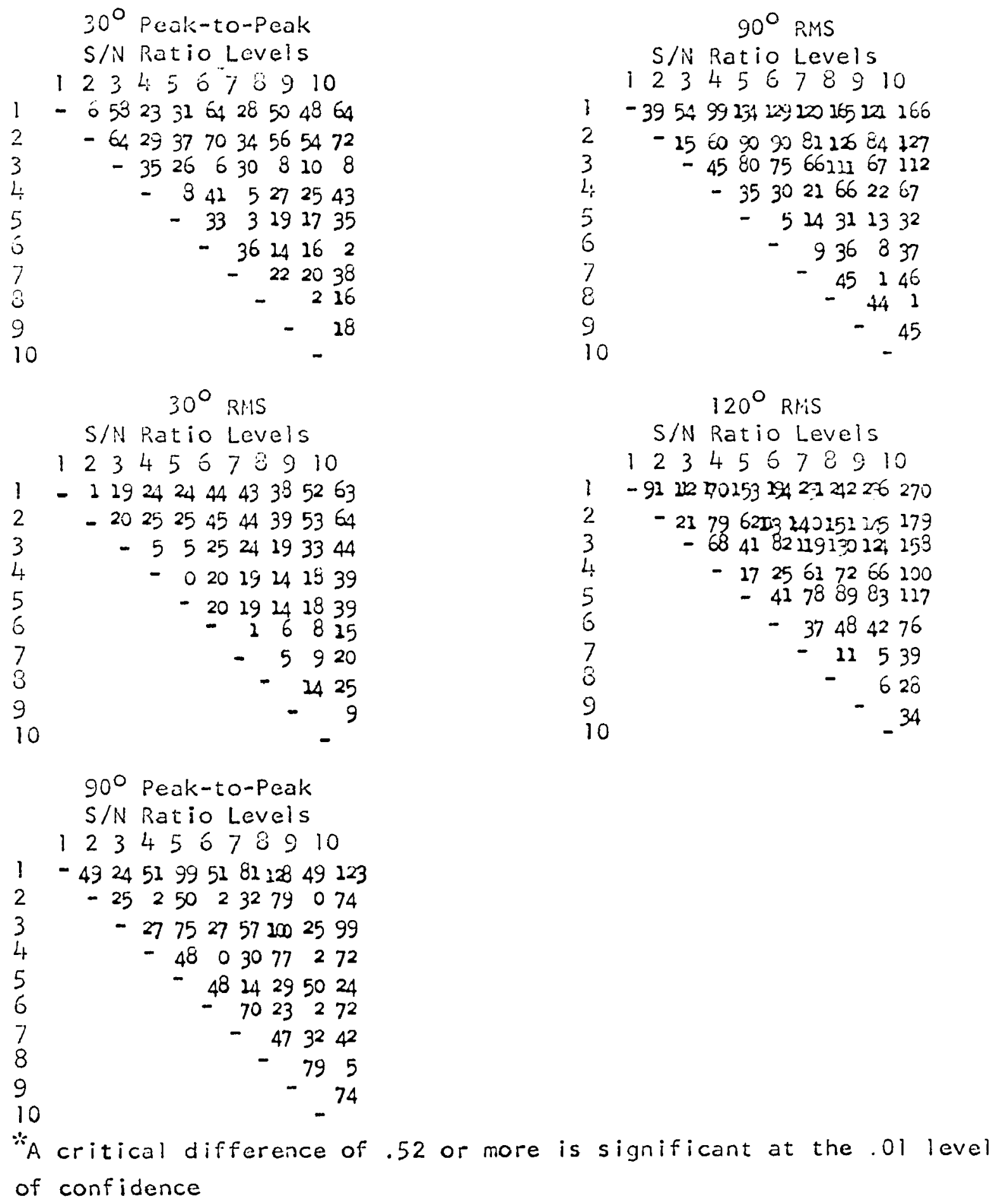


Table 16. Differences between the means at the ten signal-to-inoise ratio levels for five relative-phase conditions, two of which have been equated to a standard for peak-to-peak voltage of the conslex weveform. The means are derived from the scores of three subjects on the complex signal thit was composed of sine waves of equal subjective loudness prior to being mixed to form the complex signal.

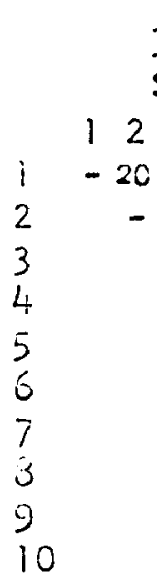

$30^{\circ}$ Peak-to-Peak

$\mathrm{S} / \mathrm{N}$ Ratio Levels

12345673910

-20 0071 su Dijijisl 106132

- 605176 b. 857106122

- 918442512652

- 25533403561

$-28951036$

- 3933188

$\begin{array}{lll}-14 & 127\end{array}$

$-1541$

$-26$

$30^{\circ}$ Bi.15

S/N Ratio Levels

12345678910

- 2055115983 5031032107

- 43987 111 9613120 135

- $35 \quad 32712473651$

- 487257928196

- 249443348

$1520 \quad 924$

- 352439

114

$-\quad 25$

10

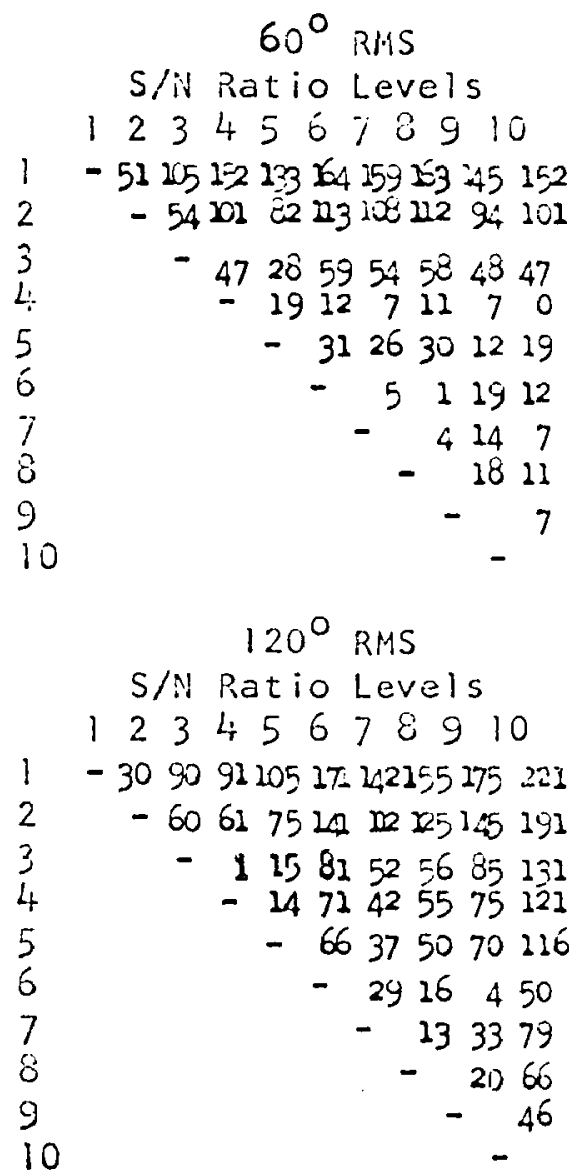

S/in Ratio Levels

$511651=2133641595345152$

54101 ट2 23 30011294101

47285954584847

$\begin{array}{llllll}19 & 12 & 7 & 11 & 7 & 0\end{array}$

3126301219

$\begin{array}{lll}5 & 1 & 1912\end{array}$

$120^{\circ}$ RMS

S/N Ratio Levels

$234567 \& 910$

5275221

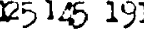

1471425575121

66375070216

$2916 \quad 450$

46

10

$60^{\circ}$ Peak-to-Peak

S/N Ratio Levels

12345678910

$-83437130620610229149183$

- 40122323286666100

- 36717166124154248

- 3535407878112

- $\quad 5434377$

- 5434377

- 383872

- 034

10

$-\quad 34$

*A critical difference of .55 or more is significant at the .01 level of confidence. 
Table 1\%. Differences between the means at the five phase-relationship conditions for ten signal-to-noise ratio levels, where two of the complex waveforms have been equated for peak-to-peak voltage to a standard. The mieans are derived from the scores of three suijects on the complex signal that was composed of sine waves of equal peakto-peak voltage prior to being mixed to form the complex waveform.

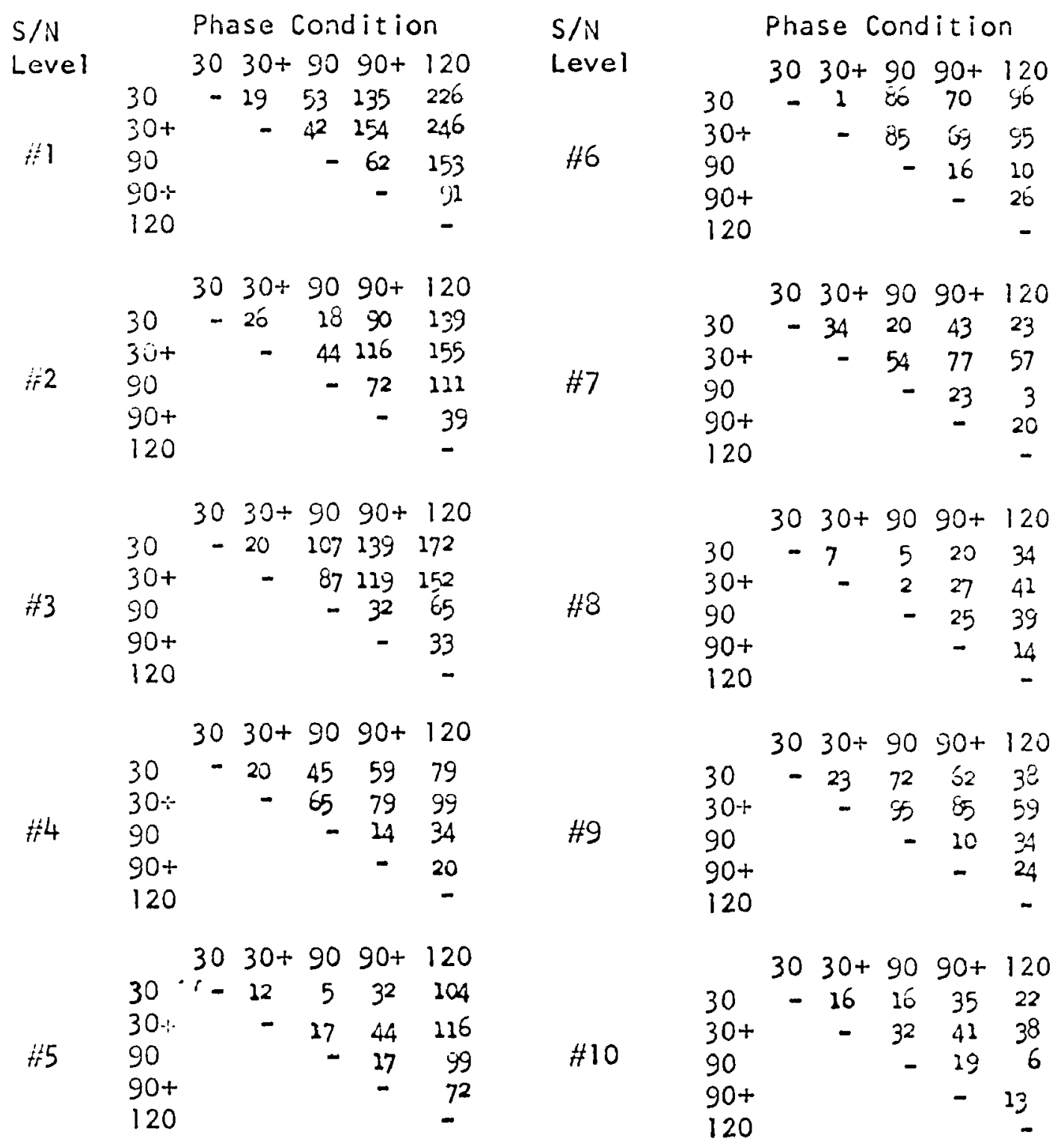

*A critical difference of .84 or more is significant at the .01 level of confidence

tDenotes phase conditions that have been adjusted in peak-to-peak voltage of the complex waveform 
Table 18. Differences between the means at the five phase-relationsip conditions for ten signal-to-noise ratio levels, where two $0 i$ ine complex waveforms have been equated for peak-to-peak voltage to a standard. The means are derived from the scores of three subjects on the complex signal that was composed of sine waves of equal subjective loudness prior to being mixed to form the complex waveform.

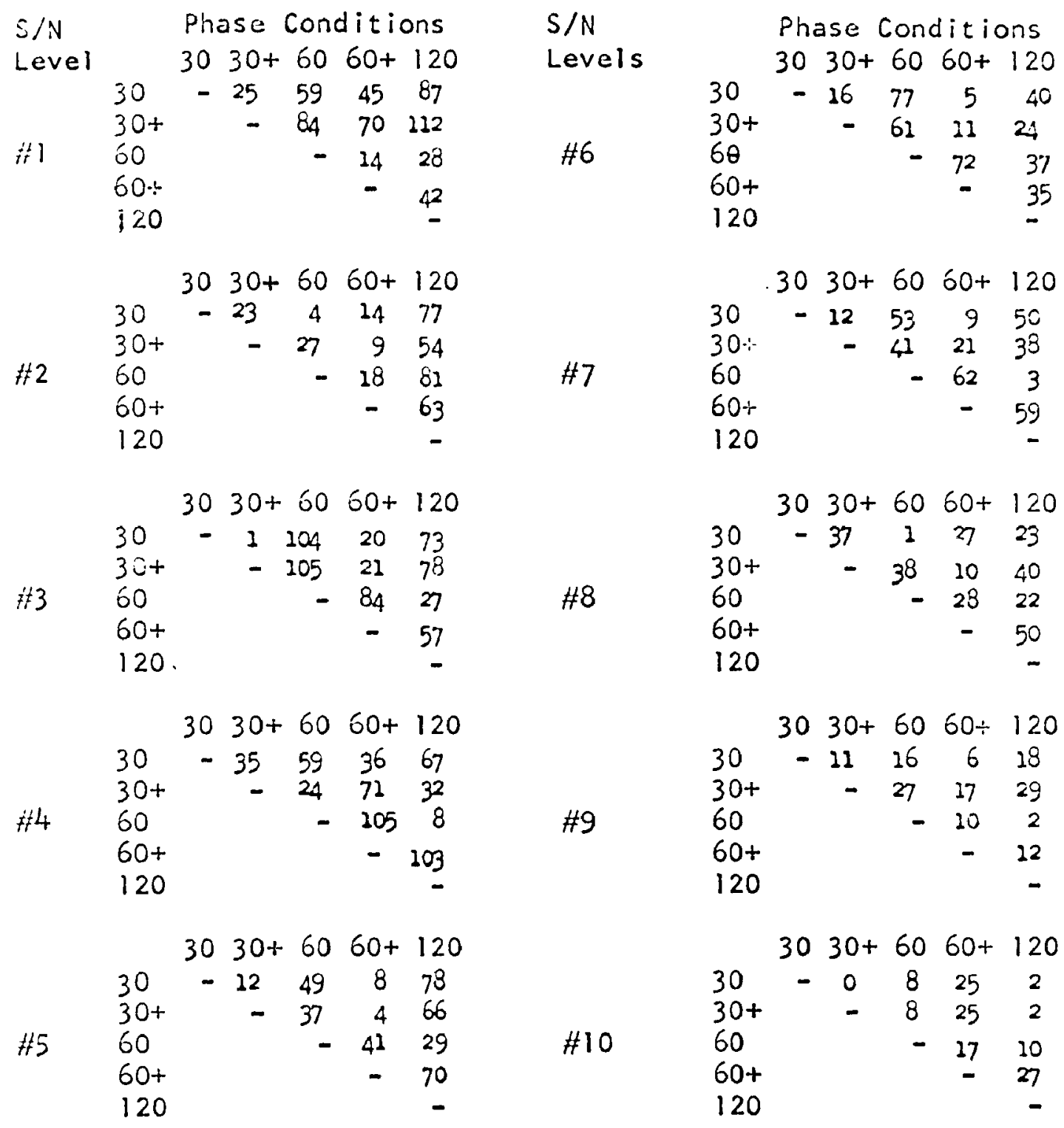

$*$ A critical difference of 1.32 or more is significant at the .01 level of confidence.

tDenotes phase conditions that have been adjusted in peak-to-peak voltage of the complex waveform. 
Hypothesis $\underline{v}$. There is no difference in the detectability of a complex auditory signal, composed of two sine waves of equal peak-topeak voltage prior to being mixed to form the complex waveform, regardless of the relative phase of the components when the signal polarity is reversed.

Hypothes is $\mathrm{Vl}_{1}$. There is no difference in the detectability of a complex auditory signal, composed of two sine waves of equal subjective loudness prior to being mixed to form the complex waveform, regardless of the relative phase of the components when the signal polarity is reversed.

In order to test these hypotheses two analyses of variance were performed on the raw-score data (Appendixes $G$ and $H$ ) that had been transformed into $\underline{d}^{\prime}$ values. The mean- $\underline{d}^{\prime}$ scores and standard deviations are 1 isted in Tables 19-20 and the graphic representation of the means of the raw scores can be seen in Figure 25. Two subjects were tested in these conditions.

On the basis of these analyses Hypotheses $V$ was rejected at the .05 level of confidence and Hypothesis VI was rejected at the .01 level. As was the case in the peak-to-peak adjusted conditions, there were no significant differences when the scores at any one phase condition were compared with earphone leads reversed and earphone leads not reversed.

These results would tend to indicate that it is not the shape of the waveform that causes the differences in the detectability of the two-component complex signal. 
Table 19. Mean d' values and standard deviations for two subjects on two relative-phase-relationship conditions where the earphone leads were reversed. The corresponding d' values for these two subjects on the phase conditions where the earphone leads were in the normal position are compared to these reversed-leads scores. All relative-phase conditions were composed of component sine waves of equal peak-to-peak voltage prior to being mixed to form the complex signal.

\begin{tabular}{|c|c|c|c|c|c|c|c|c|c|c|c|}
\hline & & 1 & 2 & $3^{S i}$ & $\begin{array}{c}\text { nal - } \\
4\end{array}$ & $\begin{array}{c}0-N o \text { is } \\
5 \\
\end{array}$ & $\begin{array}{l}\text { e Ratic } \\
6 \\
\end{array}$ & $\begin{array}{l}\text { Rang } \\
7 \\
\end{array}$ & 8 & 9 & 10 \\
\hline & $\begin{array}{c}\text { M } \\
\text { Rev. }\end{array}$ & $\begin{array}{l}0.34 \\
\text { Leads }\end{array}$ & 0.50 & 0.93 & 0.52 & 0.30 & 0.53 & 0.30 & 0.10 & 0.10 & 0.10 \\
\hline & SD & 0.48 & 0.04 & 0.23 & 0.00 & 0.25 & 0.22 & 0.25 & 0.14 & 0.14 & 0.14 \\
\hline \multirow[t]{2}{*}{$0^{\circ}$} & $\begin{array}{c}M \\
\text { RMS }\end{array}$ & 0.26 & 0.58 & 0.70 & 0.50 & 0.10 & 0.54 & 0.10 & 0.06 & 0.29 & 0.42 \\
\hline & SD & 0.37 & 0.15 & 0.56 & 0.04 & 0.10 & 0.10 & 0.14 & 0.08 & 0.12 & 0.07 \\
\hline \multirow[t]{2}{*}{$120^{\circ}$} & $\begin{array}{c}\text { M } \\
\text { Rev. }\end{array}$ & $\begin{array}{l}2.13 \\
\text { Leads }\end{array}$ & 1.66 & 1.77 & 1.13 & 1.02 & 1.35 & 0.92 & 0.77 & 0.60 & 0.58 \\
\hline & SD & 0.00 & 0.33 & 0.37 & 0.05 & 0.11 & 0.49 & 0.11 & 0.00 & 0.11 & 0.15 \\
\hline \multirow[t]{2}{*}{$120^{\circ}$} & $\underset{R M S}{M}$ & 2.49 & 1.60 & 1.92 & 1.53 & 1.09 & 1.18 & 1.13 & 0.73 & 0.92 & 0.41 \\
\hline & SD & 0.29 & 0.62 & 0.71 & 0.52 & 0.00 & 0.34 & 0.18 & 0.06 & 0.11 & 0.16 \\
\hline
\end{tabular}


Table 20. Mean d'values and standard deviations for two subjects on two relative-phase-relationship conditions where the earphone leads were reversed. The corresponding d' values for these two subjects on the phase conditions where the earphone leads were in the normal position are compared to these reversed-leads scores. All relative-phase conditions were composed of component sine waves of subjectively equal loudness prior to being mixed to form the complex signal.

\begin{tabular}{|c|c|c|c|c|c|c|c|c|c|c|c|}
\hline & & 1 & 2 & 3 & $\begin{array}{c}\text { gnal -t } \\
4\end{array}$ & $\begin{array}{c}0-\text { No is } \\
5\end{array}$ & $\begin{array}{l}\text { Rat i } \\
6\end{array}$ & $\begin{array}{c}0 \text { Rang } \\
7\end{array}$ & ${ }_{8}$ & 9 & 10 \\
\hline $30^{\circ}$ & $\begin{array}{c}\text { M } \\
\text { Rev. } \\
\text { SD }\end{array}$ & $\begin{array}{l}1.00 \\
\text { Leads } \\
0.23\end{array}$ & $\begin{array}{l}0.68 \\
0.23\end{array}$ & $\begin{array}{l}0.68 \\
0.23\end{array}$ & $\begin{array}{l}0.86 \\
0.12\end{array}$ & $\begin{array}{l}0.97 \\
0.28\end{array}$ & $\begin{array}{l}0.76 \\
0.11\end{array}$ & $\begin{array}{l}0.54 \\
0.33\end{array}$ & $\begin{array}{l}0.89 \\
0.07\end{array}$ & $\begin{array}{l}0.45 \\
0.11\end{array}$ & $\begin{array}{l}0.00 \\
0.00\end{array}$ \\
\hline $30^{\circ}$ & $\begin{array}{r}\text { M } \\
\text { RMS } \\
\text { SD }\end{array}$ & $\begin{array}{l}0.89 \\
0.29\end{array}$ & $\begin{array}{l}1.00 \\
0.45\end{array}$ & $\begin{array}{l}0.54 \\
0.10\end{array}$ & $\begin{array}{l}0.47 \\
0.66\end{array}$ & $\begin{array}{l}0.47 \\
0.00\end{array}$ & $\begin{array}{l}0.15 \\
0.21\end{array}$ & $\begin{array}{l}0.19 \\
0.26\end{array}$ & $\begin{array}{l}0.24 \\
0.33\end{array}$ & $\begin{array}{l}0.29 \\
0.12\end{array}$ & $\begin{array}{l}0.06 \\
0.06\end{array}$ \\
\hline $60^{\circ}$ & $\begin{array}{c}M \\
\text { Rev. } \\
\text { SD }\end{array}$ & $\begin{array}{l}2.84 \\
\text { Leads } \\
0.59\end{array}$ & $\begin{array}{l}1.89 \\
0.00\end{array}$ & $\begin{array}{l}1.75 \\
0.20\end{array}$ & $\begin{array}{l}1.10 \\
0.23\end{array}$ & $\begin{array}{l}1.40 \\
0.57\end{array}$ & $\begin{array}{l}1.10 \\
0.23\end{array}$ & $\begin{array}{l}0.97 \\
0.18\end{array}$ & $\begin{array}{l}0.57 \\
0.38\end{array}$ & $\begin{array}{l}0.97 \\
0.18\end{array}$ & $\begin{array}{l}0.39 \\
0.12\end{array}$ \\
\hline $60^{\circ}$ & $\begin{array}{r}M \\
\text { RMS } \\
\text { SD }\end{array}$ & 2.36 & 1.85 & 1.91 & 1.26 & 0.89 & 0.89 & 1.10 & 0.81 & 1.25 & 0.74 \\
\hline
\end{tabular}




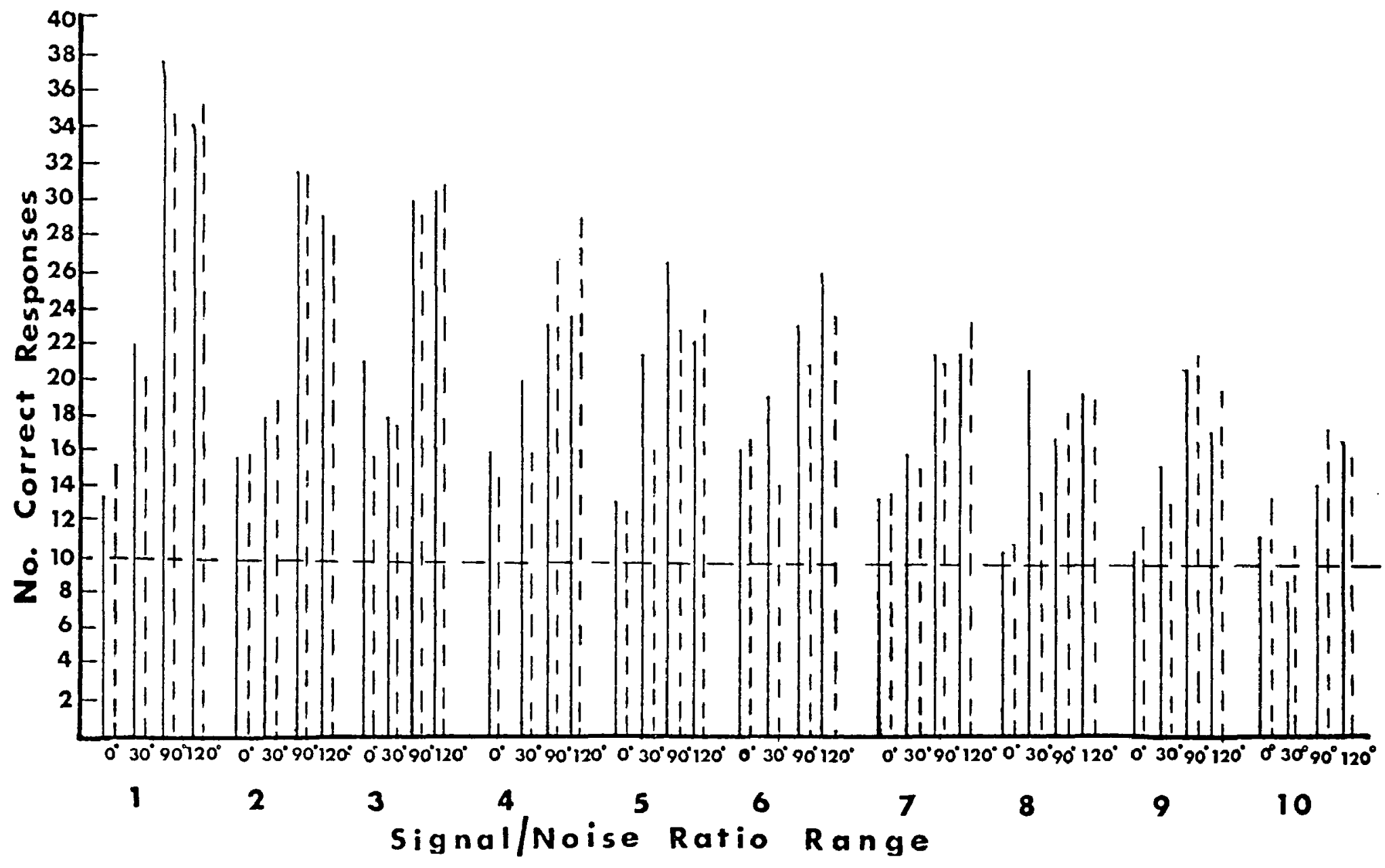

Figure 25. Averaged correct responses for two subjects on the four phase conditions where the earphone leads were reversed, as compared to the corresponding phase conditions where the leads were in normal position. Solid lines represent reversed-leads scores; dashed lines are the scores with leads in normal position. 
Table 21. Summary table for analys is of variance for two subjects on two relative-phase-relationship conditions where earphone leads were reversed, as compared to two similar phase conditions where earphone leads were in normal position. The sine wave components were of equal peak-to-peak voltage prior to being mixed to form the complex signal. Source of variance $A$ represents the variance between signal-to-noise levels. Source of variance B represents the variance between phaserelation conditions.

Source of

Variance

df

Sum of Squares

Mean Square

$F *$

A

9

12.7811

1.4201

12.00

B

3

11.7486

3.9162

12.87

$A B$

27

5.2253

.1935

4.52

Error A

9

1.0649

.1183

Error B

3

.6575

.2192

Error $A B$

27

1.1555

.0428

Total $78 \quad 32.6830$
$\because F_{.01}=5.35(\underline{\text { df }} 9,9) ; 29.46(\underline{\text { df }} 3,3) ; 2.47(\underline{\text { df }} 27,27)$
$* F_{.05}=9.28(\underline{\text { df }} 3,3)$


Table 22. Summary table for analys is of variance for two subjects on two relative-phase-relationship conditions where earphone leads were reversed, as conpared to two similar phase conditions where earphone leads were in normal position. The sine wave components were of equal subjective loudness prior to being mixed to form the complex signal. Source of variance $A$ represents the variance between signal-to-noise levels. Source of variance $B$ represents the variance between the phase-relation conditions.

\begin{tabular}{ccccc}
$\begin{array}{l}\text { Source of } \\
\text { Variance }\end{array}$ & df & Sum of Squares & Mean Square & F* \\
\hline A & 9 & 9.0856 & 1.0095 & 15.68 \\
B & 3 & 15.7155 & 5.2385 & 51.16 \\
AB & 27 & 4.5727 & .1694 & 3.18 \\
Error A & 9 & .5798 & .0644 & .1024 \\
Error B & 3 & .3072 & .0532 & \\
Error AB & 27 & 1.4365 & & \\
\hline Total & 78 & 31.6974 & & \\
*F & & & &
\end{tabular}


Table 23. Differences beiween the means at ten signal-to-noise ratio levels for four relative-phase conditions, two of which have been presented in reversed-leads manner. The means are derived from the socres of two subjects on the complex signal that was composed of sine vaves of equal peak-to-peak voltage prior to being mixed to form the complex signal.

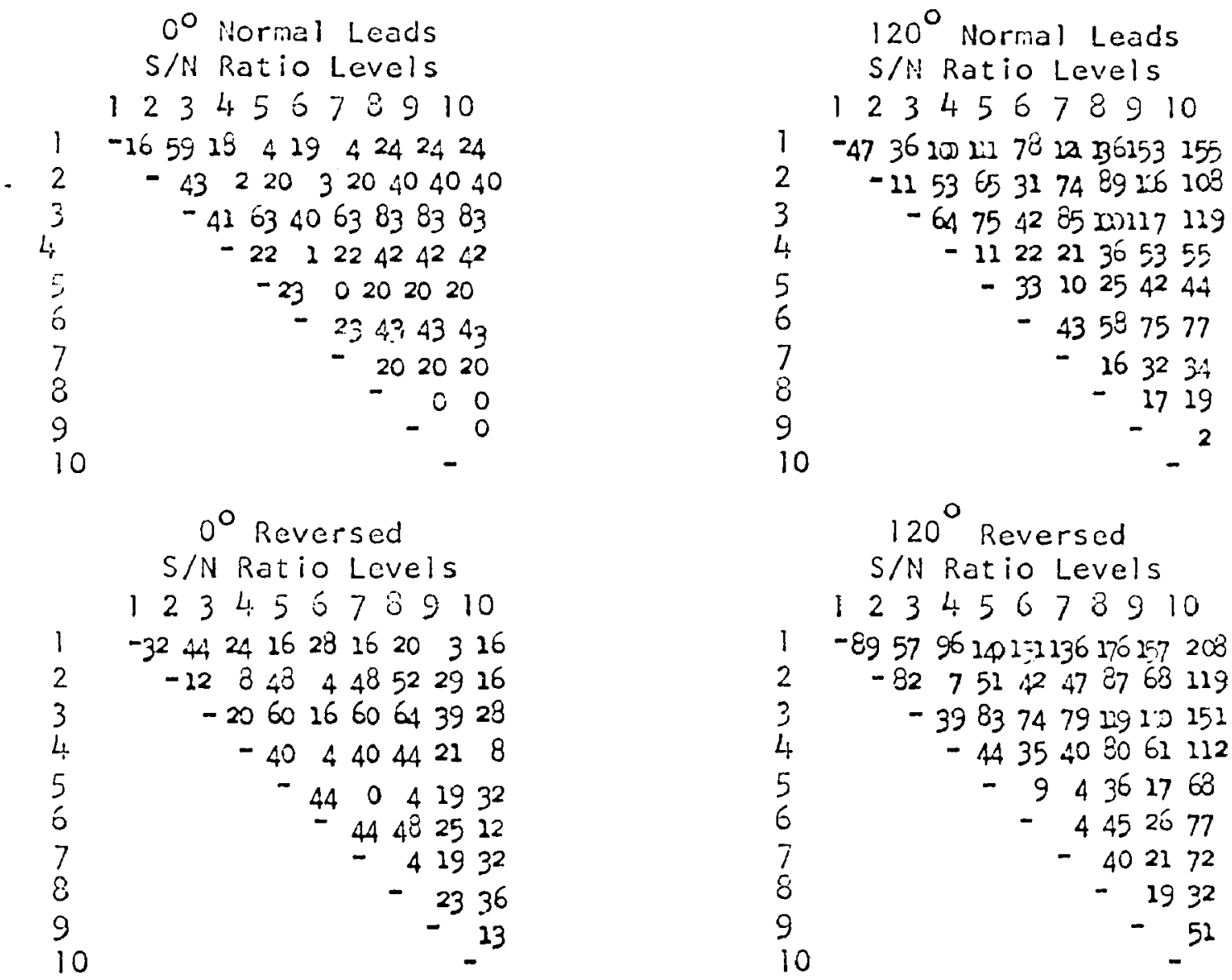

$\because$ A critical difference of .97 or more is significant at the .01 levei of confidence. 
Table 24. Differences between the means at ten signal-to-noise ratio levels for four reiar:ive-phase conditions, two of which have been presented in reversed-leads manner. The means are derived from the scores of two subjects on the complex signal that was composed of sine waves of equal subjective loudness prior to being mixed to form the complex signal.
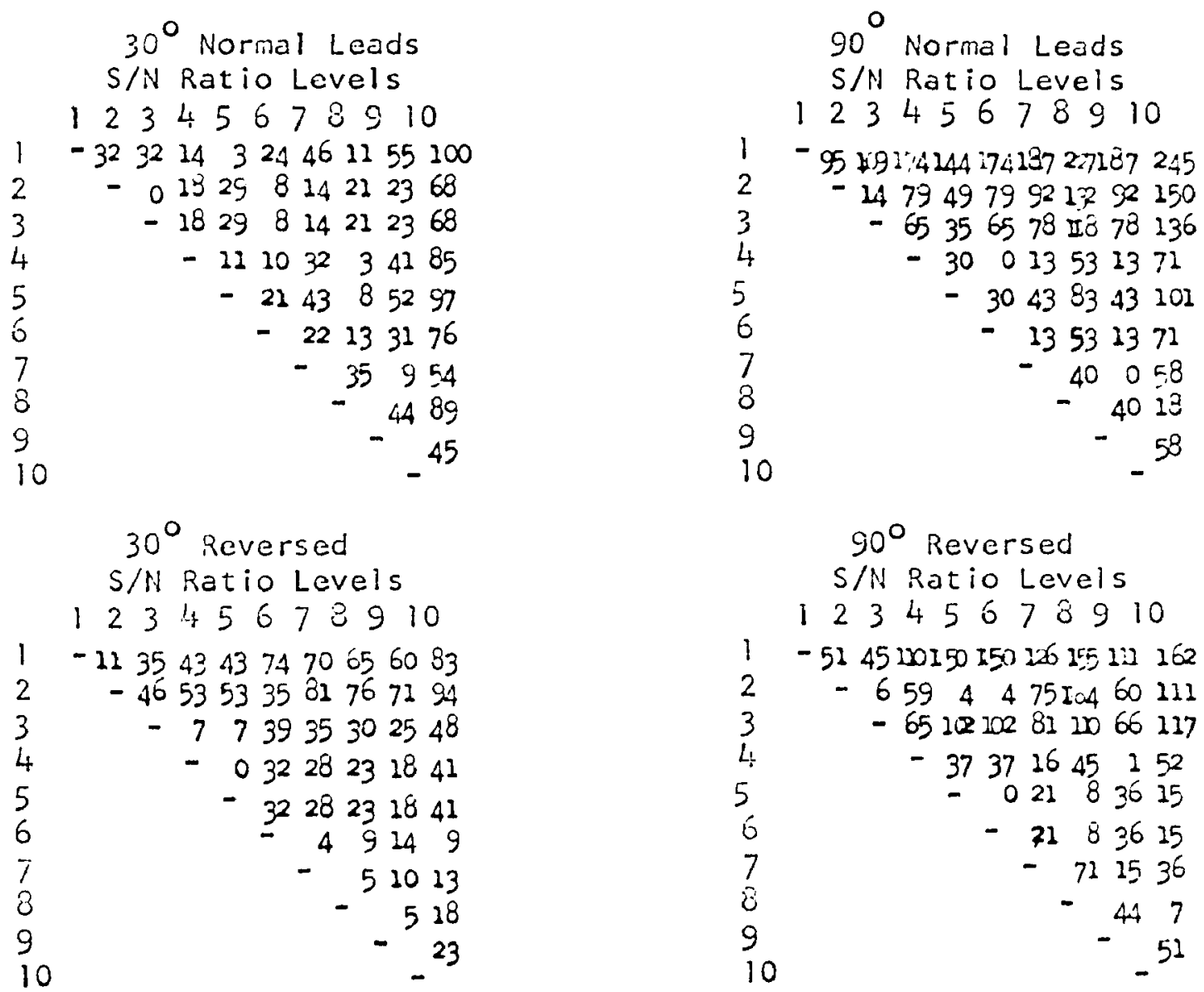

$\because$ critical difference of .72 or more is significant at the .01 level of confidence. 
Table 25. Diffcrences between the means at four phase-relationship conditions for ten signal-to-noise ratio levels, where two of the complex waveforns have been presented in reversed-leads manner. The means are derived from the scores of two subjects from the conplex signal that was composed of sine waves of equal subjective loudness prior to being mixed to form the complex signal.

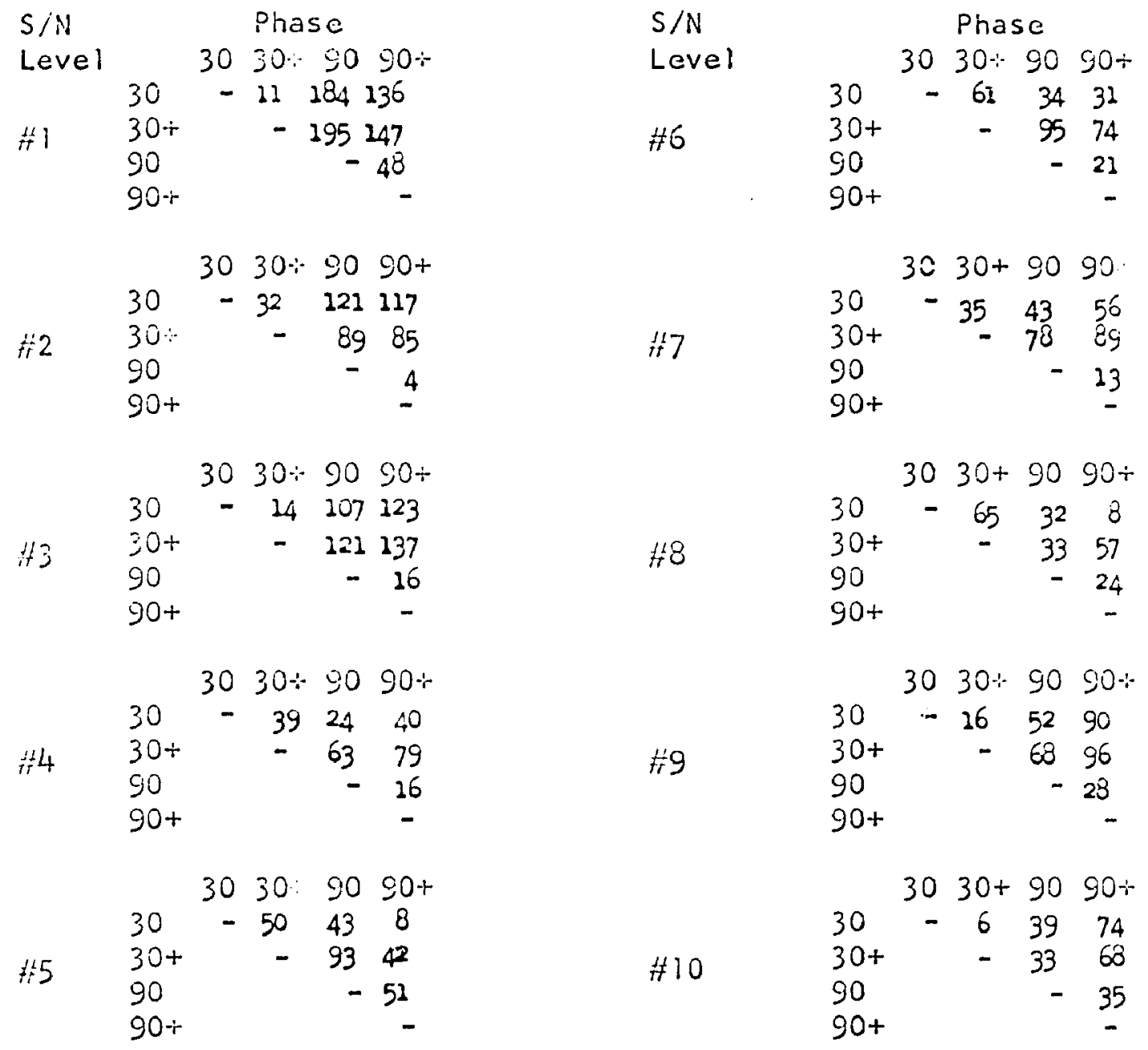

$\therefore$ A critical difference of 1.45 or more is significant at the .01 level of confidence

${ }^{+}$Denotes phase conditions that have been presented in reversed-leads manner. 
Table 26. Differences between the means at four phase-relationship conditions for ten signal-to-noise ratio levels, where two of the complex waveforms have been presented in reversed-leads manner. The means are derived from the scores of two subjects from the complex signal that was composed of sine waves of equal subjective loudness prior to being mixed to form the complex signal.

$S / N$

Level

$\# 1$

H1

1

$\begin{array}{rrrrr} & 0 & 0+ & 120 & 120+ \\ 0 & - & 8 & 116 & 110 \\ 0+ & - & 108 & 102 \\ 120 & & - & 6 \\ 120+ & & & -\end{array}$

\#3

$$
00+120120+
$$$$
\begin{array}{llll}
0 & -17 & 84 & 99
\end{array}
$$$$
0+\quad-107 \quad 122
$$$$
\begin{array}{ll}
120 & -\quad 25 \\
120+ & -
\end{array}
$$

\#4 $\begin{array}{cccc}0 & 0+ & 120 & 120+ \\ 0 & -2 & 61 & 102 \\ 0+ & - & 63 & 103 \\ 120 & & - & 50 \\ 120+ & & & -\end{array}$

\#5 $\begin{array}{cccc}0 & 0+120 & 120+ \\ 0 & -20 & 72 & 69 \\ 0+ & - & 92 & 99 \\ 120 & - & 17 \\ 120+ & & -\end{array}$

\section{Phase}

$$
\begin{aligned}
& 00+120120+ \\
& \begin{array}{llll}
0 & -8 & 82 & 65
\end{array} \\
& \text { \#6 } 0+-8164 \\
& 120 \\
& 120+ \\
& 00+120120+ \\
& \begin{array}{llll}
0 & -20 & 62 & 83
\end{array}
\end{aligned}
$$

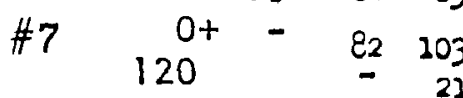

$$
\begin{aligned}
& 120 \\
& 00+120 \quad 120+ \\
& \begin{array}{lll}
0 & -4 & 67
\end{array} 3 \\
& \text { \#8 } 0+-7167 \\
& \begin{array}{ll}
120 & -2 \\
120+ &
\end{array} \\
& 00+120120+ \\
& \text { \#9 } \begin{array}{cccc}
0-19 & 50 & 82 \\
0+ & - & 32 & 63 \\
120 & & - & 32 \\
120 & & & -
\end{array} \\
& \text { \#10 } \begin{array}{ccc}
0-32 & 48 & 31 \\
0+{ }^{-}-16 & 1 \\
120 & - & 17 \\
120+ & & -
\end{array}
\end{aligned}
$$

$*$ A critical difference of .78 or more is significant at the .05 level of conf idence

tDenotes phase conditions that have been presented in reversed-leads manner. 


\section{Subject Variability}

This study originally began with four subjects, two males and two females. The subjects were chosen carefully in an attempt to find individuals who would remain conscientious toward the detection task. The results obtained from the first 12 stimulus tapes (six phase relationships and two conditions of component intensity) disclosed that one subject was performing differently than the other three. As can be seen in Appendixes $\mathrm{C}-\mathrm{H}$, this subject, RW, performed at a level of just over chance regardless of the phase relationship inherent to the stimuli. This subject was also run on the conditions where the peakto-peak voltages of the complex signals were equated, but again he performed differently than did the other three.

For this reason, a fifth subject was selected and subjected to the first 12 stimulus tapes. The results from this fifth subject were similar to those of the other three. Consequently, the data from the four subjects showing similar results were combined in all of the figures and tables.

Figure 26 shows an example of how subject RW differed from the other four at the easiest signal-to-noise ratio task on all six relativephase relationship stimulus tapes.

The results of standard pure-tone and Békésy audiometric tests indicated that RW was normal in hearing acuity. Speech discrimination and speech-reception-threshold tests also were normal. From talking with the subject it appeared that he realized what his task was in the detection situation, and there was no indications that the subject was 

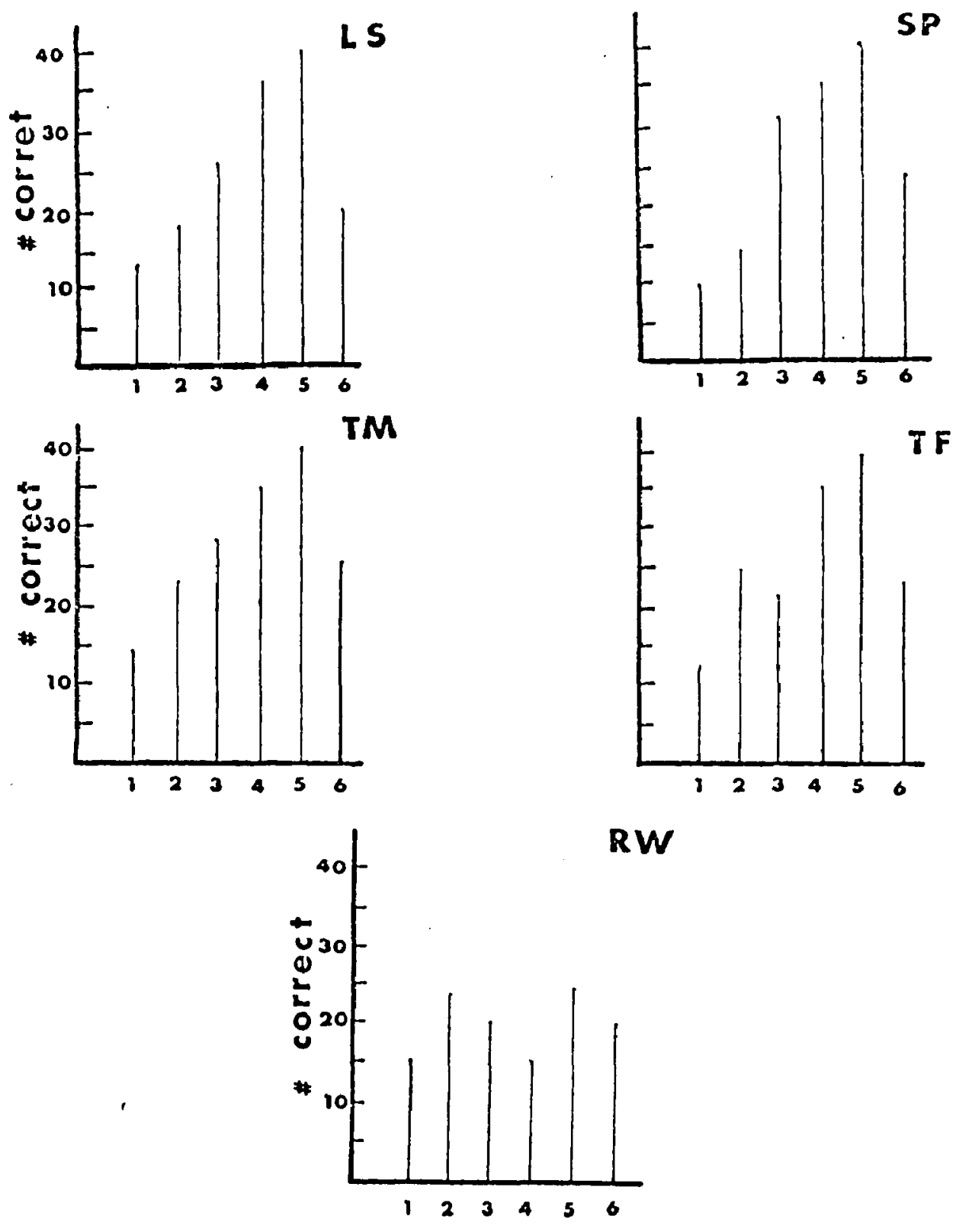

Figure 26. Number of correct responses for the six phase-relationship conditions (equal peak-to-peak voltage of the component sine waves) by all five subjects at the easiest signal-to-noise ratio task. Abscissa numbers indicate (1) $0^{\circ}$; (2) $30^{\circ} ;$ (3) $60^{\circ} ;$ (4) $90^{\circ} ;$ (5) $120^{\circ}$; (6) $150^{\circ}$. 
not performing at an optimal level. For these reasons another detectability task was created in which the independent variable was signal intensity rather than relative-phase relationships and intensity. For this task the original stimulus tape of the $90^{\circ}$ relative phase condition (equal peak-to-peak component sine waves) was re-recorded with the fundamental filtered out. A signal-to-noise ratio range of $10 \mathrm{~dB}$ was again determined after the "threshold" for the $1050 \mathrm{cps}$ signal in noise was made.

Three subjects, LS, SP and RW were given this signal detection task which, under this condition, contained 200 frames rather than 400 as in the original tapes. Under these conditions RW performed equally as well as did the other two subjects. On the following day RW was tested again and this time compared to subjects TM and TF. The performance of RW was again equally as good as these two subjects. The data from these tests are shown in Figure 27.

On the basis of these tests it was concluded that the subject differences between RW and the other four I isteners, were a function of something other than the intensity of the signal in noise.

One other test was tried on RW. He, like all of the subjects in the study, selected one ear at the beginning of the experiment and used that ear throughout the study. For this reason this subject was tested at the $120^{\circ}$ relative phase condition again, but this time while listening with the other ear. The performance, regardless of which ear was being used, was similar. 

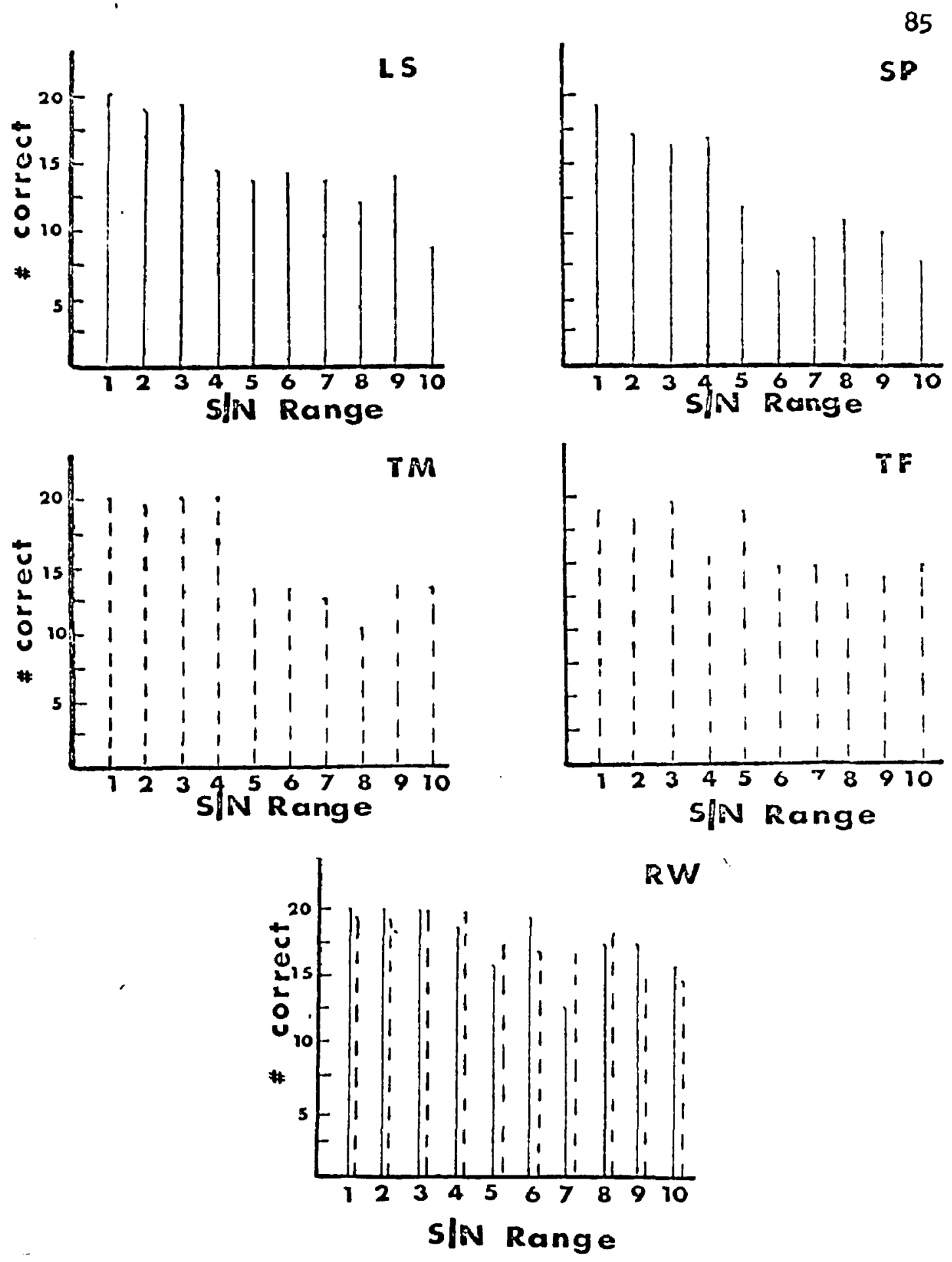

Figure 27. Data showing the performance of subject RW as compared to the other four subjects on a signal detection task where loudness was the independent variable. Solid and dashed lines indicate two different signal-to-nolse ratio tasks. 


\section{The ldeal observer}

The performance of the ideal observer can be stated for the detection task employed in this study. The formula for the detection of the two-component complex signal, as previously stated, is

$$
\underline{d}_{z}^{\prime}=\left[\left(\underline{d}_{f_{1}}\right)^{2}+\left(\underline{d}^{\prime} f_{2}\right)^{2}\right]^{\frac{1}{2}}
$$

For the signal energy and noise power employed in this study, the performance of the ideal observer over the $10 \mathrm{~dB}$ signal-to-noise ratlo range in the detection task where the component sine waves of the complex waveform were of equal peak-to-peak voltage prior to being mixed to form the complex signal is given in Table 26.

\section{Discussion}

From the results just described it would appear that Green's model for the detection of complex auditory signals is insufficient without consideration of the phase of the components. Before generating a model to incorporate a phase factor, it would be desirable to add additional harmonics, one at a time, and systematically alter their relative phases.

The theoretical implications of these findings will be discussed under three separate headings.

The Aural Harmonics Explanation. A possible explanation of the results of this study would follow in the same line as suggested by Lewis and Larsen (21). These authors attempted to determine the phase of a $120 \mathrm{cps}$ subjective difference tone produced by a complex signal which consisted of a 390 and a $520 \mathrm{cps}$ sine wave. An auxiliary $130 \mathrm{cps}$ 
Table 27. Performance of the ideal observer, stated in terms of d', in the detection task where the component sine waves were of equal peak-to-peak voltage prior to being mixed to form the complex waveform, as compared to the performance of four subjects at the six relativephase relationship conditions.

\begin{tabular}{|c|c|c|c|c|c|c|c|}
\hline $\begin{array}{l}\text { Signal-to- } \\
\text { Noise Ratio } \\
\text { Range }\end{array}$ & $\begin{array}{l}\text { d' for the } \\
\text { Ideal ob- } \\
\text { server }\end{array}$ & \multicolumn{6}{|c|}{$\begin{array}{l}\text { Averaged } d^{\prime} \text { values for four subject } \\
\text { the six Relative Phase Conditio }\end{array}$} \\
\hline $\begin{array}{r}1 \\
2 \\
3 \\
4 \\
5 \\
6 \\
7 \\
8 \\
9 \\
10\end{array}$ & $\begin{array}{l}1.47 \\
1.31 \\
1.17 \\
1.04 \\
.93 \\
.83 \\
.74 \\
.66 \\
.59 \\
.52\end{array}$ & $\begin{array}{l}00 \\
.22 \\
.28 \\
.03 \\
.06 \\
.12 \\
.41 \\
.41 \\
.19 \\
.30 \\
.20\end{array}$ & $\begin{array}{l}300 \\
.85 \\
.77 \\
.66 \\
.52 \\
.55 \\
.44 \\
.50 \\
.32 \\
.30 \\
.11\end{array}$ & $\begin{array}{r}60^{\circ} \\
1.45 \\
1.44 \\
.91 \\
1.05 \\
.71 \\
.47 \\
.62 \\
.42 \\
.34 \\
.19\end{array}$ & $\begin{array}{r}90^{\circ} \\
2.25 \\
1.85 \\
1.89 \\
1.42 \\
1.08 \\
.99 \\
.94 \\
.70 \\
1.05 \\
.61\end{array}$ & $\begin{array}{r}120^{\circ} \\
3.18 \\
2.42 \\
2.06 \\
1.50 \\
1.62 \\
1.27 \\
.83 \\
.79 \\
.77 \\
.54\end{array}$ & $\begin{array}{r}1500 \\
1.05 \\
.78 \\
.91 \\
.71 \\
.62 \\
.63 \\
.11 \\
.20 \\
.28 \\
.16\end{array}$ \\
\hline
\end{tabular}

signal was introduced by a separate audio oscillator, until the subjective difference tone was raised a just-noticeable-difference in intensity. The phase of the auxiliary 130 cps signal was systematically altered, and at each phase setting the physical intensity required to raise the loudness of the difference tone was noted. The authors suggested that if the subjective tone has a phase relationship of its own, this signal will combine with the auxiliary signal when the phases of the two are the same. When the two signals are out of phase with each other, they will interfere, and more intensity of the auxiliary tone will be required to raise the subjective tone a jnd. For the two listeners used in their study the phases at which the least intensity was required to raise the difference tone one jnd were 200 and 320 degrees. 
Trimmer and Firestone (42) also conducted a study which seems to have a direct bearing on the present findings. They employed the same stimuli used in the Chapin and Firestone (5) study---an intense lowfrequency fundamental with one of its higher harmonics added---but had the subjects adjust the phase of the higher harmonic until minimum loudness or minimum roughness was found. At these, as well as at other related phase relationships, the loudness of the complex signal was compared with the loudness of the fundamental alone. There were rather large subject differences, with one subject disagreeing between his two ears.

These authors concluded that the change in the fundamental, which was mostly a loudness change, was greater than what would have been expected from a simple interaction of an aural harmonic with an "exploring tone" of the same frequency.

Let us assume that the fundamental signal in the present study created a depression of the basilar membrane not only at the locus corresponding to its frequency, but also at loci associated with the harmonics of the stimulus. These aural harmonics will maintain some phase relationship with respect to the fundamental. Now, if we add a physical harmonic to the signal, the phase of this "real" harmonic will interact with the phase of the aural harmonic. When these two have a relative phase relationship of $0^{\circ}$, as in the Lewis and Larsen study, they will summate to a maximum, which could conceivably be translated at the basilar membrane as a more intense stimulus than either of the two components separately. When these two harmonics have a $180^{\circ}$ relative 
phase relationship, they should cause the basilar membrane to have a minimum displacement.

Figure 21 demonstrates this as a possibility. Notice that at any one signal-to-noise ratio the maximum height of the histograms results at a relative phase of the components of the complex waveform of 1200. From the reasoning of other investigators, such as Lewis and Larsen, it might be concluded that the relative phase of the aural harmonic is approximately $120^{\circ}$ with respect to the fundamental.

This conclusion is clouded by the fact that the total level of the signal-plus-noise was about $55 \mathrm{~dB}$ SPL. For aural harmonics to be produced on the basilar membrane it is usually thought that greater intensity is needed. In addition, the signal was always mixed with a complex noise.

Temporal Relationships of Nerve Potentials. A second explanation of the results follows from the model suggested by Karplus. Karplus (18) has suggested that several hair cell receptors are connected by way of "delay lines" to a neural junction where their output is added. Hair cells at a different location have different delay $t$ imes and Karplus suggests that these signals can be blocked at the junction.

It is known that the difference between the times when a 1000 cps tone and a $500 \mathrm{cps}$ tone make impressions on the oval window until they stimulate the basilar membrane is on the order of $2.5 \times 10^{-4}$ seconds (10). If we can assume that the complex wave makes two separate depressions of the basilar membrane we can picture the spike potentials from these loci as having a temporal relationship. This temporal 
relationship may be changed as we change the relative phases of the components.

It is not unreasonable, it seems, to suggest that the action potentials may partially inhibit each other in some conditions and/or facilitate each other in other temporal relationships. This speculation could not be verified through calculations of the time differences resulting from the phase shifts of the two components used in the present study.

Spatial Relationships on the Basilar Membrane. The third possible explanation of the results comes from the work with mechanical models of Békésy and Tonndorf. Békésy (3), using his model which employs the skin of the arm as the basilar membrane, noticed that when he used a fundamental with a mistuned octave, a beating effect could be felt shifting over the entire length of the arm. At either end of the "basilar membrane" he noted that as the beat traveled the whole length of the model there was an associated waxing and waning of the sensation at the end points.

Tonndorf (41), using a model much like that of Békésy, reported changes in the particle-pattern movements within the fluid when the components of a two-component stimulus were altered in relative phase. The most-noticeable locus of movement, Tonndorf reported, was in the vicinity of the displacement associated with the higher-pitched component.

While it is difficult to directly compare the findings from these models to the conditions of the present study, the possibility of 
changes in the spatial relationships associated with the phase changes of the components must be considered.

The use of the foregoing possibilities to explain the results of this study appear insufficient. It is felt that an important link in finding an explanation is to be found in the subject differences previously discussed.

\section{Summary}

This chapter was concerned with the results of the investigation. Six null hypotheses were suggested and statistical procedures were reported. The chapter also included a discussion of the findings in light of theoretical speculations which could account for the results. 


\section{CHAPTER $V$}

\section{SUMMARY}

This study was designed to investigate the detectability of a complex signal as a function of the relative phase of the components of that complex waveform. The complex waveform was composed of a fundamental of 525 cps and a second harmonic of 1050 cps. Six phase relations of the second harmonic with respect to the fundamental were used: $0^{\circ}, 30^{\circ}, 60^{\circ}, 90^{\circ}, 120^{\circ}$, and $150^{\circ}$. The voltages of the two components of the complex signal were varied in two ways: in one condition the two components were equal in peak-to-peak voltage, and in the other condition the voltages of the two were subjectively equal in loudness.

Four 100-millisecond bursts of noise, one of which contained the complex waveform, were presented to the subjects and they were forced to choose which of the four contained the signal. Ten different signal-tonoise ratios, covering a range of $10 \mathrm{~dB}$ around a subjective "threshold" value, were utilized. Forty judgments at each of these signal-to-noise ratios were used in each phase condition.

The statistical analysis of the data revealed significant differences with regard to the detectability of the complex signal as a function of the relative phase of the components. The results indicated that at the $120^{\circ}$ relative-phase relationship detectability was maximum. 
Three theoretical explanations of the results were suggested.

(a) The first possibility involved the aural harmonic principle. It has been suggested by previous authors that a fundamental will create aural harmonics which have a relative phase relationship with that fundamental. The addition of a "real" harmonic can either add to or subtract from the aural harmonic, depending on the relative phase of the "real" tone and the subjective tone. If, in the present study, an aural second harmonic was generated by the fundamental, it would appear that this subjective tone had a relative phase relationship of $120^{\circ}$ with respect to the fundamental, since detectability was maximum when the physical second harmonic had a relative phase relationship with the fundamental of $120^{\circ}$. The difficulty with using the aural harmonic principle to explain the results of this study is that the over-all intensity of the noise and signal-plus-noise was about $55 \mathrm{~dB}$ SPL. It is generally thought that aural harmonics are only produced at more intense levels of stimulation.

(b) A second possibility was that the temporal relationship between the action potentials generated by the two frequencies of the complex signal may be altered by changes in the relative phase of the components. This alteration may result in inhibition and/or facilitation of the impulses as they are passed to higher centers of the central nervous system.

(c) A third possibility involved the loci of stimulation on the basilar membrane. It is conceivable that changes in the relative phase 
of the components of the complex stimuli resulted in shifts in the loci of stimulation along the basilar membrane.

The positive contribution of this work seems to be that relative phase of the components must be taken into account in a model for the detectability of complex signals---at least for a complex signal composed of two components. 


\section{APPEND IXES}


APPENDIX A. A mathematical statement showing that RMS voltage remains constant regardless of the phase relationship of the components.

Given two sinusoidal voltages, $V_{A}(t)$ and $V_{B}(t)$ such that,

$$
\begin{aligned}
& v_{A}(t)=A \sin \omega t \\
& v_{B}(t)=B \sin (2 \omega t+\Phi)
\end{aligned} \text { where } \omega=2 \pi f \text { and }
$$

The instantaneous sum is

$$
\begin{aligned}
v(t) & =A \sin \omega t+B \sin (2 \omega t+\Phi) \\
\text { Now, } v_{r m s} & =\left[\frac{1}{2 \pi} \int_{0}^{2 \pi} v^{2}(t) d(\omega t)\right]^{\frac{1}{2}}
\end{aligned}
$$

And $v^{2}(t)=A^{2} \sin ^{2} \omega t+2 A B \sin \cot \sin (2 \omega t+\Phi)+B^{2} \sin ^{2}(2 \omega t+\Phi)$

So, $\quad \frac{1}{2 \pi} \int_{0}^{2 \pi} v^{2}(t) d(\omega t)=\frac{1}{2 \pi} \int_{0}^{2 \pi} A^{2} \sin \omega t d(\omega t)+\frac{1}{2 \pi} \int_{0}^{2 \pi} 2 A B \sin \omega t$

$$
\sin (2 \omega t+\Phi)+\frac{1}{2 \pi} \int_{0}^{2 \pi} B^{2} \sin ^{2}(2 \omega t+\Phi)
$$

But, $\frac{1}{2 \pi} \int_{0}^{2 \pi} 2 A B \sin \omega t \sin (2 \omega t+\Phi) d(\omega t)=0$

$$
\text { So } \sqrt{\frac{1}{2 \pi} \int_{0}^{2 \pi} v^{2}(t) d(\omega t)}=\sqrt{\frac{1}{2 \pi} \int_{0}^{2 \pi} A^{2} \sin ^{2} \omega t d(\omega t)+\frac{1}{2 \pi} \int_{0}^{2 \pi} B^{2} \sin ^{2}}
$$

Since $V_{A r m s}=\frac{1}{2 \pi} \int_{0}^{2 \pi} A^{2} \sin ^{2} \omega t d(\omega t) \quad$ and

$$
v_{B r m s}=\frac{1}{2 \pi} \int_{0}^{2 \pi} B^{2} \sin ^{2}(2 \omega t+\Phi) d(\omega t)
$$

Then $\quad v_{\text {rms }}^{2}=v_{\text {Arms }}^{2}+v_{B r m s}^{2}$

But $\quad P_{\text {total }}=\frac{v_{r m s}^{2}}{Z}$

So

$$
P_{\text {total }}=\frac{V_{\text {Arms }}^{2} V_{B r m s}^{2}}{Z}=P_{A}+P_{B}
$$

or, the total average power is equal to the sum of the power of each signal. 
APPENDIX B. Results of the Fourier analyses on the complex waveforms used as stimuli in this study.

A series of Fourier analyses were done on the complex signals to determine (a) the phase relationship between the harmonics; (b) the intensity differences between the harmonics; and $(c)$ the harmonic content of the signals beyond the two components originally composing the signals. To do these analyses oscillograph pictures of the complex waveforms were taken by means of a Dumond Oscillograph Record camera (Type 297) and Polaroid film (Type 46-L).

The original stimulus tapes, where the signal was on one channel, noise on the other, were played back on the tape recorder and the signal output was fed directly to the oscilloscope. This resulted in a more intense signal than was actually used in the experimental sessions, and could have introduced higher harmonics. Three pictures were taken at random from the 400 complex stimuli contained on each phase relation tape. From the six stimulus tapes where the peal-topeak voltage of the component sine waves of the complex signal were equal, one more picture each was taken. This time the output from the recorder was fed to the TDH-39 earphone. An artificial ear (Bruel \& Kjaer, Type 4212) passed the signal to an audio frequency spectrometer (Bruel \& Kjaer, Type 2109) and the oscilloscope traced the signal at this point.

The pictures were projected from a slide projector onto a grid having 48 equally spaced vertical ordinates rising from a horizontal line. The waveform was projected onto this grid so that one waveform 
covered the 48 unit line, and the relative heights of the points where the vertical 1 ines were crossed by the waveform were recorded.

The data were analyzed by means of an IBM 7094 Digital Computer System, using a system of analys is based on graphical evaluation of the Fourier coefficients by numerical integration.

The results of the analyses are summarized in the following two tables. The first table includes the results from the complex waveforms which resulted from two sine wave components of equal peak-topeak voltage. The second table includes the results from the complex waveforms composed of sine waves of equal subjective loudness.

RESULTS OF FOURIER ANALYSES. All measurements are an average of four analyses done at each relative phase relationship. Three of the four waveforms were photographed from the oscilloscope directly after leaving the tape recorder; the other picture was taken after the signal had passed through the TDH-39 earphone. The results were similar in all cases, whether being measured at the recorder output or earphone output. The component sine waves of the complex signal were equal (or nearly so, as seen by noting the absolute difference in $d B$ between the first and second harmonics, column tiree) in peakto-peak voltage prior to being mixed to form the complex waveform.

\begin{tabular}{cccc}
$\begin{array}{l}\text { Desired } \\
\text { Relative } \\
\text { Phase }\end{array}$ & $\begin{array}{l}\text { Average of } \\
\text { Measured } \\
\text { Relative Phase }\end{array}$ & $\begin{array}{l}\text { Average Absolute } \\
\text { Difference in dB } \\
\text { Between First and } \\
\text { Second Harmonics }\end{array}$ & $\begin{array}{l}\text { Aver } \\
\text { Differenc } \\
\text { Between F } \\
\text { Third Har }\end{array}$ \\
\hline $0^{\circ}$ & $13.0^{\circ}$ & 1.5 & 17 \\
$30^{\circ}$ & $36.9^{\circ}$ & 1.5 & 15 \\
$60^{\circ}$ & $64.0^{\circ}$ & 1.7 & 13 \\
$90^{\circ}$ & $95.6^{\circ}$ & 1.3 & 13 \\
$120^{\circ}$ & $123.4^{\circ}$ & 1.7 & 12 \\
$150^{\circ}$ & $159.1^{\circ}$ & 1.3 & 17
\end{tabular}


RESULTS OF FOURIER ANALYSES. All measurements are an average of three analyses done at each relative phase relationship. These waveforms were photographed from an oscilloscope which traced the output of the tape recorder directly. The component sine waves of the complex signal were of equal subjective loudness prior to being mixed to form the complex waveform. The Fletcher-Munson curves show that a 500 cycle signal should be $s$ ix dB more intense than the 1000 cycle signal for equal loudness at, or near, threshold. As can be seen in column three, the fundamental averaged $5 \mathrm{~dB}$ more intense than the second harmonic in the complex signals used in this study.

\begin{tabular}{cccc}
$\begin{array}{l}\text { Desired } \\
\text { Relative } \\
\text { Phase }\end{array}$ & $\begin{array}{l}\text { Average of } \\
\text { Measured } \\
\text { Relative Phase }\end{array}$ & $\begin{array}{c}\text { Average } \\
\text { Difference in dB } \\
\text { Between First and } \\
\text { Second Harmonics }\end{array}$ & $\begin{array}{c}\text { Average } \\
\text { Difference in dB } \\
\text { Between First and } \\
\text { Third Harmonics }\end{array}$ \\
\hline $0^{\circ}$ & $13.7^{\circ}$ & 5.0 & 18 \\
$30^{\circ}$ & $37.4^{\circ}$ & 5.0 & 17 \\
$60^{\circ}$ & $61.3^{\circ}$ & 5.0 & 17 \\
$90^{\circ}$ & $93.3^{\circ}$ & 5.3 & 17 \\
$120^{\circ}$ & $128.9^{\circ}$ & 5.0 & 18 \\
$150^{\circ}$ & $159.6^{\circ}$ & 5.0 & 21
\end{tabular}


APPENDIX C. Raw scores of four subjects on the six relative phase relationships composed of sine waves of equal peak-to-peak vol tage prior to being mixed to form the complex waveform. A raw score of 40 constitutes perfect performance, and a raw score of 10 indicates a performance at the chance level.

\begin{tabular}{|c|c|c|c|c|c|c|c|c|c|c|}
\hline ubject & 1 & 2 & $\underset{3}{\text { Sign }}$ & $\begin{array}{r}\text { to } \\
4\end{array}$ & $\begin{array}{c}\text { oise } \\
5\end{array}$ & $\begin{array}{c}\text { Ratio } \\
6\end{array}$ & $\begin{array}{c}\text { Rar } \\
7\end{array}$ & 8 & 9 & 10 \\
\hline $\begin{array}{l}\text { LS } \\
\text { SP } \\
\text { TM } \\
\text { TF } \\
\text { RW }\end{array}$ & $\begin{array}{l}13 \\
10 \\
14 \\
12 \\
15\end{array}$ & $\begin{array}{l}16 \\
10 \\
13 \\
13 \\
13\end{array}$ & $\begin{array}{r}7 \\
7 \\
9 \\
11 \\
14\end{array}$ & $\begin{array}{r}5 \\
11 \\
9 \\
11 \\
15\end{array}$ & $\begin{array}{r}10 \\
10 \\
8 \\
15 \\
16\end{array}$ & $\begin{array}{l}14 \\
18 \\
11 \\
15 \\
13\end{array}$ & $\begin{array}{l}17 \\
14 \\
14 \\
13 \\
15\end{array}$ & $\begin{array}{r}10 \\
14 \\
14 \\
8 \\
15\end{array}$ & $\begin{array}{r}13 \\
9 \\
17 \\
13 \\
14\end{array}$ & $\begin{array}{r}10 \\
17 \\
9 \\
12 \\
13\end{array}$ \\
\hline
\end{tabular}

$30^{\circ}$ Relative Phase Relationship

\begin{tabular}{cccccccccccr} 
& \multicolumn{10}{c}{ Signal - to-Noise Ratio Range } \\
Subject & 1 & 2 & 3 & 4 & 5 & 6 & 7 & 8 & 9 & 10 \\
& & & & & & & & & & \\
LS & 18 & 18 & 15 & 10 & 15 & 6 & 6 & 10 & 12 & 11 \\
SP & 14 & 11 & 15 & 15 & 15 & 16 & 15 & 16 & 8 & 11 \\
TM & 23 & 26 & 17 & 21 & 15 & 13 & 14 & 15 & 14 & 9 \\
TF & 25 & 21 & 23 & 18 & 19 & 21 & 24 & 13 & 17 & 12 \\
RW & 24 & 15 & 15 & 10 & 14 & 12 & 11 & 16 & 17 & 18
\end{tabular}

$60^{\circ}$ Relative Phase Relationship

\begin{tabular}{lccccccccccc} 
& \multicolumn{10}{c}{ Signal-to-Noise } & Ratio \\
Subject & 1 & 2 & 3 & 4 & 5 & 6 & 7 & 8 & 9 & 10 \\
& & & & & & & & & & \\
LS & 27 & 24 & 19 & 23 & 15 & 11 & 11 & 15 & 14 & 13 \\
SP & 32 & 22 & 21 & 16 & 17 & 15 & 18 & 16 & 14 & 11 \\
TM & 28 & 30 & 18 & 25 & 18 & 16 & 20 & 12 & 13 & 11 \\
TF & 22 & 32 & 25 & 26 & 23 & 19 & 20 & 17 & 13 & 12 \\
RW & 20 & 16 & 22 & 17 & 21 & 17 & 14 & 12 & 17 & 20
\end{tabular}




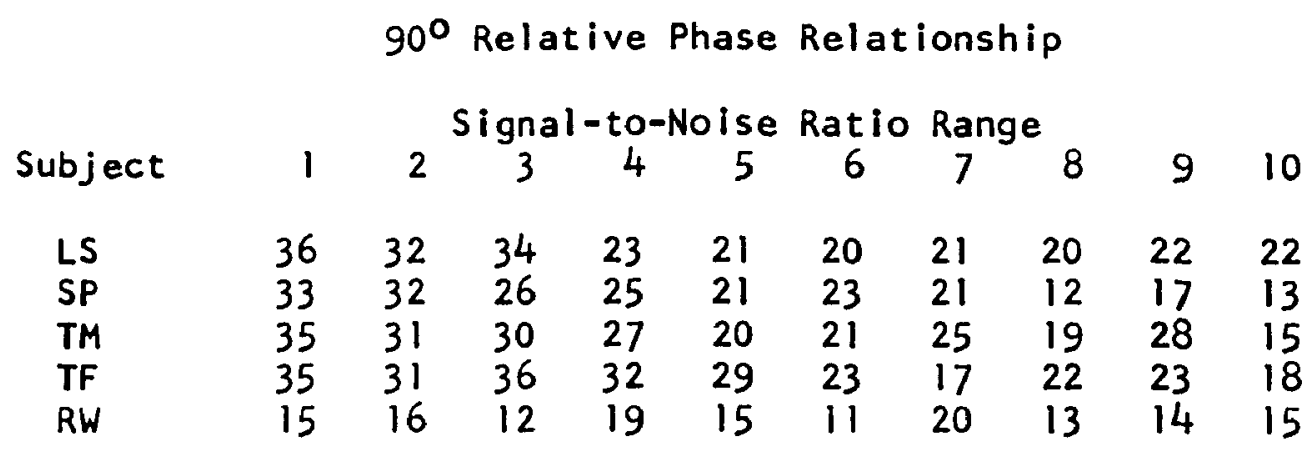

\begin{tabular}{ccccccccccc}
\multicolumn{10}{c}{} & $120^{\circ}$ Relative Phase Relationship \\
Subject & 1 & 2 & 3 & 4 & 5 & 6 & 7 & 8 & 9 & 10 \\
LS & 40 & 36 & 30 & 29 & 28 & 23 & 19 & 17 & 21 & 17 \\
SP & 37 & 33 & 34 & 25 & 26 & 26 & 18 & 16 & 16 & 13 \\
TM & 40 & 35 & 35 & 28 & 33 & 25 & 23 & 23 & 21 & 15 \\
TF & 39 & 38 & 34 & 29 & 29 & 27 & 19 & 21 & 18 & 19 \\
RW & 25 & 18 & 20 & 15 & 14 & 16 & 10 & 15 & 11 & 12
\end{tabular}

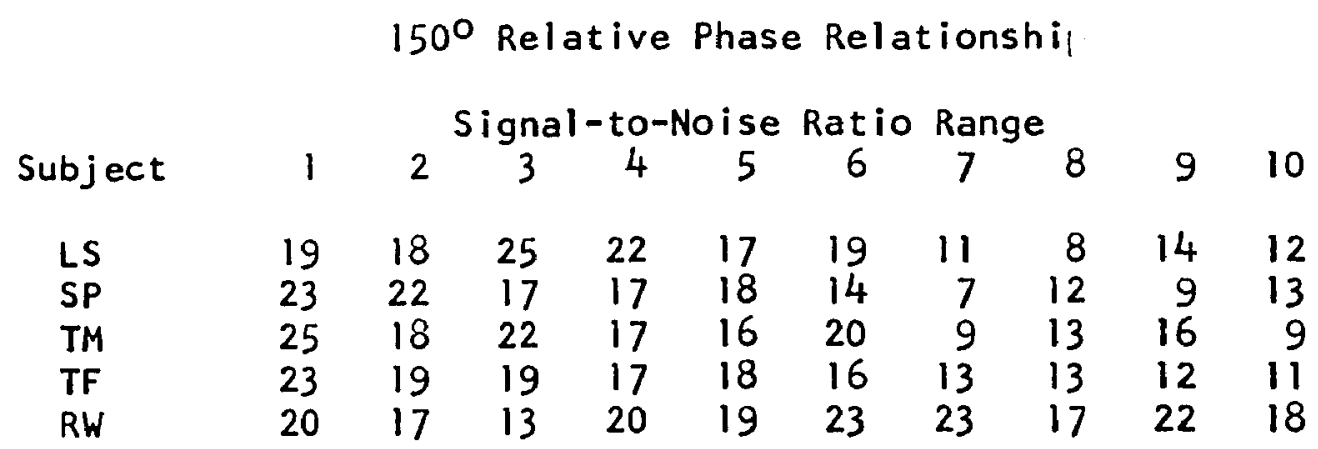


APPENDIX D. Raw scores of five subjects on the six relative phase relationships composed of sine waves of subjectively equal loudness prior to being mixed to form the complex waveform. A raw score of 40 constitutes perfect performance, and a raw score of 10 indicates a performance at the chance level.

\begin{tabular}{|c|c|c|c|c|c|c|c|c|c|c|}
\hline \multirow[b]{2}{*}{ Sutject } & \multicolumn{10}{|c|}{$0^{\circ}$ Relative Phase Relationship } \\
\hline & 1 & 2 & $\begin{array}{c}\text { Signa } \\
3\end{array}$ & $\begin{array}{c}- \text { to } \\
4\end{array}$ & $\begin{array}{c}\text { oise } \\
5\end{array}$ & $\begin{array}{c}\text { Ratio } \\
6\end{array}$ & $\begin{array}{c}\text { Range } \\
7\end{array}$ & 8 & 9 & 10 \\
\hline LS & 9 & 15 & 23 & 15 & 10 & 15 & 10 & 6 & 14 & \\
\hline$S P$ & 16 & 11 & 15 & 15 & 14 & 17 & 15 & 12 & 12 & \\
\hline TM & 16 & 18 & 13 & 16 & 12 & 17 & 12 & 11 & 12 & \\
\hline TF & 19 & 19 & 12 & 12 & 14 & 17 & 17 & 14 & 8 & \\
\hline RW & 19 & 20 & 19 & 17 & 14 & 22 & 27 & 17 & 14 & \\
\hline
\end{tabular}

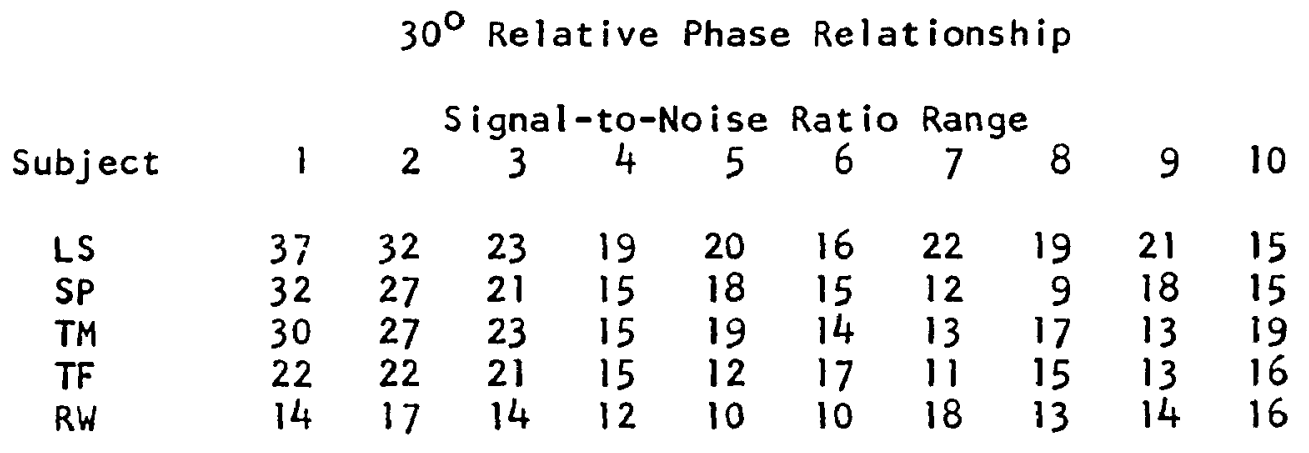

\begin{tabular}{|c|c|c|c|c|c|c|c|c|c|c|}
\hline Subject & 1 & 2 & $\underset{3}{\text { Signa }}$ & $\begin{array}{c}- \text { to- } \\
4\end{array}$ & $\begin{array}{c}\text { oise } \\
5\end{array}$ & $\underset{6}{\text { Ratio }}$ & $\begin{array}{c}\text { Ran } \\
7\end{array}$ & e 8 & 9 & 10 \\
\hline $\begin{array}{l}\text { LS } \\
\text { SP } \\
\text { TM } \\
\text { TF } \\
\text { RW }\end{array}$ & $\begin{array}{l}37 \\
37 \\
34 \\
33 \\
18\end{array}$ & $\begin{array}{l}37 \\
34 \\
31 \\
31 \\
14\end{array}$ & $\begin{array}{l}29 \\
35 \\
21 \\
28 \\
11\end{array}$ & $\begin{array}{l}28 \\
32 \\
37 \\
24 \\
11\end{array}$ & $\begin{array}{l}34 \\
24 \\
23 \\
25 \\
17\end{array}$ & $\begin{array}{l}25 \\
17 \\
16 \\
19 \\
15\end{array}$ & $\begin{array}{l}28 \\
16 \\
25 \\
17 \\
14\end{array}$ & $\begin{array}{l}25 \\
22 \\
17 \\
23 \\
20\end{array}$ & $\begin{array}{l}23 \\
16 \\
18 \\
17 \\
10\end{array}$ & $\begin{array}{r}14 \\
8 \\
16 \\
12 \\
16\end{array}$ \\
\hline
\end{tabular}




\begin{tabular}{|c|c|c|c|c|c|c|c|c|c|c|}
\hline Subject & 1 & 2 & $\underset{3}{\text { Signa }}$ & $\begin{array}{c}- \text { to- } \\
4\end{array}$ & $\begin{array}{c}\text { loise } \\
5\end{array}$ & $\begin{array}{c}\text { Ratio } \\
6\end{array}$ & $\begin{array}{c}\text { Ran } \\
7\end{array}$ & 8 & 9 & 10 \\
\hline $\begin{array}{l}\text { LS } \\
\text { SP } \\
\text { TM } \\
\text { TF } \\
\text { RW }\end{array}$ & $\begin{array}{l}37 \\
35 \\
38 \\
36 \\
15\end{array}$ & $\begin{array}{l}30 \\
34 \\
33 \\
37 \\
19\end{array}$ & $\begin{array}{l}26 \\
31 \\
27 \\
34 \\
16\end{array}$ & $\begin{array}{l}32 \\
25 \\
29 \\
34 \\
14\end{array}$ & $\begin{array}{l}25 \\
22 \\
19 \\
23 \\
16\end{array}$ & $\begin{array}{l}23 \\
22 \\
30 \\
24 \\
12\end{array}$ & $\begin{array}{l}19 \\
20 \\
22 \\
23 \\
16\end{array}$ & $\begin{array}{l}26 \\
17 \\
25 \\
25 \\
24\end{array}$ & $\begin{array}{r}18 \\
8 \\
17 \\
20 \\
12\end{array}$ & $\begin{array}{l}18 \\
13 \\
21 \\
25 \\
12\end{array}$ \\
\hline
\end{tabular}

$120^{\circ}$ Relative Phase Relationship

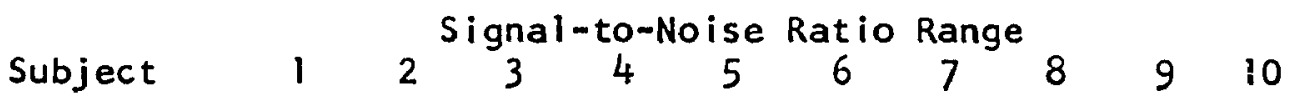

$\begin{array}{lllllllllll}\text { LS } & 35 & 24 & 27 & 24 & 23 & 21 & 22 & 18 & 20 & 16 \\ \text { SP } & 30 & 22 & 31 & 28 & 26 & 24 & 23 & 19 & 18 & 14 \\ \text { TM } & 37 & 33 & 36 & 32 & 23 & 27 & 25 & 19 & 22 & 13 \\ \text { TF } & 39 & 33 & 30 & 32 & 24 & 22 & 24 & 19 & 17 & 20 \\ \text { RW } & 12 & 18 & 19 & 13 & 22 & 15 & 19 & 15 & 20 & 22\end{array}$

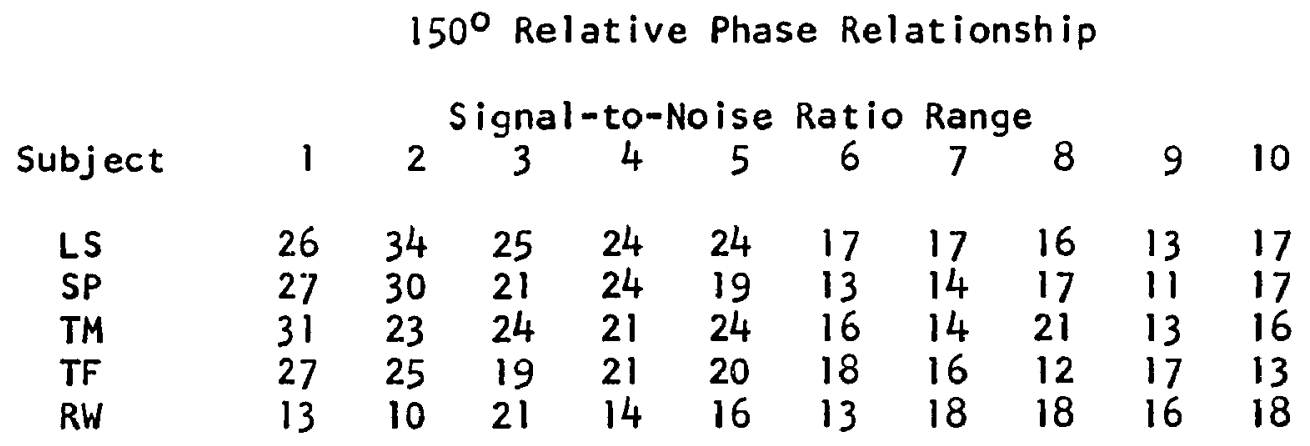


APPENDIX E. Raw scores for four subjects on the stimulus conditions where the complex waveform had been equated to a standard for peak-topeak voltage. The sine wave components of the stimulus were of equal peak-to-peak voltage prior to being mixed to form the complex waveform. A raw score of 40 constitutes perfect performance, and a raw score of 10 indicates performance at the chance level.

\begin{tabular}{cccccccccccr}
\multicolumn{10}{c}{$30^{\circ}$} & Relative Phase Relationship \\
Subject & 1 & 2 & 3 & 4 & 5 & 6 & 7 & 8 & 9 & 10 \\
LS & 26 & 24 & 15 & 21 & 23 & 14 & 17 & 13 & 19 & 12 \\
TM & 19 & 21 & 13 & 17 & 13 & 13 & 15 & 17 & 12 & 16 \\
SP & 17 & 19 & 12 & 15 & 14 & 11 & 19 & 13 & 13 & 7 \\
RW & 25 & 24 & 18 & 22 & 24 & 20 & 19 & 27 & 17 & 20
\end{tabular}

$90^{\circ}$ Relative Phase Relationship

\begin{tabular}{lcccccccccc} 
& \multicolumn{10}{c}{ Signal-to-Noise Ratio Range } \\
Subject & 1 & 2 & 3 & 4 & 5 & 6 & 7 & 8 & 9 & 10 \\
& & & & & & & & & & \\
LS & 30 & 22 & 28 & 25 & 17 & 21 & 26 & 14 & 22 & 16 \\
TM & 31 & 27 & 27 & 26 & 20 & 24 & 16 & 15 & 25 & 15 \\
SF & 26 & 22 & 25 & 19 & 15 & 25 & 17 & 12 & 24 & 12 \\
RW & 17 & 18 & 18 & 17 & 15 & 13 & 20 & 14 & 14 & 13
\end{tabular}


APPENDIX F. Raw scores for four subjects on the stimulus conditions where the complex waveform had been equated to a standard for peak-topeak voltage. The sine wave components of the stimulus were of equal subjective loudness prior to being mixed to form the complex waveform. A raw score of 40 constitutes perfect performance, and a raw score of 10 indicates performance at the chance level.

\begin{tabular}{|c|c|c|c|c|c|c|c|c|c|}
\hline Subject & 1 & 2 & $\begin{array}{r}\text { Sign } \\
3\end{array}$ & $\begin{array}{r}\text { to } \\
4\end{array}$ & $\begin{array}{c}\text { oise } \\
5\end{array}$ & $\operatorname{Ratio}_{6}$ & $\begin{array}{c}\text { Range } \\
7\end{array}$ & 8 & 9 \\
\hline $\begin{array}{l}\text { LS } \\
\text { TM } \\
\text { SP } \\
\text { RW }\end{array}$ & $\begin{array}{l}30 \\
31 \\
27 \\
20\end{array}$ & $\begin{array}{l}35 \\
21 \\
23 \\
20\end{array}$ & $\begin{array}{l}24 \\
16 \\
20 \\
17\end{array}$ & $\begin{array}{l}25 \\
18 \\
20 \\
20\end{array}$ & $\begin{array}{l}22 \\
16 \\
16 \\
14\end{array}$ & $\begin{array}{l}13 \\
13 \\
17 \\
22\end{array}$ & $\begin{array}{l}21 \\
16 \\
13 \\
23\end{array}$ & $\begin{array}{l}18 \\
20 \\
18 \\
17\end{array}$ & $\begin{array}{l}19 \\
19 \\
12 \\
17\end{array}$ \\
\hline
\end{tabular}

\begin{tabular}{|c|c|c|c|c|c|c|c|c|c|}
\hline Subject & 1 & 2 & $\underset{3}{\text { Signa }}$ & $\begin{array}{c}- \text { to- } \\
4\end{array}$ & $\begin{array}{c}\text { oise } \\
5\end{array}$ & $\begin{array}{c}\text { Rat io } \\
6\end{array}$ & $\begin{array}{c}\text { Rar } \\
7\end{array}$ & 8 & 9 \\
\hline $\begin{array}{l}\text { LS } \\
\text { TM } \\
\text { SP } \\
\text { RW }\end{array}$ & $\begin{array}{l}28 \\
27 \\
25 \\
20\end{array}$ & $\begin{array}{l}32 \\
30 \\
27 \\
21\end{array}$ & $\begin{array}{l}27 \\
19 \\
13 \\
25\end{array}$ & $\begin{array}{l}25 \\
24 \\
26 \\
18\end{array}$ & $\begin{array}{l}25 \\
19 \\
14 \\
16\end{array}$ & $\begin{array}{l}17 \\
17 \\
15 \\
20\end{array}$ & $\begin{array}{l}18 \\
20 \\
17 \\
22\end{array}$ & $\begin{array}{l}13 \\
15 \\
13 \\
26\end{array}$ & $\begin{array}{l}17 \\
17 \\
12 \\
22\end{array}$ \\
\hline
\end{tabular}


APPENDIX G. Raw socres for three subjects on the stimulus conditions where the earphone leads had been reversed from normal position. The sine wave components of the stimulus were of equal peak-to-peak voltage prior to being mixed to form the complex waveform. A raw score of 40 constitutes perfect performance, and a raw score of 10 indicates a performance at the chance level.

\begin{tabular}{|c|c|c|c|c|c|c|c|c|c|}
\hline Subject & 1 & 2 & $\begin{array}{c}\text { Signe } \\
3\end{array}$ & $\begin{array}{r}\text { to } \\
4\end{array}$ & $\begin{array}{c}\text { loise } \\
5\end{array}$ & $\begin{array}{c}\text { Rat io } \\
6\end{array}$ & $\begin{array}{c}\text { Range } \\
7\end{array}$ & 8 & 9 \\
\hline $\begin{array}{l}\text { LS } \\
\text { TM } \\
\text { RW }\end{array}$ & $\begin{array}{l}24 \\
20 \\
17\end{array}$ & $\begin{array}{l}20 \\
16 \\
20\end{array}$ & $\begin{array}{l}20 \\
16 \\
18\end{array}$ & $\begin{array}{l}21 \\
19 \\
13\end{array}$ & $\begin{array}{l}24 \\
19 \\
14\end{array}$ & $\begin{array}{l}18 \\
20 \\
12\end{array}$ & $\begin{array}{l}13 \\
19 \\
12\end{array}$ & $\begin{array}{l}21 \\
20 \\
17\end{array}$ & $\begin{array}{l}16 \\
14 \\
11\end{array}$ \\
\hline
\end{tabular}

900 Relative Phase Relationship

\begin{tabular}{lcccccccccc} 
& \multicolumn{10}{c}{ Signal-to-Noise Ratio Range } \\
Subject & 1 & 2 & 3 & 4 & 5 & 6 & 7 & 8 & 9 & 10 \\
& & & & & & & & & & \\
LS & 39 & 31 & 31 & 25 & 31 & 21 & 20 & 13 & 20 & 15 \\
TM & 36 & 32 & 29 & 21 & 22 & 25 & 23 & 20 & 23 & 13
\end{tabular}


APPENDIX H. Raw scores for three subjects on the stimulus conditions where the earphone leads had been reversed from normal position. The sine wave components of the stimulus were of equal subjective loudness prior to being mixed to form the complex waveform. A raw score of 40 constitutes perfect performance, and a raw score of 10 indicates a performance at the chance level.

\begin{tabular}{lrrrrrrrrrrr}
0 & \multicolumn{10}{c}{ Relative Phase Relationship } \\
Subject & 1 & 2 & 3 & 4 & 5 & 6 & 7 & 8 & 9 & 10 \\
& & 9 & 16 & 19 & 16 & 11 & 14 & 11 & 12 & 12 & 12 \\
LS & 18 & 15 & 23 & 16 & 15 & 18 & 15 & 9 & 9 & 10
\end{tabular}

$120^{\circ}$ Relative Phase Relationship

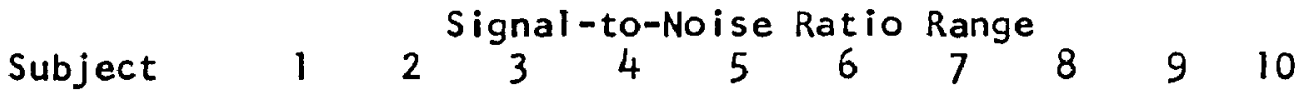

$\begin{array}{lllllllllll}\text { LS } & 34 & 27 & 28 & 24 & 23 & 22 & 20 & 19 & 16 & 15 \\ \text { TM } & 34 & 32 & 33 & 23 & 21 & 30 & 22 & 19 & 18 & 18 \\ \text { RW } & 18 & 18 & 22 & 15 & 15 & 16 & 18 & 19 & 13 & 20\end{array}$


1. Beasley, W. "The Monaural Phase Effect with Pure Binary Harmonics 1. Frequency Ratio 2:3." d. Acoust. Soc. Amer. , 1, 1930, 382402.

2. Beasley, W. "Differential Responses to Cyclic Phase Variations in Compound Sounds." J. Gen. Psychol., 5, 1931, 329-351.

3. von Btkesy, G. "Sensations on the Skin Similar to Directional Hearing, Beats, and Harmonics of the Ear." $\mathrm{J}$. Acoust. Soc. Amer., $29,1957,489-501$.

4. Clarke, F. R. and Bilger, R. D. "The Theory of Signal Detectability and the Measurement of Hearing." Modern Developments in Audiology, J. Jerger, ed. New York: Academic Press, 1963.

5. Chapin, E. K. and Firestone, F. A. "The Influence of Phase on Tone Qual ity and Loudness: The Interference of Subjective Harmonics." J. Acoust. Soc. Amer. , 5, 1934, 173-180.

6. Craig, J. H. "The Effect of Phase on the Quality of a Two-Component Tone." Dissertation, The University of Texas, 1961.

7. Craig, J. H. and Jeffress, L. A. "Effect of Phase on the Quality of a Two-Component Tone." J. Acoust. Soc. Amer. , 34, 1962, 17521760.

8. Craig, J. H. and Jeffress, L. A. "Why Helmholtz Couldn't Hear Monaural Phase Effects." J. Acoust. Soc. Aner. , 32, 1960, 884-885.

9. David, E. D., Miller, J. E. and Mathews, M. V. "Monaural Phase Effects in Speech Perception." Proceedings of the Third International Congress on Acoustics, Amsterdam: Eisevier Co., 1961

10. Fletcher, H. Speech and Hearing in Communication. Princeton, N. J.: D. Van Nostrand Company, 1953.

11. Fletcher, H. and Munson, W. A. "Loudness, Its Def inition, Measurement, and Calculation." J. Acoust. Soc. Amer. , 5, 1933, 82-108.

12. Gray, A. A. "On a Modification of the Helmholtz Theory of Hearing." j. Anatomy and Physiol. , 34, 1899, 325-350.

13. Green, D. M. "Detection of Multiple Component Signals in Noise," J. Acoust. Soc. Amer., 30, 1958, 904-911. 
14. Green, D. M. "Psychoacoustics and Detection Theory." I. Acoust. Soc. Amer. . 32, 1960, 1189-1203.

15. Green, D. M., McKey, M. J. and Licklider, J.C.R. "Detection of a Pulsed Sinusoid in Noise as a Function of Frequency." J. Acoust. Soc. Amer. , 31, 1959, 1446-1452.

16. Helmholtz, H. V. On the Sensations of Tone. Translated by A. J. Ellis. London: Longmans Green and Co., 1885.

17. Hermann, L. "Beitrage zur Lehre von der Klangwahrnehumng." Arch. f. d. ges. Physiol., 56, 1894, as cited in Beasley (2).

18. Karplus, H. B. "Mechan ism of a Correlation Theory of Hearing." Bionics Symposium, 1963. Air Force Systems Command, United States Air Force, Wright-Patterson Air Force Base, Ohio

19. Koenig, R. "Bemerkungen uber die Klangfarbe." Annalen, 14, 1881, 369-393, as cited in Beasley (2).

20. Koenig, R. "Ueber den Ursprung der Stosse and Stosstone bei Harmonischen Intervallen." Annalen, 13, 1881, 335-349, as cited in Beasley (2).

21. Lewis, D. and Larsen, M. J. "The Cancellation, Reinforcement and Measurement of Subjective Tones," Proc. Natl. Acad. Sci., $23,1937,415-421$.

22. Licklider, J.C.R. "Effects of Changes in the Phase Pattern upon the Sound of a 16-Harmonic Tone." J. Acoust. Soc. Amer., 29, 1957, $780(A)$.

23. Lindig, F. "Uber den Einfluss der Phasen auf die Klangfarbe." Ann. d. Phys., 10, 1903, 892-899, as cited in Beasley (2).

24. Lindig, F. "Ueber die Verstimmte Oktave bei Stimmabeln und uber Asymmetrietone." Ann. d. Phys., 11, 1903, 31-54, as cited in Beasley (2).

25. Lindquist, E. F. Design and Analys is of Experiments in Psychology and Education. Boston: Houghton Miff in Company, 1956.

26. Lloyd, M. G. and Agnew, P. G. "The Effect of Phase of Harmonics upon Acoustic Quality." Bull. Bureau Stand., 6, 1909, 255-263.

27. Marili, T. Detection Theory and Psychophysics. Laboratory of Electronics Technical Report No. 319 . Cambridge, Mass.: Massachusetts Institute of Technology, 1956. 
28. Mathes, R. C. and Miller, R. L. "Phase Effects in Monaural Perception." J. Acoust. Soc. Amer., 19, 1947, 780-798.

29. Meyer, M. "Ueber Kombinations und Asymetrietone." Ann. d. Phys. 12, 1903, 892-899, as cited in Beasley (2).

30. Miller, D. C. The Science of Musical Sounds. New York: The Macmillan Company, 1934.

31. Schafer, T. H. and Gales, R. S. "Auditory Masking of Multiple Tones by Random Noise." J. Acoust. Soc. Amer. , $21,1949,392-398$.

32. Schroeder, M. R. "New Results Concerning Monaural Phase Sensitivity." J. Acoust. Soc. Amer. , 31, 1959, 1579 (A).

33. Stevens, S. S. and Davis, H. Hearing, Its Psychology and Physiology. New York: John Wiley $\&$ Sons, 1938.

34. Stromsta, C. and Dawson, W. L. "A Cont inuously Variable $360^{\circ}$ Phase Shifter." J. Speech Hearing Res. , 4, 1961, 37-40.

35. Swets, J. A. "Indices of Signal Detectability Obtained with Various Psychophysical Procedures." J. Acoust. Soc. Amer. , 31, 511-513.

36. Swets, J. A., Tanner, W. P. and Birdsall, T. G. "Decision Processes in Perception." Psychol. Rev., 68, 1961, 301-340.

37. Swets, J. A., Tanner, W. P. and Green, D. M. "Multiple Observations of Signals in Noise." J. Acoust. Soc. Amer. , 31, 1959, 514-521.

38. Tanner, W. P. and Birdsall, T. G. 'Definitions of $d^{\prime}$ and as Psychophysical Measures." J. Acoust. Soc. Amer., 30, 1958, 922-928.

39. Tanner, W. P. Swets, J. A. and Green, D. M. Some General Properties of the Talking Mechanism. Electronic Defense Group, Technical Report No. 30, Ann Arbor, Michigan: University of Michigan, 1956.

40. ter Kuile, E. "Einfluss der Phasen auf die Klangfarbe." Arch. f. d. Physiol., 89, 1902, 333-426, as cited by Beasley (2).

41. Tonndorf, J. "Beats in Cochlear Models." $\underline{\jmath}$. Acoust. Soc. Amer., $31,608-619$.

42. Trimmer, J. D. and Firestone, F. A. "An Investigation of Subjective Tones by Means of the Steady Tone Phase Effect." $\mathrm{J}$. Acoust. Soc. Amer. , 9, 1937, 24-29. 